\title{
AVIATR-Aerial Vehicle for In-situ and Airborne Titan Reconnaissance
}

\section{A Titan airplane mission concept}

Jason W. Barnes • Lawrence Lemke • Rick Foch • Christopher P. McKay • Ross A. Beyer • Jani Radebaugh • David H. Atkinson • Ralph D. Lorenz • Stéphane Le Mouélic · Sebastien Rodriguez · Jay Gundlach • Francesco Giannini - Sean Bain · F. Michael Flasar - Terry Hurford • Carrie M. Anderson • Jon Merrison • Máté Ádámkovics • Simon A. Kattenhorn • Jonathan Mitchell • Devon M. Burr • Anthony Colaprete · Emily Schaller • A. James Friedson • Kenneth S. Edgett • Angioletta Coradini • Alberto Adriani • Kunio M. Sayanagi • Michael J. Malaska • David Morabito • Kim Reh

Received: 22 June 2011 / Accepted: 10 November 2011 / Published online: 20 December 2011 (C) The Author(s) 2011. This article is published with open access at Springerlink.com

J. W. Barnes $(\bowtie) \cdot$ D. H. Atkinson · S. A. Kattenhorn University of Idaho, Moscow, ID 83844-0903, USA

e-mail: jwbarnes@uidaho.edu

L. Lemke · C. P. McKay · R. A. Beyer · A. Colaprete

NASA Ames Research Center, Moffett Field, CA, USA

R. Foch · Sean Bain

Naval Research Laboratory, Washington, DC, USA

R. A. Beyer

Carl Sagan Center at the SETI Institute, Mountain View, CA, USA

J. Radebaugh

Brigham Young University, Provo, UT, USA

R. D. Lorenz

Johns Hopkins University Applied Physics Laboratory, Silver Spring, MD, USA

S. Le Mouélic

Laboratoire de Planétologie et Géodynamique, CNRS, UMR6112, Université de Nantes, Nantes, France

S. Rodriguez

Université de Paris Diderot, Paris, France 
Abstract We describe a mission concept for a stand-alone Titan airplane mission: Aerial Vehicle for In-situ and Airborne Titan Reconnaissance (AVIATR). With independent delivery and direct-to-Earth communications, AVIATR could contribute to Titan science either alone or as part of a sustained Titan Exploration Program. As a focused mission, AVIATR as we have envisioned it would concentrate on the science that an airplane can do best: exploration of Titan's global diversity. We focus on surface geology/hydrology and lower-atmospheric structure and dynamics. With a carefully chosen set of seven instruments - 2 near-IR cameras, 1 near-IR spectrometer, a RADAR altimeter, an atmospheric structure suite, a haze sensor, and a raindrop detector-AVIATR could accomplish a significant subset of the scientific objectives of the aerial element of flagship studies. The AVIATR spacecraft stack is composed of a Space Vehicle (SV) for cruise, an Entry Vehicle (EV) for entry and descent, and the Air Vehicle (AV) to fly in Titan's atmosphere. Using an Earth-Jupiter gravity assist trajectory delivers the spacecraft to Titan in 7.5 years, after which the AVIATR AV would operate for a 1-Earthyear nominal mission. We propose a novel 'gravity battery' climb-then-glide strategy to store energy for optimal use during telecommunications sessions. We would optimize our science by using the flexibility of the airplane platform, generating context data and stereo pairs by flying and banking the AV instead

J. Gundlach · F. Giannini

Aurora Flight Sciences, Manassas, VA, USA

F. Michael Flasar

NASA Goddard Space Flight Center, Greenbelt, MD 20771, USA

T. Hurford · C. M. Anderson

NASA/GSFC, Greenbelt, MD 20771, USA

J. Merrison

Universitat Aarhus Aarhus, Denmark

M. Ádámkovics

University of California, Berkeley, Berkeley, CA, USA

J. Mitchell · K. M. Sayanagi

University of California, Los Angeles, Los Angeles, CA, USA

D. M. Burr

University of Tennessee, Knoxville Knoxville, TN, USA

E. Schaller

University of Arizona, Lunar and Planetary Laboratory, Tucson, AZ, USA

\section{A. J. Friedson · D. Morabito · K. Reh}

Jet Propulsion Laboratory, California Institute of Technology, Pasadena, CA, USA

K. S. Edgett

Malin Space Science Systems, San Diego, CA, USA 
of using gimbaled cameras. AVIATR would climb up to $14 \mathrm{~km}$ altitude and descend down to $3.5 \mathrm{~km}$ altitude once per Earth day, allowing for repeated atmospheric structure and wind measurements all over the globe. An initial Team-X run at JPL priced the AVIATR mission at FY10 $\$ 715 \mathrm{M}$ based on the rules stipulated in the recent Discovery announcement of opportunity. Hence we find that a standalone Titan airplane mission can achieve important science building on Cassini's discoveries and can likely do so within a New Frontiers budget.

Keywords Titan $\cdot$ Mission concept $\cdot$ Airplane $\cdot$ UAV

\section{Introduction}

\subsection{History}

Titan was first explored by spacecraft by the Pioneer 11 during its Saturn flyby on 1979 September 1 [40]. NASA's Voyager 1 spacecraft prioritized a Titan encounter on 1980 November 12 rather than having Saturn send it on to Uranus and Neptune, like Voyager 2. Voyager 1's camera revealed that Titan's atmosphere is laden with organic haze particles, somewhat akin to smog on Earth [133]. Unfortunately incoming and outgoing light scatter off of those haze particles, preventing a clear view of the surface in visible light from space. Voyager 1 did document the distribution of haze and noted detached haze layers in Titan's upper atmosphere [133]. Given the Voyager data, scientists recognized that Titan is an organic chemist's paradise, but knew essentially nothing about the moon's surface.

The Cassini spacecraft's Titan investigation was designed primarily to follow up on the Voyager 1 chemistry discoveries. Several of its instruments, however, could be used to study the surface. The Huygens probe's DISR descended below the haze to image the surface close-up, but saw only a tiny region of what turns out to be a very diverse surface. Huygens was, however, limited in the amount of data returned ( $\sim 100 \mathrm{Mbit})$. Cassini was also equipped with a RADAR to perform reconnaissance of Titan's landscape hidden beneath the haze. After selection (but before launch), Griffith et al. [43] realized that Cassini's VIMS and ISS would also be able to see the surface. This prediction was confirmed by spatially-resolved near-infrared observations of Titan's surface from both HST [134] and ground-based adaptive optics [31]. Cassini

\footnotetext{
A. Coradini · A. Adriani

INAF, IFSI, Rome, Italy

M. J. Malaska

SCYNEXIS, Inc., Research Triangle Park, NC, USA
} 
has been a phenominal success (see [24] for a review of Cassini discoveries at Titan to date). In addition to fundamental breakthroughs regarding Titan's organic chemistry, Cassini's RADAR and near-infrared observations, along with those from the Huygens probe, have taught us what questions to ask regarding Titan's surface and lower atmosphere.

Coustenis et al. [34] recently reviewed the prospects for in situ probes throughout the solar system. In an early survey of post-Cassini Titan exploration possibilities, Lorenz [72] noted the ability for in situ elements to enter Titan's atmosphere directly from an interplanetary trajectory, and explores the relative utility of various aerial platforms. This and other concepts from the early 2000s like the Titan Vision studies [68, 87], Titan Aerorover Orbiter Mission [132], and Titan Planetary Explorer [119] focused on aerial vehicles with surface access capability.

Because use of a single vehicle for both aerial and surface science greatly increases complexity, cost, and risk, the 2007 Titan Explorer flagship study [79] separated the in situ science into an aerial vehicle and separate lander(s). The Titan Explorer flagship study [79], the European TandEM study [32], and the more recent TSSM study [120] included 3 elements: an orbiter, an aerial element (hot-air balloon), and a lander (see [76] for a review of Titan mission studies). In this scenario each mission element would independently address overlapping sets of science objectives.

In general, the use of an airplane for Titan in situ studies has been considered but dismissed without thorough investigation [36]. While the flagship studies ultimately favored balloons over airplanes as their atmospheric element, Titan airplanes had been considered several times before that. Zubrin [169], for example, suggested that a human with wings strapped to their arms could fly in the Titan environment! As for vehicles, Zubrin [168] suggested nuclear thermal rockets in a Martian context, but noted their possible utility for rocket-powered airplanes in other planetary atmospheres. Steve Howe of the Idaho National Laboratory presented an idea for a nuclear-powered Titan jet to OPAG in 2007. ${ }^{1}$ Both of these proved impractical for a planetary mission to Titan in that their development costs would be very large relative to their benefit for any individual Titan mission. In a strategic paper about the overall power requirements for flight as a function of vehicle mass, Lorenz [73] suggested that "a small (20-100 kg) unmanned aerial vehicle (UAV) would be the next logical step in Titan exploration after the Cassini mission", and proceeded to show the expected wing loading and power requirements for such an airplane. As part of the 2007 flagship study, Lorenz [75] considered a small, 1-kg battery-powered airplane that could be launched from that study's lander. Our present study is motivated by the work of Lemke [67], who demonstrated the feasibility of a RTG-powered, electrically driven, $\sim 100-\mathrm{kg}$ Titan airplane requiring no specific technological development over the present state of the art.

\footnotetext{
${ }^{1}$ http://www.lpi.usra.edu/opag/nov_2007_meeting/presentations/nuclear_plane.pdf
} 


\subsection{Strategy}

A flagship-class Titan mission could do a tremendous amount of high-quality science. The present programmatic environment, however, does not look favorable for such a mission. The prioritization of Europa over Titan for the next flagship, and the low priority for flagships in general in the 2011 Decadal Survey [142], motivates consideration of the prospects for exploring Titan with smaller missions instead.

Given the flagship studies' partition of the mission architecture into three separate vehicles, the prospect then exists for flying orbiters, aerial vehicles, and landed vehicles separately to achieve the flagships' science objectives over a period of decades instead of all at once. A few groups have proposed individual smaller missions already, including JET, a Saturn orbiter with significant Titan imaging capability [140]; TiME, a boat targeted at Ligeia Mare [147]; and TAE, an aerial balloon mission ${ }^{2}$ [49]. While less comprehensive than a large flagship mission, a series of small missions offers some programmatic and scientific advantages. The primary technical disadvantage of a series of missions is the more modest total data return possible without an orbiter to act as a relay. The resulting program might resemble NASA's recent strategy for Mars exploration.

Around the time of the loss of the FY10 \$1.5B Mars Observer spacecraft in 1993, NASA initiated a strategy of launching small, less expensive missions to Mars every 26 months instead of one large mission every 20 years. This program eventually earned the name "Mars Exploration Program", part of the broader strategy termed "faster, better, cheaper" by then NASA administrator Dan Goldin. Each mission left much to be desired relative to a flagship mission. Over the last 15 years, however, the entirety of the Mars Exploration Program, viewed holistically, may have led to better scientific results than would have resulted had Mars Observer succeeded. Frequent flight opportunities led to a sustainable exploration program with achievable funding profiles that built and maintained a community of scientists and allowed missions to follow-up on discoveries on a timescale shorter than a scientific career.

Titan could be explored the same way. With an Earth-like surface shaped by rainfall and atmospheric interaction, a rich and complex chemistry, and the astrobiological potential of complex organic molecules interacting with liquid water, Titan is one of the three most interesting targets in the solar system for planetary exploration. Like Mars, but unlike Europa, Titan can be explored inexpensively. Although cruise times to Titan are long ( $~ 7$ years), arrival at Titan is easy. Titan's dense atmosphere with a large scale height is perfect for decelerating landers and aerial elements cheaply and with low heating and acceleration loads. Orbiters at Titan can be mass-efficient, too, if they utilize aerocapture (e.g. [34]).

\footnotetext{
${ }^{2}$ http://users.sch.gr/gbabasides/joomla/
} 
Mars missions need lower Earth-departure velocities and have shorter cruise times, but face moderately more challenging EDL procedures upon arrival. In contrast, despite its high level of scientific interest previous mission studies have shown that it takes well upwards of \$1B to build anything to both get to Europa and survive the radiation environment there. Venus missions enjoy frequent and low Earth-departure velocity trajectories, but face a large gravity well, high entry heating loads and accelerations, and an extremely challenging surface environment on arrival.

Hence Titan is one of only a handful of solar system destinations for which low-cost exploration is even possible (the others being Mars, the Moon, some Venus architectures, and small bodies). The combination of Titan's extraordinary level of scientific interest and the fortuitous case that Titan exploration can be done inexpensively leads us to the conclusion that a robust Titan Exploration Program could achieve high science-per-dollar by launching missions (of the New Frontiers cost level) to Titan at a rate of one every 7-12 years.

\subsection{AVIATR}

We investigate the possibility for using an airplane to address the science questions assigned to the flagships' aerial elements. Doing so would improve the feasibility and reduce the cost and risk for a potential future flagship mission. Alternately the mission could be an element in a series of smaller complementary missions. The result is what we call Aerial Vehicle for In-situ and Airborne Titan Reconnaissance (AVIATR) (Fig. 1).

As a single mission element, AVIATR does not obviate the need for one or more Titan orbiters and/or landers. Instead, the science that AVIATR could do complements the science that can be accomplished from both orbiting and landed platforms (see a comparison of the imaging-based science that can be addressed by various Titan mission architectures in Figs. 2 and 3).

As a focused, New-Frontiers-class mission, AVIATR does not aim to accomplish all of the science that could possibly be done from an airplane platform. For instance, AVIATR does not have a mass spectrometer. We aim instead to accomplish the science that can best and most appropriately be done from an airplane, leaving other science objectives for those platforms that can best accommodate them. The aforementioned mass spectrometer, as an example, would fit better on an atmospheric probe like Huygens where it would not be constrained by the mass and volume considerations of heavierthan-air flight.

In addition to its own science, AVIATR could be a pathfinder for future landed missions at Titan - one of our objectives is to "Identify potential landing sites of scientific interest and constrain their safety". Using our full instrument complement would allow us to discover places on Titan at which future missions may elect to land. These places may be of interest for geological, geophysical, chemical, meteorological, or astrobiological reasons. The best spatial resolution of the AVIATR cameras will be of the same order as that 


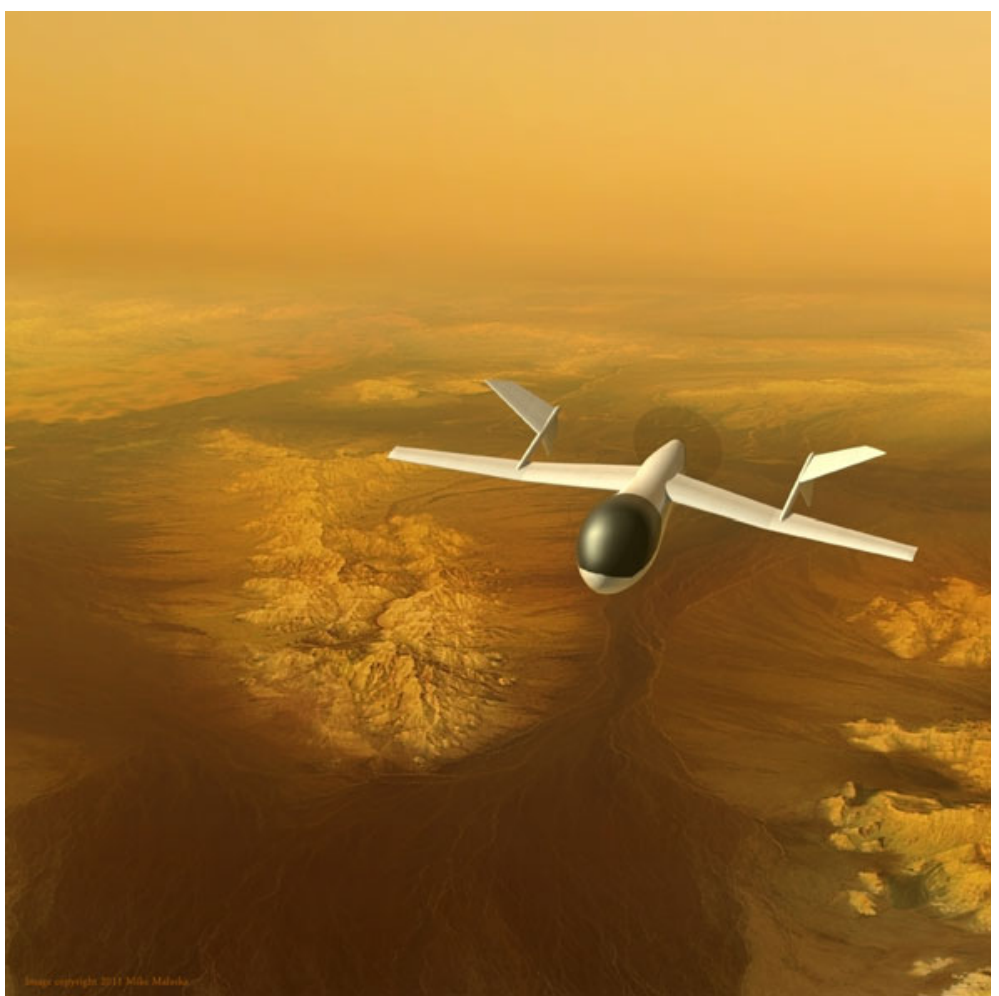

Fig. 1 An artist's rendering of the AVIATR airplane flying over the surface of Titan

of HiRISE at Mars $(25 \mathrm{~cm} / \mathrm{pixel})$, and this data will be able to constrain the engineering safety of surface environments for landers. Such landingsite candidate analysis may include characterization of rock hazards, slope determinations, the persistence of liquid, and rover trafficability. Our global wind field measurements can reduce the size of the landing ellipse for those future missions as they descend through the atmosphere to their destinations.

It is of interest to note that airplanes (and balloons) were advocated at Mars to attain similar high-resolution imaging goals, bridging the scale gap between imaging from fixed or roving landers, and orbiters. However, the large imaging instrument HiRISE on the low-orbiting $(\sim 300 \mathrm{~km})$ Mars Reconnaissance Orbiter now achieves $0.25 \mathrm{~m}$ image sampling [93, 94], eroding the case for such aerial platforms for imaging. The equivalent orbital imaging capability is impossible for Titan, since the atmosphere is both physically and optically thick, forcing orbiters to altitudes higher than $1,000 \mathrm{~km}$, so a near-surface (aerial) vehicle is necessary to achieve a high enough resolution to characterize the landscape. Although balloons can achieve large-scale mobility, the wind field limits the range of locations that can be visited by a single vehicle. Airships are efficient at very low speeds, but at speeds much larger than 


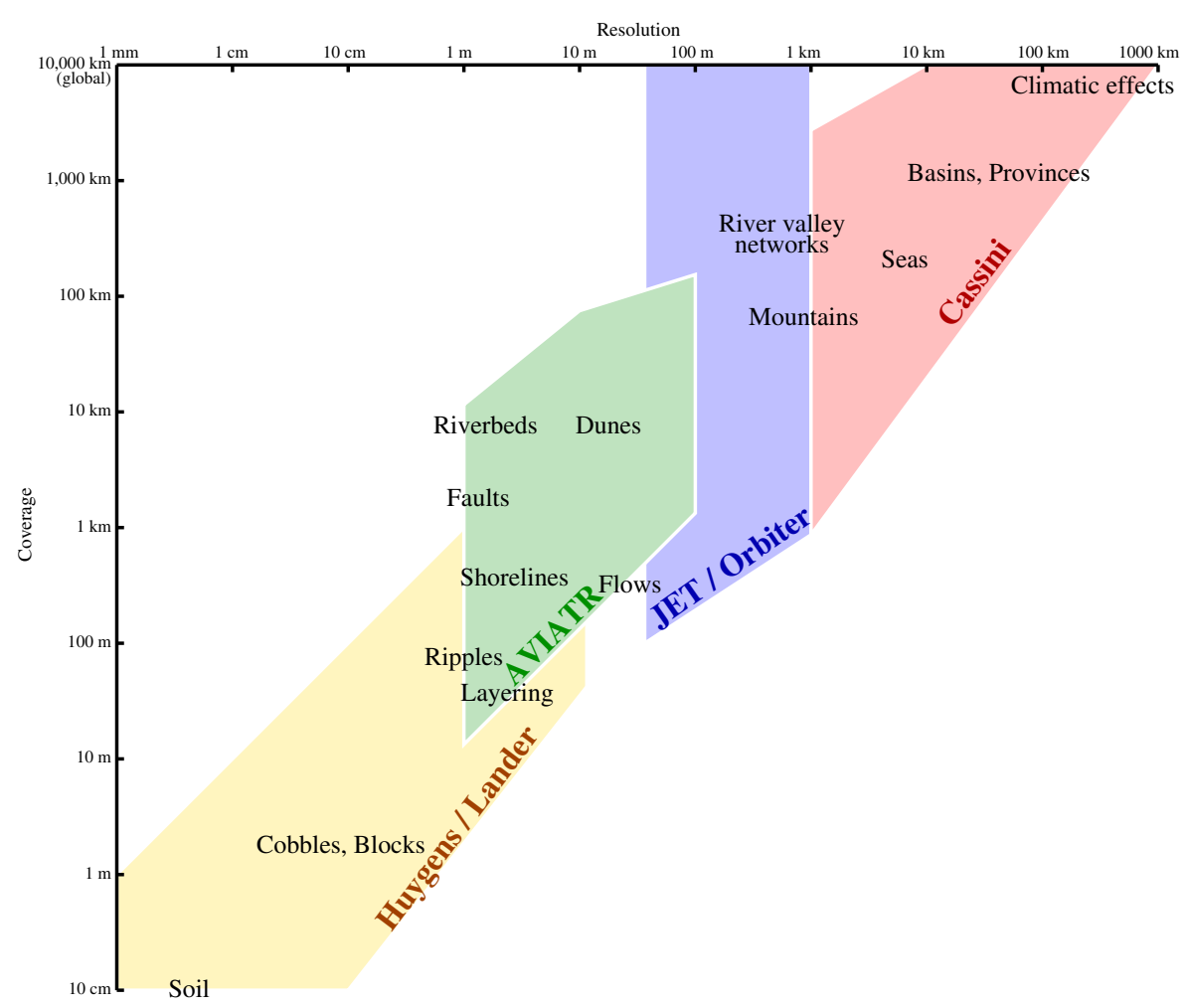

Fig. 2 This cartoon shows the spatial resolution $(x)$ and field-of-view $(y)$ necessary to explore the indicated surface features and processes. AVIATR is complementary to both Titan orbiter and Titan lander missions

expected near-surface winds $(\sim 1 \mathrm{~m} / \mathrm{s})$ they require more propulsive power in the low-gravity Titan environment than do airplanes [73].

\subsection{Mission architecture}

Our science objectives (Section 2.3) require an aerial platform above Titan's surface (see Fig. 3). An airplane allows precision flying and the operational freedom to fly high or low over a target of interest (to capture data at various resolutions just by adjusting the altitude), as well as the ability to return and fly over a target repeatedly. As we shall demonstrate, an airplane allows for a diverse and comprehensive scientific capability in a compact package.

\subsubsection{Engineering drivers}

The supply of ${ }^{238} \mathrm{Pu}$ (plutonium-238) is critical for our ability to explore the outer solar system, and also a potentially limiting resource. The radioactive decay of plutonium-238 provides the heat that powers RTGs, which can power 
Near-IR Remote Sensing Capabilities

\begin{tabular}{|c|c|c|c|c|}
\hline & Orbiter -- $1500 \mathrm{~km}$ & Airplane -- $10 \mathrm{~km}$ & Balloon -- $10 \mathrm{~km}$ & Lander $--10 \mathrm{~cm}$ \\
\hline $\begin{array}{l}\text { best imaging } \\
\text { resolution }\end{array}$ & $50 \mathrm{~m}$ & $\begin{array}{cc}1.0 \mathrm{~m} \quad \text { (true } \\
\text { resolution }--0.3 \mathrm{~m}\end{array}$ & $0.5 \mathrm{~m}$ (from TSSM) & $0.005 \mathrm{~m}$ \\
\hline imaging coverage & global & $\begin{array}{l}\text { many local, selected } \\
\text { locations }\end{array}$ & $\begin{array}{l}\text { many local, haphazard } \\
\text { locations }\end{array}$ & $\begin{array}{l}\text { single local selected } \\
\text { location }\end{array}$ \\
\hline $\begin{array}{l}\text { stereo imaging / } \\
\text { topographic } \\
\text { mapping }\end{array}$ & no / very challenging & $\begin{array}{l}\text { stereo at any desired } \\
\text { location, any desired } \\
\text { angle, any frame }\end{array}$ & $\begin{array}{c}\text { stereo possible at haphazard } \\
\text { locations using overlapping } \\
\text { nadir footprints --- } \\
\text { uncontrolled vehicle azimuth } \\
\text { and drift velocity }\end{array}$ & $\begin{array}{l}\text { Possible with IMP-style } \\
\text { camera for immediate } \\
\text { vicinity of landed vehicle }\end{array}$ \\
\hline $\begin{array}{l}\text { Repe } \\
\text { capal }\end{array}$ & yes & yes & no & nothing but repeat imaging \\
\hline $\begin{array}{l}\text { Specular reflection } \\
\text { observations }\end{array}$ & $\begin{array}{c}\text { yes, when geometry is } \\
\text { right }\end{array}$ & yes, whenever desired & not by design & $\begin{array}{l}\text { one observation } p \\
\text { if landing in la }\end{array}$ \\
\hline $\begin{array}{l}\text { best spe } \\
\text { spatial re }\end{array}$ & $250 \mathrm{~m}$ & $10 \mathrm{~m}$ (possibly better) & $2.5 \mathrm{~m}$ (from TSSM) & $0.1 \mathrm{~m}$ \\
\hline Instrument format & $\begin{array}{l}\text { pushbroom, snapshot } \\
\text { both possible }\end{array}$ & $\begin{array}{l}\text { pushbroom, snapshot } \\
\text { both possible }\end{array}$ & snapshot IFU needed & as desired since stationary \\
\hline $\begin{array}{l}\text { spect } \\
\text { cover }\end{array}$ & global & $\begin{array}{l}\text { many local, selected } \\
\text { locations }\end{array}$ & $\begin{array}{l}\text { many local, haphazard } \\
\text { locations }\end{array}$ & single selected location \\
\hline $\begin{array}{l}\text { atmospheric } \\
\text { absorptions, } \\
\text { scattering }\end{array}$ & bad & half as bad & half as bad & $\begin{array}{l}\text { none with on-board } \\
\text { illumination }\end{array}$ \\
\hline $\begin{array}{l}\text { typical spectral } \\
\text { resolution }\end{array}$ & 500 (from TSSM) & 250 & 250 & $\begin{array}{l}\text { arbitrary since no limits to } \\
\text { integration time }\end{array}$ \\
\hline
\end{tabular}

Fig. 3 This table compares the imaging and spectroscopic capabilities of various possible platforms for Titan exploration. An airplane is complementary to both an orbiter and a lander. The airplane's imaging capabilities compare favorably to those of a balloon

spacecraft where there is insufficient sunlight for solar panels to operate. NASA is presently investing in a new type of RTG, called the ASRG. The ASRG produces similar electrical wattage to the old-style RTF, the MMRTG. Due to the increased efficiency $\left(\sim 26 \%\right.$ for the $\mathrm{ASRG}^{3}$ instead of $\sim 6.25 \%$ for the MMRTG), however, it requires less ${ }^{238} \mathrm{Pu}$ and therefore produces less waste heat. Given the present scarcity of ${ }^{238} \mathrm{Pu}$ for spacecraft power systems, future use of inefficient MMRTGs appears dubious as NASA switches over to the new Stirling power source.

A traditional hot-air balloon will not work on Titan with an ASRG owing to its lower heat production. A linearized performance analysis [74] shows that the maximum lifting capability of a hot air balloon (for given atmospheric parameters, balloon mass/area and heat transfer coefficent) varies as the square of heating power. While a practical balloon system of $>100 \mathrm{~kg}$ is feasible with the waste heat from an MMRTG (2,000 W), as investigated in the 2007 Titan Explorer mission, the $500 \mathrm{~W}$ of heat from an ASRG can support less than $10 \mathrm{~kg}$, i.e. less than the mass of the ASRG itself. In short, a conventional singlewall ASRG hot air balloon cannot fly on Titan: the higher thermal power density of an MMRTG is required.

\footnotetext{
${ }^{3} \mathrm{http} / /$ discovery.larc.nasa.gov/PDF_FILES/ASRGInformationSummaryJuly2010.pdf
} 
In contrast, the AVIATR mission is specifically enabled by the use of ASRGs. The power density (in Watts per kilogram) and longevity of the ASRG allow an electrically-powered aircraft to fly on Titan [67]. The combined worstcase power of two ASRGs (having a combined mass of $64 \mathrm{~kg}^{4}$ ), when allowing for additional power requirements for computers, actuators, and instruments, leaves $\sim 80 \mathrm{~W}$ to power the propeller for straight-and-level flight operations. The propeller's thrust on an airplane with singly folded wings can keep aloft an airplane with a mass up to $\sim 120 \mathrm{~kg}$. Other nuclear power sources, such as the MMRTG, cannot satisfy the physical requirements for heavier-than-air flight at Titan subject to appropriate engineering and risk constraints. Thus the use of an ASRG makes the AVIATR mission concept possible [67].

Heavier-than-air flight on Titan is easier than anywhere else in the solar system. With over 4 times more air and 7 times less gravity than Earth, flight on Titan is 28 times easier than it is here (in the sense that a vehicle with the same contours flying at the same velocity on both planets could lift 28 times more mass). It is over 1,000 times easier on Titan than on Mars.

The airplane solution has a lower programmatic and comparable operational risk posture to a balloon as well. Development of balloon envelope materials, design for a mechanism for suspension of the MMRTG within the balloon, and deployment of the balloon in descent all require further research. The materials for the AVIATR airframe are entirely conventional, based on designs for military and civilian UAVs that operate in Earth's cold stratosphere. The viability of in-air aircraft deployment like AVIATR's has been demonstrated previously in Earth's atmosphere, originally in support of of the proposed Mars airplane mission, Ares [19]. Various tactics can be used to counter the possible effects of the entry vehicle rotating on descent as Huygens did, such as the release of weights on cables to carry away angular momentum, steerable descent vanes, or aircraft spin recognition and mitigation strategies. As a heavier-than-air vehicle, AVIATR is more robust to atmospheric turbulence and shear than a balloon would be, though flight through a fully-developed convective storm is still inadvisable.

A potential risk for an airplane lies in the challenges of long-duration flight. While efforts are under way to develop UAVs for long-duration flight on Earth, the greater challenges of flight on Earth relative to flight on Titan mean that no full-scale comparative test is possible. Solar-powered UAVs on Earth have a duration record of $82.6 \mathrm{~h}$ (the QinetiQ Zephyr). By necessity, solarpowered airplanes on Earth are very light aircraft with low wing-loading (as measured in Newtons per square $\mathrm{cm}$ of wing area), leading to vulnerability to atmospheric disruption. With continuous, reliable nuclear power from its two ASRGs, AVIATR is designed with higher wing loading which leads to a more robust airframe and no upper limit on flight duration.

We have developed a thorough and robust strategy to address the challenges of long-duration flight. The inherent stability of the AVIATR aircraft design

\footnotetext{
${ }^{4}$ http://discovery.larc.nasa.gov/PDF_FILES/ASRGInformationSummaryJuly2010.pdf
} 
allows it to return to straight and level flight in the case that autopilot control fails. Nearly all aircraft have this ability, including private, commercial, and military airplanes, for instance. Oscillations about straight and level flight can develop and grow, however, over longer timescales. To address this problem we have a set of stabilizing vanes that deploy automatically if the autopilot fails, inhibiting oscillatory attitude modes. At that point, the aircraft flies stably while pointing its antenna at the Sun (and Earth), waiting for instructions in safe mode. To avoid hardware failures, the propeller is driven by a brushless motor, and the actuators are optimized for long-term use. With these precautionary steps, a nominal 1-year mission duration is eminently achievable.

\subsubsection{Science drivers}

If the mission architecture decision were based on science alone, then an airplane would still prove a competitive choice when compared to a hot-air balloon (Montgolfière). As a passive platform, a hot-air balloon necessarily drifts with the local winds. While some rudimentary directional control might be gained by using altitude changes once the local wind structure is determined, the hot-air balloon as envisioned in the TSSM study cannot autonomously fly to a location to study it. AVIATR can.

When it arrives at a study location, AVIATR can linger as long as necessary for the science. In particular, for imaging targets AVIATR flies in at high altitude $(14 \mathrm{~km})$ to take lower-resolution, context views of the target area. Then it would swoop down to low altitude $(3.5 \mathrm{~km})$ for high resolution views. We fly a predesigned raster pattern at low altitude to build up as large a mosaic of the target area as needed (see Fig. 32 and Section "Mosaics" for more details).

AVIATR is designed to be able to easily climb or descend as needed for engineering and science purposes. When not using power to transmit data back to Earth, we instead use the excess power to climb. This technique stores that extra energy as gravitational potential energy in a process that we call a 'gravity battery'. For a downlink cycle, we cut (or greatly decrease) power to the propeller, initiating a descent and using the extra power liberated to increase the transmitted power of the uplink to Earth, greatly improving its bandwidth. This daily climb and glide also allows us to generate atmospheric structure and wind profiles roughly once per (Earth) day.

AVIATR also has no latitude restrictions for where it can go. A balloon entrained in primarily zonal winds near the equator would have no mechanism by which to travel to the polar regions to observe lakes and shoreline processes. Even if it were possible to get there, it is not clear that it would be desirable to send a balloon to the poles where Titan's most violent meteorological activity takes place. AVIATR is both able to fly to the poles and is sufficiently robust to survive there.

Finally, because AVIATR flies at a significant fraction of Titan's rotational velocity ( $12 \mathrm{~m} / \mathrm{s}$ at the equator), by flying west we can stay on Titan's dayside for most of the time, thus maximizing our scientific and downlink duty cycle. 


\subsection{Presentation}

In this paper we describe the Titan airplane mission concept that resulted from our iterative design process. This point-design with 2 ASRGs was scoped and found to be viable within a New-Frontiers-class cost cap. An alternate airplane design as part of a flagship mission is also possible, but we have not yet investigated such a design in detail. In Section 2 we describe the scientific goals, objectives, and tasks for the AVIATR mission concept. We then discuss its engineering in Section 3, and our ideas for mission operations in Section 4. In Section 5 we conclude, placing our ideas into context and discussing their future prospects.

\section{Science}

\subsection{Cassini-Huygens discoveries}

Just three solar system bodies besides Earth have both significant atmospheres and a solid surface: Venus, Mars, and Saturn's moon Titan. The solid surfaces and lower tropospheres of all of these bodies interact with each other strongly. Because this type of interaction drives surface geology and atmospheric activity, the solid bodies with air resemble one another in ways that airless bodies or giant planets cannot. They comprise a family.

The family members' comparability to the Earth makes them of particular scientific interest. Like the Earth, Mars, Venus, and Titan have mountains, sand dunes, and clouds. Both Mars and Earth have giant channels carved by megafloods. But it is fluvial erosion, ultimately driven by rainfall, that drives geological evolution over most of Earth's land surface. The erosive power of runoff breaks Earth's mountains into sediments and then deposits the sediments into low-lying seas.

Cassini and Huygens have revealed that Saturn's moon Titan is a sedimentary world, too. Like on Earth, the sedimentary processes are driven by interactions between the planet's lower atmosphere and its surface. Atmospheric haze settles on the surface [135]. Wind drives the formation of giant sand dunes [80]. Rain erodes mountains [8]. Ephemeral streams carve channels [155]. At the equator the streams carry sediments into low-lying plains like the Huygens landing site [57]. At the poles, runoff deposits sediment into lakes and seas [146]. Evaporation then completes the cycle, replenishing atmospheric methane for rainfall and haze production (e.g. [22]).

The number and complexity of processes acting on Titan create a diversity of surface landforms exceeded only on Earth itself among solar system planets. Figure 4a shows a full-disk Cassini view of Titan that evidences some of this diversity. The whole moon shows dramatic changes in landforms from the equator to the poles. Titan's equatorial region (latitudes less than $30^{\circ}$ ) is half covered in sand seas composed of large longitudinal sand dunes [78]. The sand 


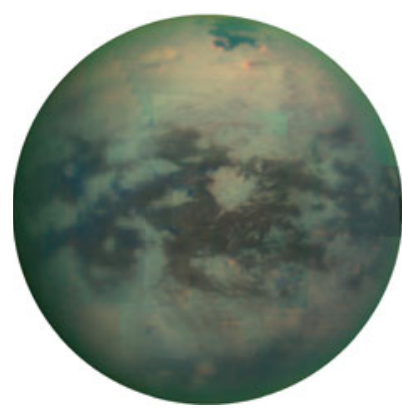

(a)

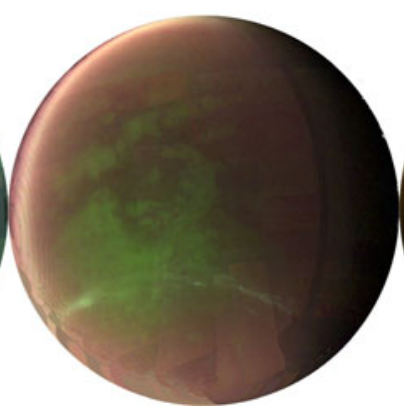

(b)

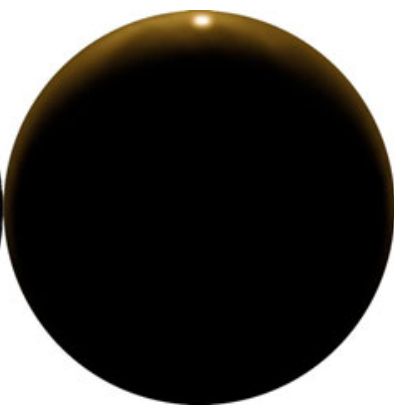

(c)

Fig. 4 Global views of Titan from the Cassini VIMS instrument acquired on the T67 flyby (a; 5 April 2010), the T17 (b; 7 September 2006), and the T58 flyby (c; 18 March 2006). North is at the top in these orthographic projections of mosaiced VIMS cubes. The colors for a are assigned with red at $5 \mu \mathrm{m}$, green at $2 \mu \mathrm{m}$, and blue at $1.3 \mu \mathrm{m}$, which shows spectral variability of surface features [7]. This view shows some of Titan's surface diversity, with Kraken Mare near the north pole, and sand dunes, mountains, and plains near the equator. Part b shows Titan in a color scheme designed to bring out atmospheric features with green as the surface, pink/red as haze, and blue-white as clouds. Part b shows some convective storm activity at $40^{\circ} \mathrm{S}$ latitude. Part $\mathbf{c}$ is a monochromatic $5 \mu \mathrm{m}$ image showing a specular reflection of the Sun off of the northern lake Jingpo Lacus [11, 144].

is composed of organic compounds [135], and looks dark brown in the color scheme used in Fig. 4.

The vast equatorial sand seas of Fensal, Aztlan, Senkyo, Belet, and ShangriLa form a nearly complete belt around the equator (see map, Fig. 5). They are interrupted only by the large bright region Xanadu. First seen from HST observations [134], Xanadu's unique spectrum shows that it is not composed of pure water ice [7] as had initially been assumed [134]. RADAR observations

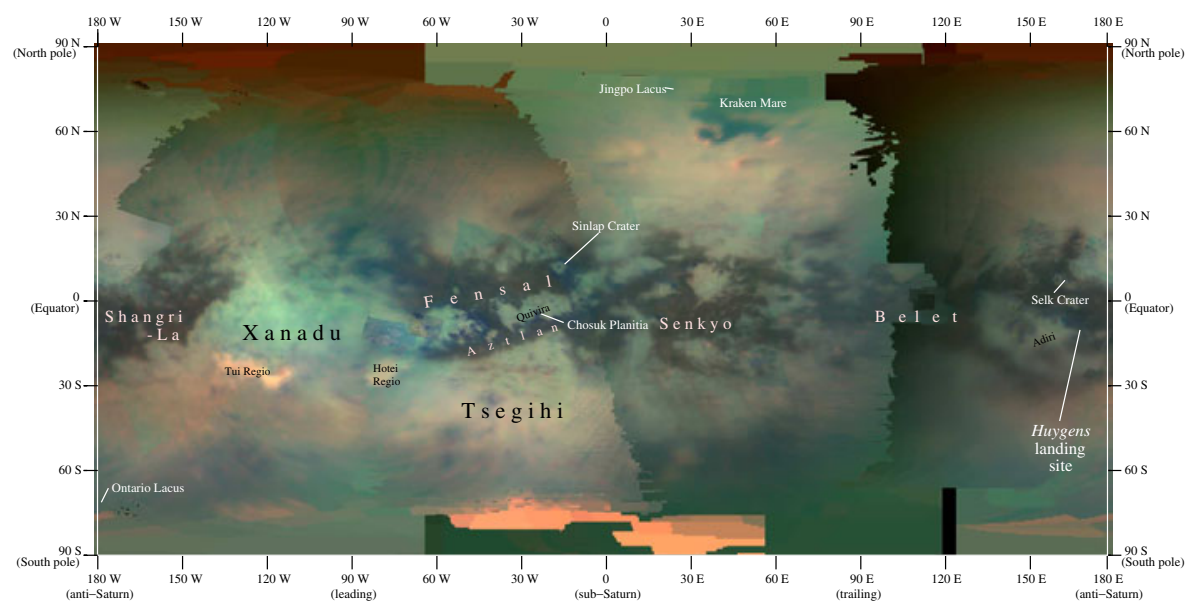

Fig. 5 Global map of Titan in cylindrical projection. Created with data from the Cassini Visual and Infrared Mapping Spectrometer (VIMS) instrument [9] 
indicate Xanadu to be alternately tectonically tortured into mountain ranges and riven by $[8,26,116]$. The cause for Xanadu's distinctiveness remains unknown.

Just off the southern edge of Xanadu are Tui Regio and Hotei Regio. Their spectra show them to be nearly free of water ice, thus making them relatively bright at 5-microns as compared to the rest of Titan [5]. The strong spectral contrast for Tui and Hotei along with their lobate shapes as viewed at near-infrared and RADAR wavelengths originally suggested that they may be cryovolcanic features $[6,137,161]$. While terrestrial volcanoes effuse liquid rock, since Earth's crust is made of rock, a volcano on Titan would exude Titan's crustal material in liquid form-hence the term cryovolcano. Cryovolcanism on Titan has been suggested as a mechanism to replenish atmospheric methane [139, 149]. New evidence suggests instead that these areas are correlated with evaporites, or dried-up lake bed sediments $[12,106]$, commonly found in depressions, as are many volcanic deposits. Disentangling these origins, or choosing one over the other, remains a task in action. These areas are also of astrobiological interest if liquid water mixtures encounter surface organics, as might happen with cryovolcanism or impact melts [109].

The remainder of Titan's tropics looks like the Huygens landing site: mostly optically-bright, rough, highlands surrounded by small dark plains covered with water-ice cobbles $[135,136]$. Fluvial networks are common within Titan's optically-bright terrains [38, 81]. Clearly, then, it rains near the equator at least occasionally, if not as a continuous drizzle (e.g. [1, 154]). But with widths of individual links of $\sim 1 \mathrm{~km}$ [8], Cassini cannot resolve structure within the features themselves or even distinguish river channels from river valleys. Cassini has observed other water-ice-rich fluvial depositional plains like the landing site [121] and analog areas (like Chosuk Planitia; [57]), and also noted water-ice-rich ejecta-derived plumes from impact craters Sinlap [65] and Selk [138]. That the water-ice-rich unit covers only a few percent of Titan's surface area, however, is surprising considering that Titan's low bulk density (1.88 $\mathrm{g} / \mathrm{cm}^{3}$ ) indicates that water-ice makes up a substantial fraction of its total mass.

Titan's midlatitudes $\left(30^{\circ}-60^{\circ}\right)$ are more inscrutable. Both RADAR and near-infrared imaging show a lower degree of surface albedo and spectral contrasts here than they do at both the equator and the poles [7]. The enigmatic Ganesa Macula seen by RADAR was first interpreted as a dome [145] but is now understood to be a topographic depression, and the bright flyvial networks that abut its eastern flank lie thin the midlatitudes. The changing interpretation of Ganesa Macula serves as an excellent example of the need for detailed topographic data for key geographical features. In nearinfrared wavelengths a large area called Tsegihi shows modest contrast from the rest of the midlatitudes, but as yet the data do not have any obvious interpretation. Heavy rainfall may ultimately cause the midlatitudes' bland contrasts. Convective storms [45] have been seen regularly at $40^{\circ}$ south latitude throughout the Cassini mission [25, 122, 123] and are predicted to move to $40^{\circ}$ north in the coming season [103]. While this storm belt and the blandlands spatially correlate, whether they are causally related is unclear. 
The poles are Titan's 'lake district'. Large bodies of liquid are exposed northward of $60^{\circ}$ [146], including the giant sea Kraken Mare [144]. Fractional lake coverage in the south is much smaller. The largest southern lake is Ontario Lacus. But transitory ponding [158] and surface wetting [159] also occur in the wake of large storms. The seas are filled with liquid ethane, presumably in solution with liquid methane and dissolved nitrogen [21]. Bathtub rings [10], paleoshoreline features [162], and Cassini imaging [159] around Ontario Lacus indicate a history of lake-level changes over seasonal, orbital, and/or geological timescales. Titan's cloud menagerie is most diverse over the poles. During southern summer frequent, large conglomerations of convective storms were present $[20,113,122,123]$. With the onset of southern autumn these have petered out. During northern winter the entire pole was covered with a lowoptical-depth, high-altitude ethane cloud $[44,66]$. With the arrival of northern summer, this cloud has also faded. In its place are numerous smaller methane storms, possibly of lake-effect origin [22].

Cassini and Huygens have revealed Titan to be a diverse, active, and dynamic world. When the Cassini mission was being designed, next to nothing at all was known about the surface and lower atmosphere of Titan. In order to follow up on Cassini's discoveries, a new mission is needed.

\subsection{Titan's context}

By exploring Titan's present, AVIATR would open a window to both the moon's past and its future. Searches for layering, shoreline effects, and compound dune forms constrain the long-term climatic history of Titan from the 100,000-year timescale to gigayear timescales. Understanding Titan's global circulation, methane cycle, and putative cryovolcanic sources would allow us to project whether the lakes are persistent or if they will dry out as methane loss continues.

These questions allow us to place Titan into context with the Earth and other volatile-rich worlds (Fig. 6). Triton, Pluto, and other KBOs represent one endpoint along a continuum of volatile inventory status. Neptune's moon Triton (Fig. 6a) has its volatiles frozen out onto the surface and in the

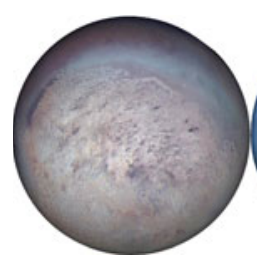

(a)

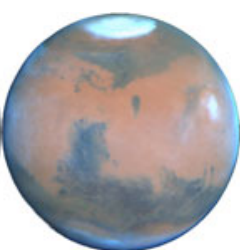

(b)

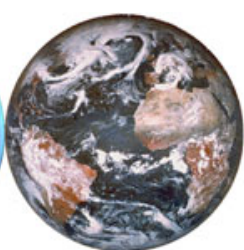

(c)

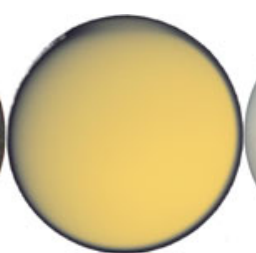

(d)

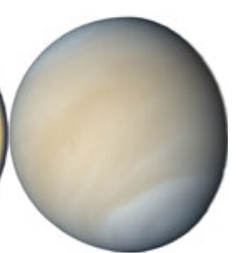

(e)

Fig. 6 Triton (a; from Voyager 2, NASA/JPL/USGS), Mars (b; from HST, NASA/STScI), Earth (c; from Clementine, USGS), Titan (d; from Cassini ISS, NASA/ESA/SSI), and Venus (e; Mariner 10, Malmer of http://unmannedspaceflight.com/) ordered by the state of their volatile inventory from frozen (left) to boiled away (right) 
subsurface. If Triton's global temperature increased, as will occur in the Sun's red giant phase, then its volatiles would vaporize turning red-giant-Triton into something that perhaps looks like Saturn's Titan does today [97]. Thus it is also possible that Triton represents Titan's past. Four billion years ago when the Sun was young and faint ( $70 \%$ of current solar luminosity), Titan may have been cold enough for the nitrogen in its atmosphere to have been frozen out on the surface. With a correspondingly higher albedo, Titan could have been stuck in such a state until the Sun's increasing luminosity vaporized the nitrogen and methane that had been frozen on its surface, creating the Titan that we see today. If this scenario is correct, then Titan may not have been a sedimentary world for its entire history. AVIATR would look for evidence of Titan's longterm history, in particular using exposed outcrops of layered materials to assess that history and its timescale.

Mars represents the next step along the volatile status continuum (Fig. 6b). Its primary volatile, water, is predominantly stored as both subsurface and polar ice. Water's activity on Mars is significant, however, in that it forms glaciers, has an appreciable atmospheric vapor pressure, and may occasionally burst onto the surface as a liquid [27, 37, 89]. Earth (Fig. 6c) has stable, extensive surface liquids. Earth's tropopause effectively seals in its surface water, preventing it from escaping into space via photolysis. In the past Earth has transitioned repeatedly to a Mars-like state and back again during snowball Earth episodes [52].

To the right of Earth in the volatile status diagram lies Titan (Fig. 6d). Titan has its volatile species, methane (and, to a lesser extent, ethane) as surface liquid and as atmospheric vapor. Titan's high tropopause temperature allows significant quantities of methane into the upper atmosphere. There solar ultraviolet light initiates a chemical cascade that converts methane into reactive species that eventually lead to complex organic molecules. Because the produced hydrogen gets lost to space via Jeans' escape, the process is irreversible. Titan's methane is leaking to space. As the Sun continues to ramp up in luminosity, Earth may heat up to the point that its water starts being lost to space, similar to the way that Titan's methane is presently being irreversibly lost. Titan's present may thus resemble Earth a few billion years from now.

The endpoint of the volatile sequence is Venus (Fig. 6e). Venus already had its water vaporized, photolyzed, and lost to space billions of years ago [35, 58]. Titan affords us the opportunity to watch first-hand what Venus' past might have been like. Hence Titan is Venus in slow-motion, and Venus is a possible future for Titan once all of its methane has been lost.

Titan's present also yields analogs for other planetary bodies' surfaces. Because Titan is so much easier to explore than any other icy moon (see Section 1.2), its surface can be treated as an analog for Ganymede, Callisto, Europa, Enceladus, Triton, the Uranian moons, and smaller icy satellites. While fluvial networks and lakebed deposits on Titan will not be applicable to these other bodies, some tectonism, cratering, and regolith properties will.

Titan surface processes are also analogs for terrestrial planets. The sand dunes on Titan are strikingly similar in height and spacing to to the dunes 
in Earth's large sand seas. Titan's dunes thus provide a test for hypotheses regarding sand dune formation and evolution (e.g. [83, 126]). The resulting theory has application to dunes on Mars, Earth, and Venus. The large fluid discharge rates inferred from some of Titan's channel systems and outflow plains [57] imply catastrophic flooding that resembles that seen on Mars and in the Channeled Scablands on Earth. Titan lakes share striking morphological similarities with Earth lakes in semi-arid regions [18, 84]. For comparative planetological purposes, no other solar system body can compete with Titan for planetary analogs of pluvial, fluvial, and limnological structures. The relative rates of erosion on Earth and Titan can provide insight into the relative sediment supply and discharge rates on both bodies.

With complex organic molecules in contact with liquid water in impact melts and cryovolcanic flows, Titan is a target of high astrobiological interest [107]. AVIATR is not an astrobiology-focused mission. AVIATR's instrument complement can, however, contribute to astrobiology by identifying locations on Titan where liquid water can interact with organic molecules and by finding and mapping the geographic distributions of organic species.

\subsection{AVIATR science goals}

The theme of our Titan airplane mission concept, AVIATR, is exploration of the diversity of Titan's surface and lower atmosphere. Our Science Goals are (see also Fig. 7):

Goal 1 Surface Geology. Ascertain, from above, the key elements of Titan's geological processes, their history, their relative levels of activity, and their global distributions and morphologies.

Goal 2 Atmospheric Science. Characterize, from within, the global diversity and local conditions of Titan's present-day atmosphere.

In the iterative process between designing our science goals and our hardware, we have elected to pursue those science questions that are best addressed using an aerial platform. The essential advantage of an airplane is its targeted mobility. AVIATR can fly to any location on Titan, and can do so at a range of altitudes (nominally 3.5-14 km). Science objectives that do not utilize our platform's mobility would best be pursued using alternate mission architectures, for instance an atmospheric probe like Huygens, a lander, or an orbiter.

Instead, AVIATR focuses on understanding the reasons for the differences in Titan's surface and atmosphere across its globe. It is not a chemistry-focused mission like Cassini-Huygens. While AVIATR would look for diversity of Titan's surface composition, it does not carry a mass spectrometer, for instance. To make a significant contribution over and above what Huygens and Cassini have done in this area would require a sensitive and high-mass-resolution instrument. Such an instrument would likely be more massive than could be 


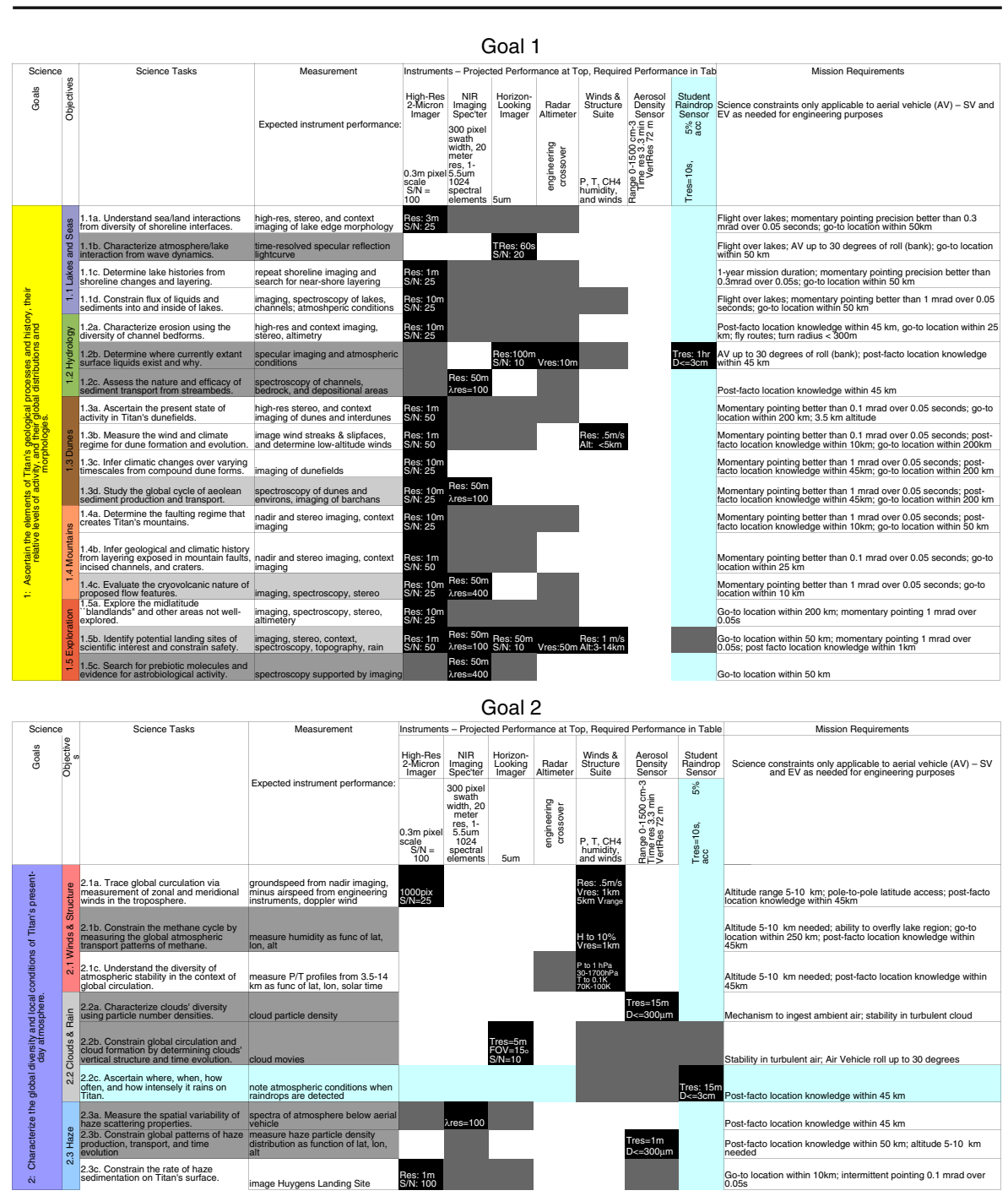

Fig. 7 This figure shows the AVIATR Science Traceability Matrix

easily carried by an aerial vehicle. Additionally, there would be little utility in having such an instrument aboard an aircraft, as opposed to on board an atmospheric probe or lander where instrument mass is less critical. We also considered an atmospheric electricity sensor as described for a balloon in the TSSM study report [120], but determined that its likely return given the altitude range traversed by AVIATR did not merit its inclusion in our baseline payload suite.

In particular we follow in the footsteps of the Titan Explorer and TSSM mission studies in separating the aerial and landed Titan in situ platforms. 
AVIATR is not designed to land or interact directly with the surface. Doing so would greatly complicate the design, driving costs well outside even a New Frontiers budget, and it would distract from our core goal of exploring global diversity. We leave landed science for future landed vehicles, and instead concentrate on global characterization.

The AVIATR payload does not include a magnetometer due to the limited use of such measurements so close to Titan. While measuring Titan's magnetic field has the potential to reveal the moon's interior in unique and valuable ways, single-point measurements of Titan's magnetic field would be uninterpretable without simultaneous measurement of Saturn's field exterior to Titan's atmosphere. Essentially, making sense of the induced magnetic response in Titan from the perturbing field would require knowledge of that perturbing field and its time derivative in order to interpret the measurement. Thus without an orbiter flying simultaneously with an in-situ mission, the utility of a magnetometer on the latter is compromised.

A long-wavelength subsurface sounding RADAR, like SHARAD on MRO [130] would be of great use on an airplane to study Titan's global diversity of subsurface structure. Lemke [67] had suggested this type of instrument for a Titan airplane. In the end we descoped a RADAR sounder on the basis of mass, power, and bandwidth concerns.

AVIATR is a focused, science-driven mission that would study Titan's surface and lower atmosphere using a combination of in-situ and remotesensing measurements.

\subsubsection{Science objective 1.1: lakes and seas}

Despite early anticipation of a global ocean on Titan [86, 127], one does not exist [163]. It came as somewhat of a surprise, then, when Cassini finally found Titan's expected surface liquids hiding out near the poles [146]. Despite rapid progress toward understanding these first extraterrestrial surface liquids, Cassini will not be able to solve all of the outstanding questions about these enigmatic features.

Task 1.1a Understand sea/land interactions from the diversity of shoreline interfaces. Since the south polar Ontario Lacus was first observed by Cassini ISS in 2004 [158], dozens of methane/ethane-filled lakes have been observed filling depressions on Titan's surface [21,71, 146]. These north and south polar features evidence the mobility of alkane fluids, likely through rainfall and subsequent river runoff and deposition in regional lows. The morphologies of lake margins, the interface between these collected fluids and the basins that contain them, provide information about the history of the lake basins and the associated atmospheric and fluvial processes. Variations in lake marginsgradual, abrupt, dendritic, and smooth-all give evidence of the underlying geology and the processes that have acted on it. Observations reveal evidence of extremely shallow basins, similar to playas or pluvial lakes on Earth [84], 
deeper basins and changes in lake levels over time [10], and fluvial- and wavedominated shorelines [85, 162]. AVIATR could carefully observe all lake margins to determine the histories of lake basins, changes to lakes over time, and the related connection between the surface and atmosphere of Titan.

Task $1.1 \mathrm{~b}$ Characterize atmospheric/lake interaction from wave dynamics. Low-level winds incite wave activity in Earth's bodies of water, and similar effects should occur on Titan. Observations so far, though, show both Ontario Lacus [166] in the south and Jingpo Lacus [11] in the north to be smooth and wave-free. Lorenz et al. Lorenz et al. [85] point out that in order to reconcile the lack of wave activity with theory, either the near-surface winds must have been quiescent at the time or the viscosity of Titan's liquids must be higher than that of a methane/ethane mixture. AVIATR can systematically monitor wave activity on Titan's lakes using specular reflection lightcurves, following the method of Barnes et al. [11]. While flying over a sea, as the specular point nears a shoreline, it will fade slowly for rough seas and wink out rapidly for quiescent ones. Variations in predicted wave heights given sizes of lakes or locations within them can be observed, helping to determine the velocity of winds at the surface, directly measure the energy available for shoreline erosion, and constrain the viscosity of liquids across lakes.

Task 1.1c Determine lake histories from shoreline changes and layering. Titan's south-polar region is home to the $\sim 15,000 \mathrm{~km}^{2}$ Ontario Lacus (Fig. 8a), which contains a well-developed delta system [162] as well as a prominent strandline (paleo-shoreline) annulus $\sim 10 \mathrm{~km}$ outboard from the current lake surface that indicates recession of the lake surface [10]. In contrast, the north-polar lakes contain a much greater volume of liquid, but even those lakes potentially
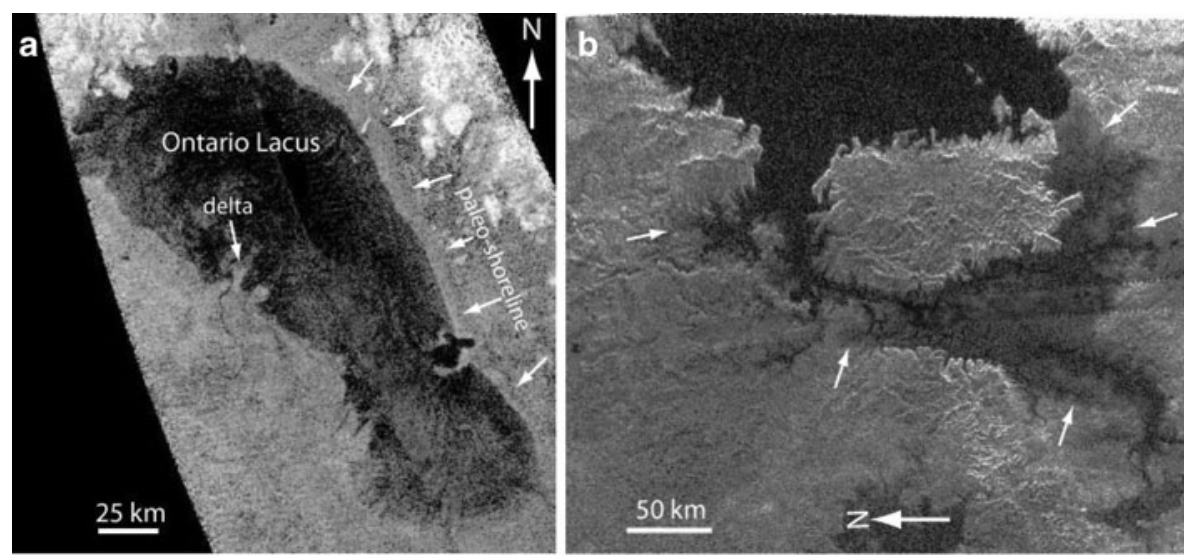

Fig. 8 Cassini RADAR images of Titan's lakes. a Ontario Lacus in Titan's south-polar region [162]. White arrows along the eastern edge of the lake show a paleo-shoreline from a past lake highstand. b North-polar lake Kraken Mare showing an embayed shoreline due to a drowning of topography during lake infill 
contain strandlines that imply lake highstands that exceed current lake levels (Fig. 8b). Furthermore, the lakes exist in a variety of stages of fill, with some depressions appearing completely dry [51]. The lake systems are thus dynamic, although it is not known for sure if they are seasonally dynamic [105] or instead respond to longer climatic variations [2]. The analysis of paleo-shorelines thus provides important insights into the evolution of the lake and atmospheric systems.

By targeting the shorelines of both northern and southern hemisphere lake systems during the transition out of their respective hemispheric equinoxes, AVIATR could capture details of shoreline variability not resolvable in Cassini RADAR observations. Seasonal fluctuations, such as receding and advancing shorelines, can be monitored over time. Observations of exposed, sedimentary layering in near-shore canyons can reveal the history of deposition associated with lakes.

Task 1.1d Constrain flux of liquids and sediments into and inside of lakes. Observations of lake-feeding fluvial networks, in the vein of looking for specular reflections to determine if they are liquid-filled, should enable us to determine the current flux of liquids from these regions into the lakes. Systematic observations of many of these systems, taken over time, can provide strong estimates for total fluid flux into the lakes over our observational time frame. These estimates can be coupled with rainfall measurements and observations to link the flux of fluids from the atmosphere, over the land surface, and into the ocean, fully closing the hydrologic ${ }^{5}$ system loop on Titan. Variations in fluid spectra in rivers and at lake margins can enable us to determine composition, volumes, and velocities of sediments carried into lakes.

\subsubsection{Science objective 1.2: hydrology}

Titan's fluvial features provide a powerful tool to better understand both the atmosphere and the surface. However, the spatial resolutions and coverage of the Cassini data are insufficient to determine the nature, origin, or implications of these fluvial features. Increasing spatial resolution increases geologic interpretability [167], as illustrated at Mars by HiRISE. The exploration situation at Titan today perhaps best resembles that at Mars in the early 1970s. The best-resolution Cassini data have a resolution similar to Mars Mariner 9 data.

\footnotetext{
${ }^{5}$ In this paper we use terms like 'hydrologic', 'hydrology', and 'moisture' to refer to a generalized volatile system, and not necessarily to one involving water $\left(\mathrm{H}_{2} \mathrm{O}\right)$. Such a system would behave physically like water does on the Earth, with evaporation, rain, and atmospheric and surface transport, but in Titan's case the volatile involved is likely methane, or a methane/ethane mixture. In using this generalization, we follow previous abstractions of Earth-based concepts: 'hydrodynamics' was broadened to include general fluid dynamics, and the concept of 'geology' to represent processes that occur on planets other than Earth. The alternative, to refer to 'alkanology' or 'volatilology' instead, we think would unnecessarily obscure the processes involved.
} 
The resolution of the Huygens DISR images is orders of magnitude better and show a variety of fluvial networks within the HLS region alone. With its greatly improved resolution and overflight pattern, AVIATR would provide data at a range of intermediate resolutions to enable both the wide identification and the precise characterization of fluvial features on Titan.

Task 1.2a Characterize erosion using the diversity of channel bedforms. While Mariner 9 data at Mars showed valley networks, isolated higher resolution data revealed channels inset within these networks, revising interpretations [89] and enabling the first paleodischarge estimates from data (e.g. [55]). The importance of context and continuous coverage is illustrated by the Context Camera (CTX [90]), which provides data intermediate in resolution with sufficient coverage for geologic context with adequate resolution for robust interpretations of that geology. Mapping and characterization of entire networks can yield estimates of rainfall runoff rates, sediment production, and discharge calculations using the slope-area method. The characterization of network morphologies would provide new information not only on fluvial but also tectonic and atmospheric processes (cf. [26]) on a global scale. The characterization of individual fluvial features would reveal whether they are fluvial channels or alluvial valleys.

AVIATR has the go-to capability to view terrain at all latitudes, which would provide a global characterization of fluvial features. With its descend and climb capability, AVIATR achieves a range of resolutions from Mariner 9 to HiRISE pixel scales between its cameras. These data would enable the discovery and mapping of networks at better than Cassini SAR resolution ( $c f$. the networks as the Huygens landing site).

Task 1.2b Determine where surface liquids currently exist and why. RADAR [146, 166] and Visual and Infrared Mapping Spectrometer (VIMS) [21, 144] observations show that Titan's lakes are filled with liquid. These lakes are likely fed by flow through surface networks (e.g. [81]) or subsurface flow (e.g. [51]) following rainstorms [45, 113]. Surface moisture at the Huygens landing site [111] also evidences an active methane-based hydrological cycle. So liquids should exist outside the lakes, either in lakes smaller than can be seen by RADAR or VIMS or as streams of fluid carrying methane seaward today.

We could map these putative surface liquids by identifying their specular reflections. AVIATR would acquire a short sequence of images at $5 \mu \mathrm{m}$ wavelength looking at the specular point. Areas with liquid stand out because they change in brightness dramatically as they move toward or away from the specular reflection point. Non-liquid areas with near-lambertian reflection would not change in brightness.

Task 1.2c Assess the nature and efficacy of sediment transport from streambeds. Large terrestrial streambeds are filled with sediments that have been carried down the channel from upstream. The composition of the rocks in a dry streambed thus represents the bedrock of the entire drainage basin. 
AVIATR's spectrometer would allow comparison of the spectrum of Titan streambeds to the spectra of the surrounding catchment area. Given a sufficiently variegated catchment area, the composition of the streambed can reveal the relative erosion rates in the contributing area. Initial VIMS spectra from Cassini indicate the viability of this approach, as both streambeds and steep mountains show an enhanced water ice signature relative to the rest of Titan [8]. Collins [30] predicts that erosion rates on Titan should be similar to those on the Earth. In that case, other factors such as jointing or local slopes may drive differential erosion rates instead of composition.

The size of streambed-lain sediment particles, from boulders down to silt and clay, is representative of the flow that deposited them. While AVIATR would not be able to resolve $\sim 10 \mathrm{~cm}$ cobbles, it would be able to identify boulders with diameters $\geq 1 \mathrm{~m}$. Detailed spectroscopic analysis of unresolved sediments would reveal the particle size. The combination of these techniques would allow us to determine the nature of flow and sediment transport in Titan's channels.

\subsubsection{Science objective 1.3: dunes}

Dunes record some of the most recent activity on a planetary surface, they are important indicators of the erosive and depositional processes that produce sand, and they help determine the persistence of wind in the near-surface atmosphere. We pursue the following Science Tasks to evaluate the conditions on Titan that have led to the current state of the dunes.

Task 1.3a Ascertain the present state of activity in Titan's dunefields. Planetary dune forms record wind directions and strengths [78, 115] and the thickness of the atmospheric boundary layer [4, 83], and require the presence of sands that can be moved by winds. Thus, it is critical to understand whether dunes on Titan are currently active to know if measured Titan conditions are those that produced the atmospheric and sedimentological processes necessary for dune formation and evolution. Dunes on Titan are not carved by channels or overlain by other features visible at Cassini RADAR resolution, and many of the regions in between Titan's dunes are sand-free [9]. Thus, the dunes are among the youngest surface features on Titan and could possibly be active. AVIATR could search for two major features-dune crests and ripplesto determine the current level of activity of Titan's dunes (Fig. 9). Dune crests form along the long axis of linear dunes and record the effects of the most recent winds on the dune summits. These are typically several meters high above the dune surface and have asymmetric profiles [61]. Ripples are smaller features, several to tens of centimeters in wavelength on Earth, and form from grain collisions resulting in downwind motion (e.g. [3]). Lorenz et al. [83] calculates that ripples on Titan should be of order $\sim 1.5 \mathrm{~m}$ in size. Since these features change so quickly [131], their orientations would record the immediate wind strength and direction. Both features, dune crests and 


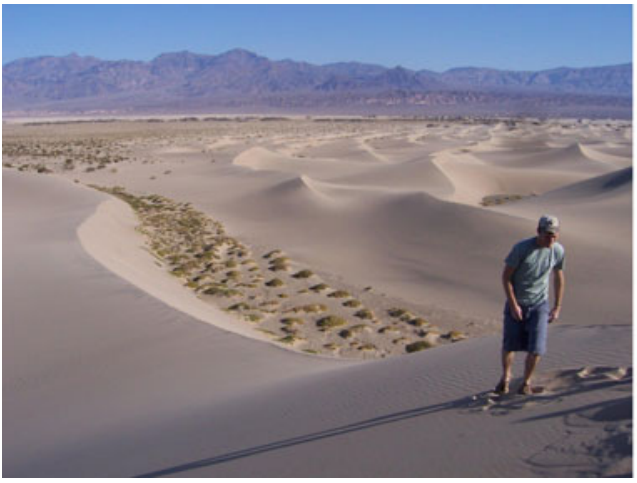

(a)

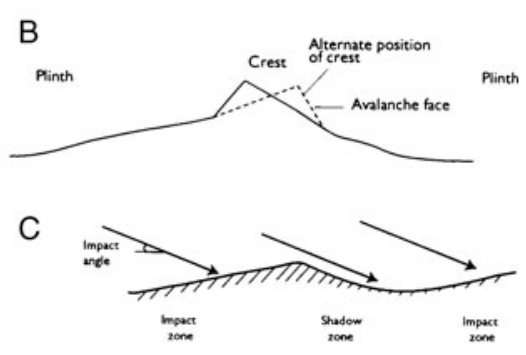

(b)

Fig. 9 a Crests and ripples (near the student's feet) at Stovepipe Wells, Death Valley National Park. b Linear dune crest, steep avalanche slope contrasts with gentler upwind slope. c Model for ripple formation. Particles are impacted on the upwind side and transported downwind. $\mathbf{b}$ and $\mathbf{c}$ from Lancaster [61]

ripples, indicate dunes that are currently active. Otherwise these features would quickly round or become flattened by fluvial erosion.

Task $1.3 b$ Measure the wind and climate regime for dune formation and evolution. From an airplane we can obtain measurements of wind speed and direction. If we determine that dunes on Titan are currently active, then wind speed and direction measurements can tell us the current conditions that enable the formation and evolution of dunes. These measurements would be valuable for solar system dune research, since it is thought by some researchers that most of the large, linear dune fields on Earth are remnants of Pleistocene conditions. If this is true, and Titan dunes are found to be active, then Titan is the only location in the solar system where we can study currently forming and evolving, large, linear dune fields. If we find that Titan's dunes are stabilized and no longer forming or moving in a region, then our measurements of the current conditions can be compared with our predictions for conditions required for dune formation and evolution. This can help us determine what changes have occurred that lead to dune stabilization. Aerial observations of dunes interacting with topographic obstacles could help us to determine wind directions on Titan, which is currently challenging for modelers [151] and observers [78]. We could also measure relative humidity from our platform to help constrain climatic conditions pertinent for dune formation on Titan.

Task 1.3c Infer climatic changes over varying timescales from compound dune forms. Large dune fields can record climatic conditions over long time scales. Three sets of linear dunes in Mauritania ranging in age from 24,000 years to today, each recording different climatic conditions required for their growth, 
are superimposed on each other as compound dunes [62]. By analyzing overlapping dune forms, we can determine how stable climatic conditions are for a given region. The observation of a single, global set of linear dunes with no small superposed forms would tell us these dunes are highly mature, and that climate conditions have been stable and wind directions and sand supply constant over significant time scales. If Titan's dunes respond as Earth's do, then we can directly test whether Saturn's Milanković cycles significantly affect Titan's climate as suggested by Aharonson et al. [2].

Task 1.3d Constrain the global cycle of aeolian sediment production and transport. Based on spectroscopy and modeling, it is thought Titan's dune sands are composed of organic species ultimately derived from atmospheric haze particles [135], and are possibly aromatic hydrocarbons [29]. However, how these sands move from the atmosphere into sand seas is unknown. AVIATR's instruments would allow spectral inspection of sand source regions, both at the fringes of dune fields and at the uniform midlatitudes, perhaps linking some of these regions with fluvial processes. These data would allow us to try to determine the mode of transportation of particles from one region to the other. Differences in wind speed and direction with latitude on Titan could be measured from our aircraft, and these coupled with observations of regional variations in topography would help us to understand the placement of dune fields. Finally, we would seek correlations between sand sources and the local organic haze concentrations from the atmosphere using the AVIATR aerosol sensor.

\subsubsection{Science objective 1.4: lithosphere}

Titan is not the only icy moon with an active surface. But given the ease of surface access that Titan's thick atmosphere provides, close-up observations of Titan's surface activity would provide our first look at the processes that shape icy moons throughout the outer solar system. Doing so helps to place other active moons, like Europa [59], Enceladus [141], and Ganymede [112], into context.

Task 1.4a Determine the faulting regime that creates Titan's mountains. The surface of Titan shows diverse topography in response to dynamic internal and surface processes. Chains of eroded mountain ranges within $50^{\circ}$ of the equator $[8,114]$ and rectilinear fluvial networks [26] may imply geologically recent tectonism. Mountains can form in all faulting environments (thrust, normal, and strike-slip) and multiple faulting styles may, in fact, be present [116]. Therefore accurate characterization of the tectonic regime on Titan requires unequivocal identification of fault types along range-fronts and characterization of the spatial patterns of fault types.

AVIATR can capture regional mosaics of individual mountain ranges (e.g., Fig. 10), allowing range-front fault patterns to be regionally mapped. Highresolution imaging of targeted fault scarps via the 2-micron imager would 
Fig. 10 This 2008 May

Cassini RADAR view shows east-west oriented mountains (light-colored areas) on Titan. Arrows show RADAR-dark lineaments, potentially fault scarps

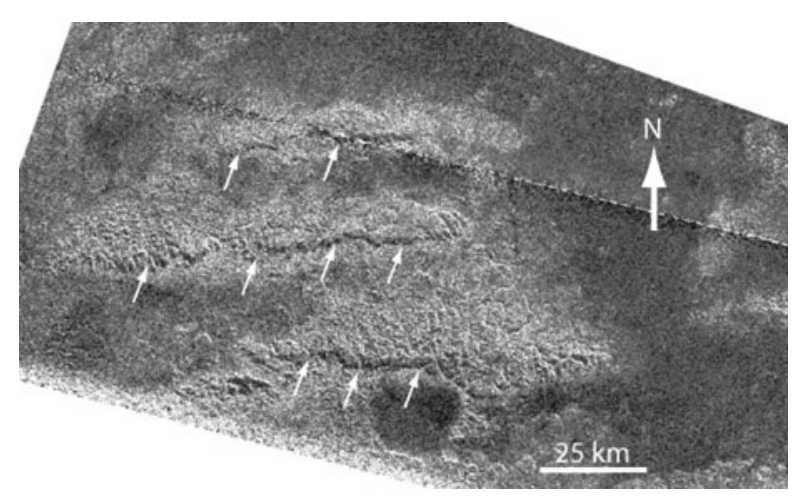

elucidate fault types. Stream crossings of fault traces are good target sites as they may illustrate fault offset-sense. Identification of fault types would indicate principal stress orientations, providing a framework for theoretical studies of the source of stresses that drive tectonics on Titan.

Task $1.4 b$ Infer geologic and climatic history from layering exposed in mountain faults, incised channels, and craters. Unraveling the geological history of the Earth is facilitated by analysis of the stratigraphy (layering), which reveals a sequence of events and the conditions that existed at each point in time. Titan offers opportunities for analogous investigations given its dynamic surface, with river drainages that dissect mountainous topography. RADAR observations [56] and spectral analyses [8] of mountains suggest unique nearsurface compositions relative to adjacent terrains such as river drainages, possibly reflecting compositional differences between lowland surface materials (rich in hydrocarbons) and shallow crustal materials (likely richer in water-ice) exposed in mountain uplifts. The meter-scale spatial resolution of the AVIATR spectro-imager would illuminate compositional variability. Pervasive denudation of mountains by river drainages provides opportunities to image the compositional stratigraphy and thus illuminate variability in Titan's upper crustal make-up. Near-surface stratigraphy would reveal the recent geologic history of Titan including changes in geological conditions and driving climatic forces. Layering in impact crater walls and eroded canyonlands would add to the body of data on erosion and sedimentary processes, providing additional constraints on past climatic conditions (Fig. 11). The meterscale spatial resolution of the AVIATR spectro-imager would also reveal differences in composition between different layers.

Task 1.4c Evaluate the cryovolcanic nature of proposed flow features. Several different surface features observed by Cassini to have lobate or flow-like morphologies have been postulated to have cryovolcanic origins $[6,64,70$, $110,137,139,161]$. Titan's large size suggests enough internal heat to generate subsurface melts and surface eruptions [149]. Prior searches for such eruptions 


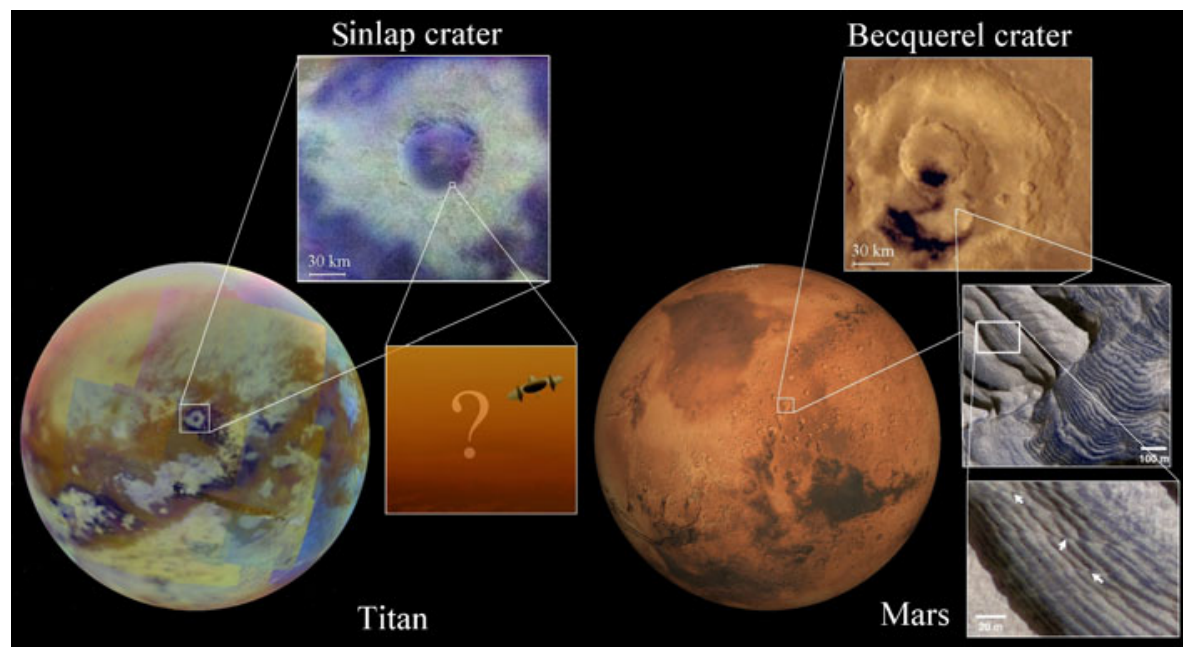

Fig. 11 Comparison between Sinlap impact crater on Titan and Becquerel crater on Mars. Submeter resolution HiRISE images (bottom right, adapted from Chuang et al. [28]) reveal series of regular layers in the martian crater floor. Similar features would be resolvable in images taken by AVIATR

have been inconclusive as a result of resolution constraints (e.g., at $300 \mathrm{~m}$ or coarser, flow features from surface processes are difficult to distinguish from those produced by eruption of internally derived material; [106]) and the lack of an empirical prototype on which to premise the search (e.g., we do not know what a cryoflow should look like). However, paired observations, including 5- $\mu \mathrm{m}$ anomalies from VIMS, suggest that some of the flow-like materials may be recent and unique $[6,137]$. We would observe and interpret flow-like features at much higher spatial scale with AVIATR on Titan in the context of several leading hypotheses: cryovolcanic eruption, deposition, or dissolution. If cryovolcanic, a flow should be lobate and elevated, may issue from a fissure or isolated vent, and may have unique spectral characteristics. If fluvial, a flow should be fed by a clear channel that originates from high elevations. If a flow is from dissolution, the materials should have overlapping, rounded, steep margins, and should form depressions rather than be elevated. These distinguishing features should be clearly visible at our resolutions, allowing us to resolve the question of whether cryovolcanism, and thus internal activity, is important in Titan's recent past.

Task 1.4d Use crater forms to infer the nature of erosion and Titan's lithosphere. So far, very few impact craters have been unambiguously identified on Titan by Cassini [38, 65, 138, 165], implying the surface of Titan is geologically young. These craters display various stages of degradation, due to variations in age, regional erosion processes, or sedimentation infilling rates. Detailed morphological analyses of leading crater forms, which were hampered by the limited spatial sampling of Cassini's instruments, would be possible with the 
imaging instruments on AVIATR. Meter-scale spatial resolution would allow a detailed morphological and compositional study of central peaks, crater rims, and ejecta blankets. Central peaks provide a window into the vertical heterogeneity of the crust by excavating materials from between one fourth to one tenth of the crater diameter [99]. In addition, the exact shape of crater bowls, constrained by AVIATR stereoscopic imagery, would provide information on the relaxation of crater topography and thus the rheologic properties of the crust.

\subsubsection{Science objective 1.5: exploration}

In addition to hypothesis-driven science intended to answer specific questions, AVIATR would also spend some of its resources to explore new areas at high spatial resolution and to lay the groundwork for future missions.

Task 1.5 a Explore the midlatitude "blandlands" and other areas not wellexplored by Cassini-Huygens. So far, less than $40 \%$ of the surface of Titan has been imaged by the SAR onboard Cassini. The total surface coverage might rise up to $60 \%$ by the end of the Cassini mission in 2017. On the other hand, if almost all the surface will be mapped at $\sim 15-20 \mathrm{~km} /$ pixel with VIMS, only a few percent will be seen with sampling better than $5 \mathrm{~km} /$ pixel, although it is generally agreed that a subkilometric resolution is mandatory to allow any thorough geologic and geomorphologic study. The mid-latitudes $\left( \pm 30^{\circ}\right.$ to $60^{\circ}$ ) are so far particularly poorly imaged in RADAR. Yet they contain very important surface features that might bridge the gap between actual processes and past processes on Titan, and for comparison with the better-documented tropics and polar regions.

In particular, the very few RADAR swaths crossing these latitudes reveal that several empty lakes are partially buried under sediments down to latitudes of $50^{\circ} \mathrm{N}$. Several surface cryovolcanic or sediment-laden flow features have been recognized at $50^{\circ} \mathrm{N}$ near Ganesa Macula [70]. On the opposite hemisphere, at about $55^{\circ} \mathrm{S}$, numerous fluvial features have been recognized in the third radar swath [88]. The overall impression generated by this third radar data was that of a landscape that is descending in elevation toward the pole, dissected by rain- or spring-fed fluvial channels, and ending in a now- or recently- wet high altitude basin bordered by scalloped and embayed terrain [88]. However, no well resolved optical images are available to further constrain the geomorphology of these areas, which would be easily observed by AVIATR instruments. The meter-scale resolution of the off nadir camera would allow us to place constraints on the main characteristics of drainage basins, by investigating the width of the channels and their tributaries, which in turn give strong constrains both on the nature of the substrate and the climatic conditions.

There is a persistent cloud belt located at almost all longitudes on Titan at $40^{\circ} \mathrm{S}$ since 2004 [122-124]. The question is still fully open as to whether feedbacks exist between surface features and cloud occurrence in these mid- 
latitudes. Surface features at $\sim 40^{\circ} \mathrm{S}$ may partially control the longitudinal structure of the cloud belt, as it is observed by Cassini just above the southern part of Xanadu, where clouds are found to be very rare [123]. Inversely shortlived mid-latitude clouds may rain down and produce transient geological features like small and very localized lakes or fluvial networks. These could be finely inspected by AVIATR.

Finally, the polar areas have not been well imaged with the optical cameras of Cassini, due to the very strong atmospheric scattering induced by the observing geometry. AVIATR, by operating under most of the scattering haze layers, would provide very sharp images and spectra of the liquid-filled areas in these polar regions. AVIATR could possibly reveal surface changes in the north, where the lakes and sea level could have significantly decreased during the summer season, which will end in 2023.

Task $1.5 b$ Identify potential landing sites of scientific interest and constrain safety. The AVIATR mission would likely discover new and intriguing things about Titan that are likely to motivate future landed (or floated) missions. In our landed forays to Mars, orbital spacecraft that surveyed the planet provided both the context for the kinds of science investigations that a lander could carry out as well as detailed information on the potential landing site safety characteristics of a given site (e.g. [16]). AVIATR can perform that kind of reconnaissance for a potential future Titan mission.

Areas identified for more detailed study can be targeted by AVIATR. AVIATR can help discover and map interesting mineral outcrops with its spectrometer, and its cameras can provide both regional context and highresolution coverage for assessing geomorphology, rock counts, areas of interest, and rover trafficability. Our ability to capture stereo imagery would allow us to make terrain models to judge various landing site safety criteria like slopes of various length scales as well as determining trafficability.

Task 1.5c Search for prebiotic molecules and evidence for astrobiological activity. The key requirements for life are often listed (e.g. [95]) as (1) a source of energy, usually sunlight or chemical redox reactions; (2) carbon; (3) liquid water; and (4) some combination of other elements such as nitrogen, oxygen, phosphorous, and sulfur. This list is clearly based on life as we know it here on Earth. One of the intriguing aspects of Titan is that it has all of these requirements for life with one substitution: liquid methane instead of liquid water.

Benner et al. [15] first suggested that the liquid hydrocarbons on Titan could be the basis for life, playing the role that water does for life on Earth. Benner et al. [15] pointed out that "... in many senses, hydrocarbon solvents are better than water for managing complex organic chemical reactivity". Two papers in 2005 followed up on this logic by computing the energy available for methanogenic life based on the consumption of organics in Titan's atmosphere with $\mathrm{H}_{2}$ in the atmosphere [96,129]. Organic molecules on the surface of Titan (such as acetylene, ethane, and solid organics) would release energy if they 
reacted with hydrogen to form methane. Acetylene gives the most energy, at over $334 \mathrm{~kJ} / \mathrm{mole}$ of $\mathrm{C}_{2} \mathrm{H}_{2}$ through the reaction

$$
\mathrm{CH}_{4} \text { by: } \mathrm{C}_{2} \mathrm{H}_{2}+3 \mathrm{H}_{2} \Rightarrow 2 \mathrm{CH}_{4}
$$

However, this reaction is kinetically inhibited, thus creating an opportunity for biological metabolisis. Life can thrive in an environment that is rich in chemical energy but requires a catalyst for the chemical energy to be released.

McKay and Smith [96] predicted that if there were life on Titan living in liquid methane then that life should be widespread on the surface because liquid methane is widespread on the surface. In addition to the lakes mentioned above, we have direct evidence that the surface of Titan at the landing site of the Huygens Probe near the equator was moist with methane. Methanebased life would have a lot of environments in which to live. McKay and Smith [96] predicted that life at the surface of Titan would consume near-surface hydrogen and that this might be detectable. The depletion of hydrogen is key because all the chemical methods suggested for life to derive energy from the environment on Titan involve consumption of hydrogen [96, 129]. Acetylene, ethane, and solid organic material could all be consumed as well. The key conclusion of that paper (last line of the abstract) was "The results of the recent Huygens probe could indicate the presence of such life by anomalous depletions of acetylene and ethane as well as hydrogen at the surface."

It has been long appreciated that there is not as much ethane on the surface of Titan as expected prior to Cassini (e.g. [54, 164]). Now, Clark et al. [29] are reporting depletions of acetylene at the surface. The depletion of ethane and acetylene become significant in the astrobiological sense because of a recent report of a flux of $\mathrm{H}_{2}$ into the surface [148]. The determination by Strobel [148] that there is a flux of hydrogen into the surface of Titan is not the result of a direct observation. Rather it is the result of a computer simulation designed to fit measurements of the hydrogen concentration in the lower and upper atmosphere in a self-consistent way. If correct, this is the key that suggests that these depletions are not just due to a lack of production but are due to some kind of chemical or biological reaction at the surface. These depletions are exactly what is expected if Titan has life-certainly not proof of life but very interesting if confirmed.

The AVIATR mission would be able to confirm the surface concentrations of ethane and acetylene in much more detail than is possible with Cassini. In particular AVIATR would be able to determine if suface depletions of these potential feedstocks is associated with present lakes, dried lake beds, or shorelines-all possible indicators of the role of liquid in the depletion.

In terms of more conventional water-based life, AVIATR would be able to map the surface for locations of possible hydrothermal activity which might bring water-ammonia mixtures to the surface in contact with the tholin produced in the atmosphere. Laboratory experiments $[108,109]$ show that this can result in the formation of prebiotic organic molecules that may have unique signatures in the spectral infrared [109]. 


\subsubsection{Science objective 2.1: winds \& structure}

One of only four terrestrial Solar System bodies with a thick atmosphere, Titan offers a rare opportunity to study a unique regime of atmospheric dynamics. Titan's 1.5 bar nitrogen atmosphere with a condensible trace gas species most closely resembles Earth's. However Titan's superrotating zonal winds share similarities with Venus. Winds on planets other than Earth are measured by tracking cloud features, which act as tracers of the atmospheric circulation. Unlike Earth, Titan is shrouded in a thick stratospheric haze and lacks widespread cloud coverage, making remote observations of global winds a challenge. The Huygens probe measured one complete wind and structure profile $[17,60]$. But with its go-to, in situ capability, AVIATR would enable characterization of the entirety of Titan's troposphere.

\section{Task 2.1a Trace global circulation via measurement of zonal and meridional} winds in the troposphere. AVIATR's expected lifetime of one year is wellsuited to characterize time-dependence that is expected for Titan's winds. The table below illustrates several potential sources of wind variability. Gas Chromatograph Mass Spectrometers (GCM) predict a large tropospheric seasonal cycle which causes reversals in zonal and meridional winds (e.g. [103, 150]). Thermal tides from the day-night difference in solar heating operate on Titan's diurnal cycle (16 Earth days), although their influence is likely to be somewhat weak in the troposphere [152]. Saturn's gravitational tide is semi-diurnal (8 Earth days) and strongest in the lower troposphere [153]. A variety of wave phenomena may also occur due to local and global instabilities. These operate on a range of relatively short timescales from hours to days. Cloud formation may be triggered globally by "teleconnection" through propagating wave phenomena, for instance [128]. GCMs predict the occurrence of large-amplitude, global-scale disturbances that drive atmospheric superrotation [102].

\begin{tabular}{llll}
\hline Source & Time scale & Zonal wind & Meridional wind \\
\hline Seasonal cycle & 15 years & $\leq 10 \mathrm{~m} / \mathrm{s}$ & $\leq 1 \mathrm{~m} / \mathrm{s}$ \\
AVIATR-1 year & & & \\
Thermal tide & 16 days & $<0.5 \mathrm{~m} / \mathrm{s}$ & $<0.5 \mathrm{~m} / \mathrm{s}$ \\
Gravitational tide & 8 days & $\sim 2 \mathrm{~m} / \mathrm{s}$ & $\sim 2 \mathrm{~m} / \mathrm{s}$ \\
Waves & hours to days & $\sim 5 \mathrm{~m} / \mathrm{s}$ & $\sim 5 \mathrm{~m} / \mathrm{s}$ \\
\hline
\end{tabular}

With a lifetime of a year, AVIATR would characterize the time-varying wind components identified above on time scales shorter than the seasonal cycle. Observations of these waves would allow characterization of their sources, which are due to localized phenomena like methane storms, global forcing like tides, global instabilities like those driving superrotation, or some other yetto-be-discovered source. Seasons cause significant changes in the atmospheric overturning circulation, or Hadley cell, every $\sim 15$ years. A year of observation would therefore provide a snapshot of the seasonal circulation pattern. Global 
characterization of this pattern is a fundamental test of current GCMs which predict a seasonal reversal of Titan's Hadley cell and large changes in the pattern of tropospheric zonal winds. Preliminary observations during the early stages of the AVIATR Titan mission would help maximize the return of the later stages by enhancing the accuracy of model wind predictions employed for mission planning. Accurate wind prediction is also relevant to future Titan missions, which would then benefit by having narrower landing ellipses.

\section{Task $2.1 b$ Constrain the methane cycle by measuring the global atmospheric} transport patterns of methane. Titan's methane abundance has been measured only once in situ, by the Huygens GCMS [111]. The Huygens measurement revealed a low-latitude methane abundance that has constant concentration with altitude below $8 \mathrm{~km}$ and is saturated at higher altitudes. The surfacelevel saturation ratio of methane measured by Huygens was $<50 \%$, which is somewhat puzzling considering the surface itself was moistened with methane. A reanalysis of Voyager data suggests the same surface-level humidity existed decades ago, so these conditions may be persistent over long periods of time [98].

Simple arguments show why this might be the case. There is a large amount of liquid-equivalent methane vapor-a 5-m ocean worth-in Titan's atmosphere. Energetic arguments suggest that only a very small fraction of this amount $-7 \mathrm{~cm}$ - can be evaporated by the available radiative energy in a 7.4 Earth year Titan season [42]. On the other hand, clouds have now been observed at high- and mid-southern latitudes, near the equator, and near the north polar lakes. Convective cloud formation would need an enhancement in surface-level methane vapor relative to the Huygens measurement in order to energize vigorous storms [14]. A key question to be answered by AVIATR then is: Does the methane concentration vary in space and/or time?

AVIATR would provide global, in situ measurements of the distribution of atmospheric methane vapor. With its go-to capabilities, AVIATR would be able to observe targets of opportunity that are permanent, like polar lakes, or more temporary events that may arise during the mission. For instance, large storms historically tend to form quickly and dissipate on the order of days (e.g. [48]). AVIATR's $6 \mathrm{~m} / \mathrm{s}$ cruise speed allows it to cover $\sim 1,000 \mathrm{~km}$ in two days. Low-level measurements before and after a large storm would help constrain regional and global models of Titan's methane cycle.

Task 2.1c Understand the diversity of atmospheric stability in the context of global circulation. During its descent to the surface, Huygens measured the atmospheric lapse rate in Titan's troposphere [39]. The lapse rate plays a key role in determining whether and when convective (cumulus) clouds form. As such, measurement of the lapse rate can help to constrain global cloud distributions as a function of season, and can more directly constrain the inputs to Global Circulation Model (GCM). McKay et al. [98] compared the Huygens temperature profile to the two obtained in 1980 from a Voyager radio occultation [69] (Fig. 12). By obtaining two vertical atmospheric pressure/temperature 
Fig. 12 Titan atmospheric temperature profiles as measured from Huygens and Voyager (from McKay et al. [98])

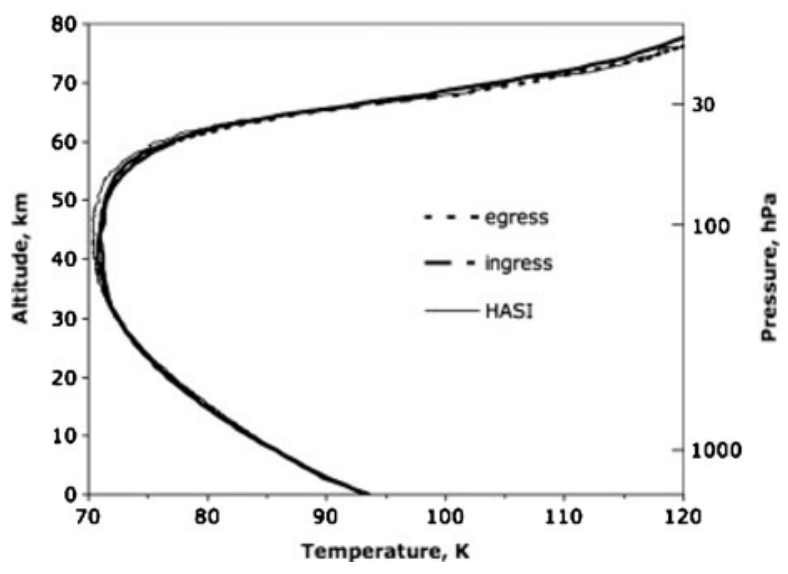

profiles every Earth day, AVIATR would acquire over 600 such profiles, and would do so at a variety of latitudes, longitudes, and local solar times. The resulting matrix of profiles would provide strong constraints on Titan's atmospheric state at the time, and may allow for observations of its timeevolution if there are strong enough changes over the 1-year nominal mission.

\subsubsection{Science objective 2.2: clouds \& rain}

While Venus, Mars, and the giant planets have clouds, Titan is the only other place in the solar system where it rains [159]. Cassini has gauged the global distribution of Titan's clouds [25, 122, 123, 158, 160]. AVIATR would offer a fresh perspective, sampling particles from within clouds, watching clouds evolve vertically, and measuring raindrops.

Task 2.2a Characterize clouds' diversity using particle number densities. As on Earth, the clouds on Titan are varied in origin. Cassini has variously seen convective "thunderstorm" clouds (but without the thunder; [45]), fog [23], lake-effect clouds [22], and polar ethane clouds [46]. All of these clouds have different optical depths and heights, and evolve with time. The ADS onboard AVIATR was designed to measure atmospheric haze particle radii and densities, but if and when AVIATR flies through clouds we would use it to ascertain the particle size and number density of cloud particles as well.

Task 2.2b Constrain global circulation and cloud formation by determining clouds' vertical structure and time evolution. An important goal of AVIATR is to explore Titan's methane hydrological cycle. We wish to better understand how the circulation controls the locations where clouds and precipitation most often occur, and how the moist convection in turn modifies the circulation. Where, how often, and how intensely precipitation occurs bears on such questions as to whether the polar lakes are fed primarily by rain or underground 'aquifers', whether heavy rains occur at low latitudes in the present climate and 
contribute significantly to the formation of the channels seen in Cassini DISR images [155], and what processes return methane to the atmosphere to balance the loss due to precipitation. We do not yet have a complete picture of where and how often clouds form on Titan, nor how often it rains. Titan's clouds have been observed in various latitude regions that vary seasonally. Some clouds form in areas of strong insolation and therefore suggest a convective origin driven by surface heating. These likely trace large-scale convergence by the atmosphere's overturning circulation. Other clouds have been claimed to form over specific geographic features on the surface [125]. Depending on the season, convective methane clouds will likely occur near the summer pole and midlatitudes and may also occasionally occur in the tropics [104]. Frequent ground-based monitoring of Titan will be undertaken by our team in order to target short-lived cloud events.

AVIATR would allow us to examine cloud vertical structure at a variety of latitudes for both small- and large-scale cloud systems. Convective clouds at Titan's southern midlatitudes have been observed to evolve vertically on short (30 min) timescales with updraft velocities of $\sim 10 \mathrm{~m} / \mathrm{s}$ [45]. Convective cloud altitudes can be used as a probe of the stability and humidity profile of Titan's atmosphere [13, 47, 48, 53]. AVIATR, flying at altitudes of 3-14 $\mathrm{km}$, is perfectly positioned to observe cloud base formation and subsequent cloud evolution with the Horizon-Looking Imager (HLI). Measurements of cloud base altitudes by AVIATR at different latitudes would allow us to probe the local surface methane humidity. Profiles of temperature, specific humidity, and winds in the vicinity and inside the clouds would allow us to measure the Convective Available Potential Energy (CAPE), strength of updrafts and downdrafts, and degree of saturation below the 14-km level, all essential measurements for understanding the onset of moist convection, precipitation, and overall cloud dynamics.

Cloud formation itself does not necessarily indicate the presence of precipitation since low methane humidity near the surface causes raindrops to evaporate. Microphysical modeling suggests that raindrops may reach the surface when evaporative cooling is taken into account [41]. The surface of Titan shows areas with drainage networks having various morphologies $[8,26,38,81]$. With strong similarities to river networks found on Earth, Titan's valley networks were likely eroded by surface runoff associated with precipitation, most likely methane. One network, Elivagar Flumina, possibly formed due to flash flooding from very heavy precipitation.

The Titan atmosphere holds a $5 \mathrm{~m}$ global ocean worth of methane vapor. Like strong storms on Earth, convective clouds evolve in as little as two hours [45], suggesting that methane is raining out of the atmosphere. The total depth of condensed methane exceeding saturation in the troposphere could be a meter or more (both liquid and graupel). If this amount of methane were to precipitate out of the atmosphere in two hours, the resulting runoff would be more than sufficient to move large boulders. The total solar insolation only allows an average of a few $\mathrm{cm}$ of methane rainfall per year, but significant erosion due to rain and rivers can occur if precipitation events are severe, 
albeit rare. While convective clouds have often been seen, and geological features seem to present a record of fluvial erosion, substantial precipitation has avoided direct observation. Turtle et al. [158] report possible evidence of precipitation in the south polar region revealed by changes in ponding of hydrocarbon liquids seen in ISS images, and Turtle et al. [159] show surface changes from a tropical rainstorm. Elsewhere, only at most a light drizzle has been observed [82,154]. AVIATR would have a unique capability to constrain the frequency, intensity, and location of rain on Titan's surface by passively detecting the impact momentum of droplets that encounter the aircraft in flight. These in-situ measurements would determine whether surface fluvial erosion is the result of Titan's past or present climate.

Task 2.2c Ascertain where, when, how often, and how intensely it rains on Titan. ISS observations of a storm-wetted surface [159] have empirically confirmed theoretical predictions that rain reaches Titan's surface [41]. The origin of the observation in question was a very widespread storm event raining onto equatorial bright terrain. Smaller-scale storms, rain on dark terrains like the sand dunes, or light drizzle [1] could not be detected this way. While flying through Titan's lower atmosphere, the SRD on AVIATR would listen for raindrops impacting its strike plate. Assuming that such drops were falling at their terminal velocity, we can then back out the drops' radius distribution (assuming a density) and number density, which would allow a general investigation of Titan's rain storm systems.

\subsubsection{Science objective 2.3: haze}

Titan is enshrouded by a haze of aerosol particles. These solid particles are produced at very high altitude in Titan's stratosphere at $\sim 350 \mathrm{~km}$. There, gaseous $\mathrm{N}_{2}$ and $\mathrm{CH}_{4}$ that primarily compose Titan's atmosphere dissociate into more and more complex organics and nitriles which lead to form heavy H-C-Nbearing molecules of a few tens of nanometers in diameter. These "monomers" stick to each other and grow into fractal aggregades that then start to settle down towards the surface forming an extensive, dense, and ubiquitous layer of haze [63]. It is known from Voyager and Cassini-Huygens observations that the Titan's haze is vertically and geographically structured (Fig. 13). AVIATR would be in a particularly advantageous in situ position to thoroughly observe and characterize the lowest part of the Titan's haze between 3.5 and $14 \mathrm{~km}$.

Task 2.3a Constrain global patterns of haze transport and time evolution. As observed in details by the Huygens probe near the equator during its descent into Titan's atmosphere in 2005 January-the only in situ measurement of vertical haze properties so far-the distribution of haze particles is not homogeneous with altitude [156]. The haze presents two abrupt changes in properties at $\sim 80$ and $\sim 30 \mathrm{~km}$. Between 30 and $80 \mathrm{~km}$, the haze fractal particles are thought to have accumulated additional material (liquid or solid ethane and methane) in the spaces between the monomers. In the lowest 

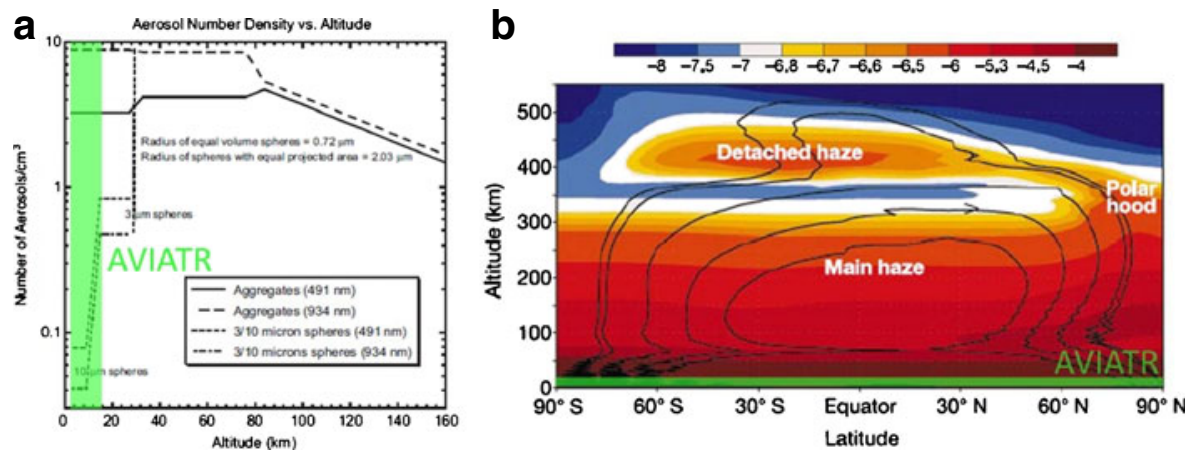

Fig. 13 a The haze number density and aerosol size and shape as a function of altitude at tropical latitudes as inferred from the Huygens observations (from Tomasko et al. [156]). b Twodimensional planetary distribution of Titan's haze scaled extinction (from [118]). The detached haze appears as a secondary layer at $\sim 400 \mathrm{~km}$ overlying the main haze (below $300 \mathrm{~km}$ ) from one pole to the other. The haze is preferentially accumulated near the pole. The wind direction is illustrated by the stream function integrated from $L_{s}=274^{\circ}$ to $L_{s}=353^{\circ}$, where $L_{s}$ is the solar longitude (northern spring equinox occurs at $L_{s}=0$ ?). The winds are from the south polar region (summer) toward the north polar region (winter). Green rectangles show the altitude and latitude domains to be explored by the AVIATR plane

$30 \mathrm{~km}$, Titan's atmosphere tends to become much clearer with larger but fewer particles.

Since the Voyager 1 and 2 flybys in 1980's and from Global Circulation Model (GCM), we also know that Titan's haze presents seasonal large-scale geographic structures at high altitude $[117,118,143]$, with an extensive polar hood above the winter pole and a detached haze layer $(\sim 400-500 \mathrm{~km}$ altitude) extending from the winter to the summer pole to above the main haze layer. At low altitude, the haze is predicted to lose its large scale structures to become more homogeneously mixed [118]. Unfortunately, the Huygens observations of the haze were limited to a unique location at a given period of time. On their side, GCMs lack spatial and time resolution and have been hitherto poorly constrained by observations. As a result, Titan's haze properties as a function of latitude, longitude, and time remain still poorly known, particularly near the surface. At low altitude, winds, local-scale circulation and cloud formation result in the transport of aerosols, which leads to regional variation in the aerosol size distribution. Some aerosols serve as cloud condensation nuclei that are scavenged in the process of cloud formation, and others are likely entrained in droplets during precipitation [54]. The mobility of AVIATR would provide the critical observations necessary to evaluate the interaction of aerosols with the ambient environment and meteorology during an entire terrestrial year from tropical to polar regions. Direct haze concentration measurements from the Aerosol Density Sensor (ADS) would determine the haze particles' radii amd density from various latitudes, longitudes, and altitude in the $3.5-14 \mathrm{~km}$ range. 
Task 2.3b Measure the spatial variability of haze scattering properties. While seasonal variation in the global distribution of stratospheric aerosol has been connected to the general circulation, large-scale changes to tropospheric aerosol are poorly constrained by observations. The spatial distribution of aerosol scattering is generally considered to be globally uniform-matching the scattering phase functions measured by Huygens-because observations from outside the atmosphere alone are not uniquely constrained by a particular aerosol scattering model. The meteorology that occurs on Titan suggests that this simplification will not withstand closer scrutiny. AVIATR would provide the spatial, vertical, and temporal resolution required to monitor the changes in aerosol scattering properties, by making downward probing measurements from diverse locations within the atmosphere.

With the ability to measure upward fluxes at various altitudes, AVIATR would provide Huygens/DISR quality interpretation of the aerosol scattering efficiency and phase function at multiple times and geographic locations. The $1-5.6 \mu \mathrm{m}$ spectral bandpass covers wavelengths that are diagnostic of hydrocarbons, constraining aerosol composition via the reflectivity spectrum. Even in the absence of changes due to short time-scale meteorology, the aerosol morphology and composition is expected to vary with altitude. Hydrocarbon condensation and deposition onto the aerosol will change the composition of at least the surface layers during sedimentation. Understanding the evolution of the aerosol as it forms and passes through the atmosphere may lead to improved predictions of the composition and structure of the material that eventually reaches the surface.

Task 2.3c Constrain the rate of haze production and sedimentation on Titan's surface. After sedimentation down to the surface, Titan's atmospheric aerosols presumably form a deposit of complex refractory organics and frozen volatiles. Their continuous deposition at the surface over geological times constitutes one of the major sinks in Titan's carbon cycle. The surface accumulation rate of aerosols highly depends on their production rate at high altitude and the microphysical processes that govern their fate throughout the atmosphere. This still needs to be fully understood. Using microphysics to model the growth and fate of Titan's atmospheric aerosols, studies $[118,157]$ predict a deposition rate of $0.1 \mu \mathrm{m}$ per Titan year. Once at the surface, aerosol particles are also thought to partly compose the sand that make up the extensive dunefields observed by Cassini in Titan's tropical regions. They are very good tracers of ongoing erosion processes (eolian and fluvial) at Titan's surface. Titan's aerosol sedimentation rate, balance of carbon cycle, and erosion mechanisms are poorly constrained at present. We demonstrate that the AVIATR mission is able to bring direct clues to address these questions through its mobility and capability to provide imaging and spectroscopy of the Huygens probe and parachute, which landed at Titan's surface almost two decades before AVIATR's arrival. An example of the martian Phoenix lander viewed and resolved from orbit by the Mars Reconnaissance Orbiter (MRO) meter-scale resolution imagers is given in Fig. 14. 


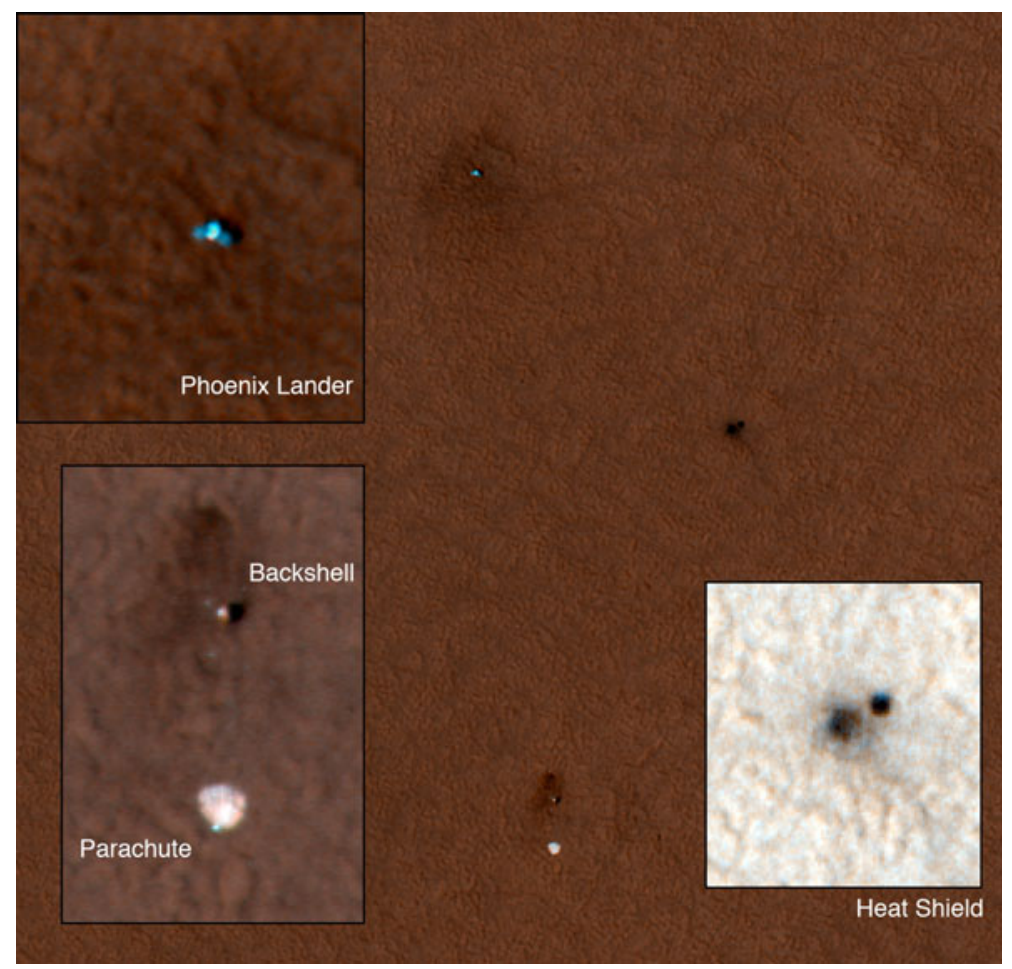

Fig. 14 Phoenix lander, parachute, backshell and heat shield imaged at sub-meter resolution by the HiRISE instrument onboard Mars Reconnaissance Orbiter (MRO) (NASA/JPLCaltech/University of Arizona)

The complementarities between cameras and imaging spectrometer would give the opportunity to see direct evidences of aerosol deposits on the probe and parachute over almost a 20 -year interval. The $2 \mu \mathrm{m}$ camera would provide the high-resolution views of the probe and its parachute, giving a first visual inspection for the presence, or not, of deposits. Simple calculations show that a theoretical contrast between probe material (aluminum and nylon) and aerosols of $25-75 \%$ can be expected in Titan's infrared atmospheric windows. Looking at probe spectra would bring an indication of the percentage of aerosols covering each 'probe pixel' (Fig. 15). Reference spectra of atmospheric deposits can be provided in-situ by areas surrounding the probe. A complete radiative transfer model simulating the effect of a thin coating [50] would also provide a more quantitative estimate of the deposit thickness.

The calculated area of the aerosol deposit on the Huygens probe and its parachute would give us the first observational constraint on the aerosol sedimentation rate and the strength of the erosion processes at Titan's surface. If the aerosols totally cover the probe and its parachute, it would provide a lower limit on the haze sedimentation rate and evidence for low energy or 
a

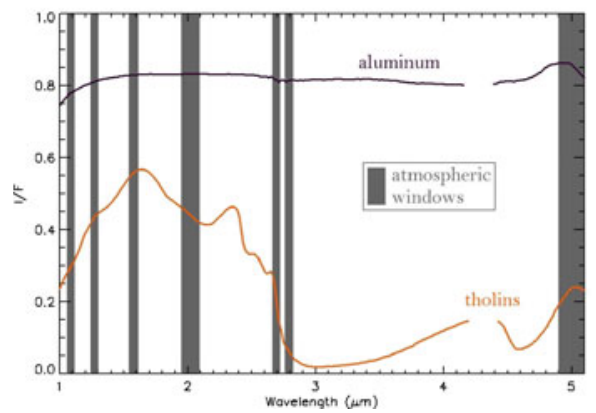

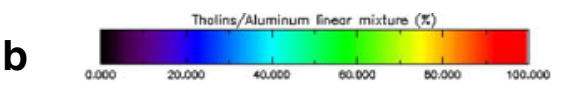

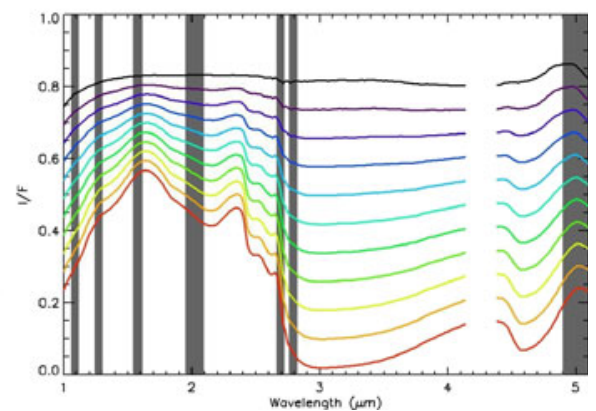

Fig. 15 a Near-IR spectra of Titan's aerosol analogs (orange) and metallic aluminum (black). In Titan's spectral windows (grayed regions), tholins and aluminum have a strong reflectance contrast. b Simple calculations of linear mixtures of tholins and alumimum (red: $100 \%$ tholins and $0 \%$ aluminum and black: $0 \%$ tholins and $100 \%$ aluminum)

negligible erosion at surface. If no coverage is detected, it would confirm the very low sedimentation rate predicted by models and put an upper limit on it. In the case of partial coverage, it would be a direct indicator of ongoing erosion at Titan's surface. In that case, it would also be possible to retrieve the sedimentation rate through the modeling of the deposit thickness.

\section{Engineering}

Our engineering development for AVIATR was directed toward a pointdesign that could be proposed to the 2010 NASA Discovery program AO. The AVIATR airplane was designed at NRL and Aurora Aerospace. Initial design for the other elements was done at NASA Ames Research Center (by LL), followed by a detailed JPL Team-X study that occurred 3-5 August 2011. Although the final budget as determined by JPL Team-X (FY10\$715M) did not allow us to propose, the rest of the design is predicated on the stipulations in the AO including launch date, launch vehicle constraints, and the availability of ASRGs.

\subsection{Mission elements}

The AVIATR-unique flight system (the spacecraft "stack", or SC-see Fig. 16) would be composed of three main subsystems, the Air Vehicle (AV), the Entry Vehicle (EV), and the Space Vehicle (SV). In addition, standard Payload Adapter components are required on the Launch Vehicle (LV) side of the interface. These subsystems and components are described in detail below. 


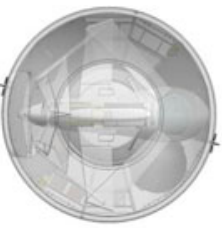

(a)

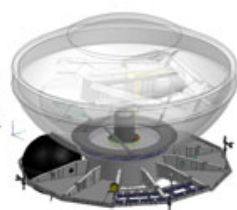

(b)

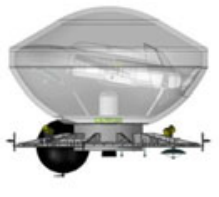

(c)

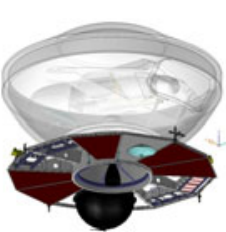

(d)

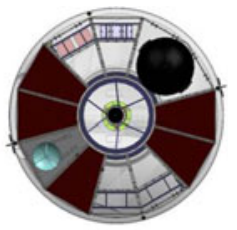

(e)

Fig. 16 Rendering of the AVIATR Spacecraft (SC) (stack): shown as viewed from the $+z$ direction showing the heat shield of the EV (a), as viewed obliquely from above and to the side (b), seen directly from the side (note that the Air Vehicle (AV) launches upside-down) (c), as viewed obliquely from below and to the side (d), and as viewed from $-z$ where the SV mounts to the launch vehicle (e)

\subsubsection{Air Vehicle}

The AVIATR Air Vehicle (AV) would be an Unpiloted Aerial Vehicle (UAV) of conventional layout (Fig. 17). The general AV layout consists of a streamlined fuselage, a folding high wing attached at mid-fuselage (Fig. 19), conventional empennage, and a two-bladed pusher propeller. The fuselage would be of monocoque shell construction, with the shell constructed of two epoxy-fiberglass face sheets separated by a polyurethane foam core. The foam core serves as a shear-load carrying member between the face sheets and also as a thermal insulating barrier. Due to its insulating qualities, the double wall fuselage also serves as a warm electronics box. The fuselage contains all components which need to function at or near room temperature, including avionics, communications gear, science instruments, flight control actuators, and power system components (Fig. 20). The ability to place scientific instruments and electrical components in a benign thermal environment (instead of in a 90K gondola in ambient conditions as for a hot-air balloon) leads to significant cost and risk reduction.

Electrical power would be supplied by two Advanced Stirling Radioisotope Generators (ASRGs) supplying electrical power. An air intake at the nose

Fig. 17 Three-dimensional view of the exterior of the AVIATR Air Vehicle (AV) as configured for flight. We show a comparison of the vehicle's size in Fig. 18

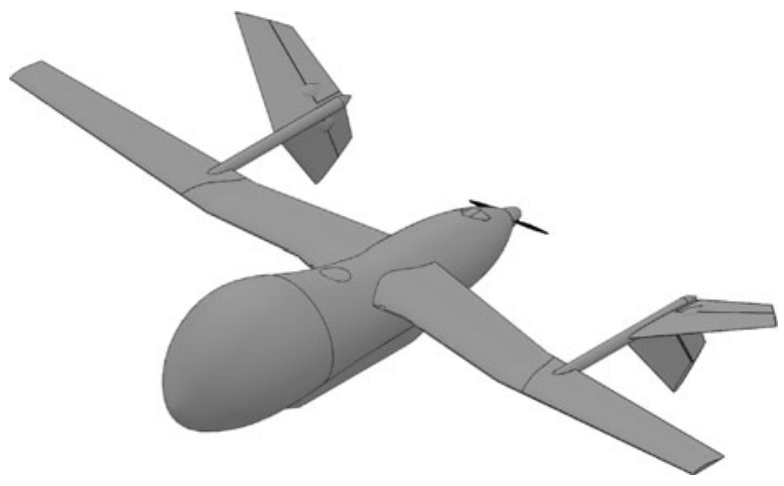




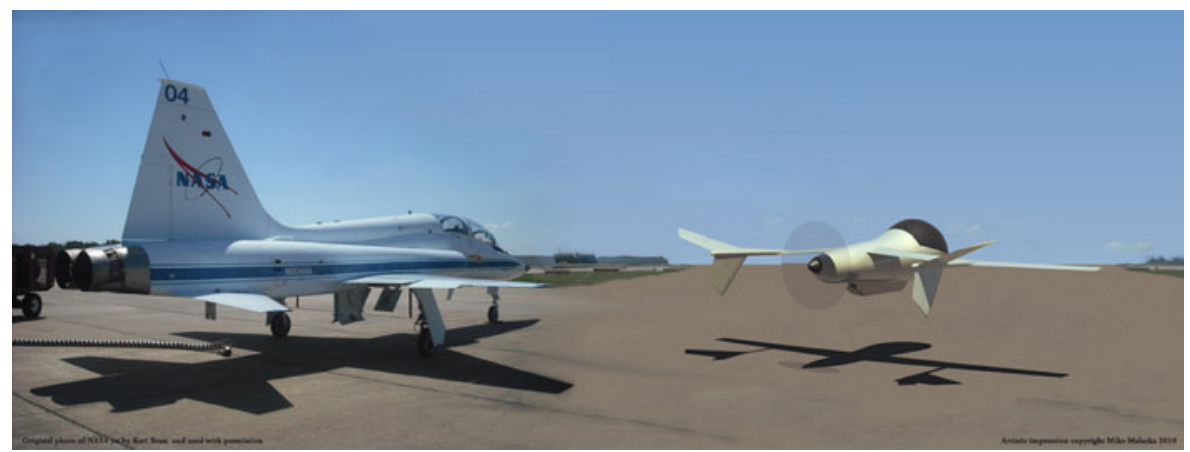

Fig. 18 Here we allow for a comparison of AVIATR's size with that of a NASA T-38N (left). (Photo of T38N by Keri Bean)

of the AV admits cold outside air into a duct, which directs the air to the cold side of the ASRGs and maintains their power output within the nominal range. Interior baffles direct the cooling airflow on a circuit throughout the fuselage where it picks up waste heat from the power-consuming components. An exhaust port at the aft end of the fuselage allows the heated air to exit. We assume that ASRG power with our advective cooling system would be the same as that of an ASRG radiating to space, for a total of 2 ASRGs at $128 \mathrm{~W}$ each (254 W total), as seems conservative based on Lorenz [77].

A two-bladed propeller powered by a rare-earth-magnet-driven brushless DC motor supplies AV propulsion. Science cameras are mounted directly to the underbelly of the fuselage structure behind double-pane transparent windows. All flight control servo actuators are mounted internal to the fuselage and transmit control forces and torques to aerodynamic surfaces via thermally insulating pushrods and torque tubes. Penetrations of the fuselage for control rods and tubes have air flow baffles to prevent excessive heat leaks.

Fig. 19 This AV rendering, with a transparent fuselage, shows the AV internal structural elements, the wings, the stabilizers, and the control surfaces

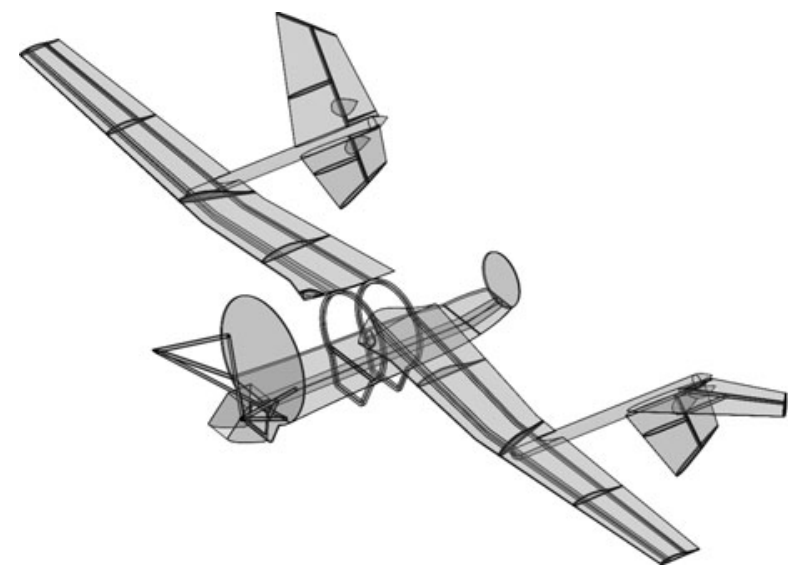


Fig. 20 Fuselage of the AV showing the internal configuration of individual components

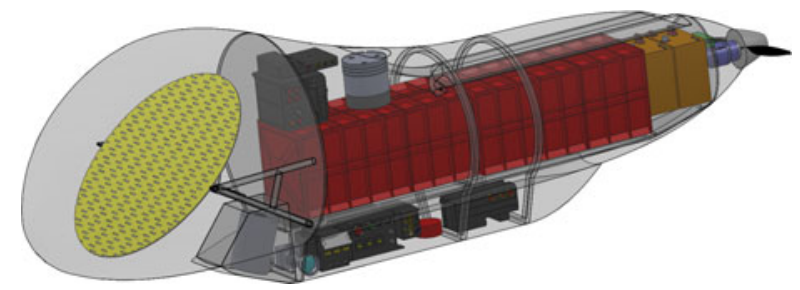

The AV communicates directly to Earth through a steerable high gain antenna enclosed in a streamlined aerodynamic fairing. The antenna is parabolic, with an elliptical cross-section. The long axis of the ellipse (its steering axis) is placed parallel to the fuselage and is buried inside the Outer Mold Line (OML) of the fuselage. The antenna is steerable inside the OML over a roll range of $\pm 90^{\circ}$, centered on the zenith. Radio signals are supplied by the communication system to the antenna via 75-Watt Traveling Wave Tube Amplifiers (TWTAs) operating in the $\mathrm{X}$ band. The AV uses a SDST that also provides redundancy for the transponder on the SC during cruise.

The AV flight control system uses purpose-built and triply redundant crossstrapped autopilot computers. The AV autopilot receives flight data from an inertial measurement unit, a radar altimeter, and an air data assembly. The inertial measurement unit is a Northrop-Grumman Scalable IMU containing four cross-strapped hemispherical resonator gyros and four cross-strapped accelerometers. A purpose-built sun sensor operating at 5 microns aids in acquiring long-term navigation fixes. The radar altimeter is a military-standard Honeywell model 9550, which measures the AV's height above the ground in the range from 0 to $15 \mathrm{~km}$ altitude. Air data is supplied by a system consisting of a purpose-built pitot tube and static ports. Flight control servo actuators are purpose-built units supplied by Honeybee robotics, with a MTBF of 10,000 h.

Separate from the autopilot, the AV has a C\&DH computer for telecommunications, sequencing, and command and storage for the science instruments. The AV computer is nearly identical to that in the SV and provides redundancy for the SV computer during cruise. Different from the SV computer, the AV computer will have 64 GBs of on-board non-volatile memory for storage of science data. No such sized memory units are currently space-qualified, and one would need to be developed for use on AVIATR.

A preliminary mass budget is shown in Table 1 . Note that the mass budget shown assumes that the ASRGs mass $21 \mathrm{~kg}$ each, as they did early in the Discovery AO process. The projected mass of the ASRGs later increased to $32 \mathrm{~kg}$. While custom modifications to the ASRGs could bring their mass down a bit (AVIATR does not need the radiator vanes, for instance), we have not recalculated the mass budget for the more massive value. The aircraft design itself has been iterated with the new value-with the ASRGs at $20 \mathrm{~kg}$ we had designed a single monolithic wing design, but with the heavier ASRGs the design would not close without a folded wing (Fig. 21). 
Table 1 AV mass budget (for 21-kg ASRGs)

\begin{tabular}{lc}
\hline Air Vehicle (AV) & Mass $(\mathrm{kg})$ \\
\hline Element & 18.7 \\
\hline Airframe structure & 6.8 \\
Insulating foam & 2 \\
Antenna cowl & 2.5 \\
Wings & 1 \\
Elevons/Empennage & 1 \\
Spin control system & 42 \\
ASRGs & 1 \\
Power control & 1 \\
Batteries & 0.5 \\
Propeller & 0.5 \\
Prop. shaft/bearings & 0.5 \\
Motor & 2 \\
Servos & 0.5 \\
Autopilots & 7.1 \\
IMU & 0.5 \\
Sun sensor & 0.25 \\
Air data sensors & 4.4 \\
Radar altimeter & 5 \\
High gain antenna & 5.5 \\
TWTA & 0.5 \\
Transceiver & 12.5 \\
Science payload & 115.75 \\
Total & \\
\end{tabular}

\subsubsection{Space Vehicle}

The Space Vehicle (SV) is a purpose-built cruise stage that is mounted to the Entry Vehicle (EV) aeroshell aft-body. The SV structure has mount points for attachment to the Launch Vehicle (LV) at aft $(-z)$, and to the EV in the fore $(+z)$. The mount point for the EV can be separated by explosive bolts, and contains pyro-actuated cable cutters to sever electrical and thermal umbilicals to the AV. Subsystems contained within the SV are: propulsion, Guidance, Navigation, and Control (GN\&C), Command and Data Handling (C\&DH), power, communications, and thermal control. We show a rendering of the SV detached from the EV in Fig. 22.

The simple blowdown monopropellant propulsion subsystem consists of one 110 -cm diameter spherical titanium pressure vessel, a propellant management system, one $445 \mathrm{~N}$ rocket thruster for high $\Delta v$ maneuvers, four $22 \mathrm{~N}$ thrusters for roll control during major maneuvers (thrust vectoring), and eight $1 \mathrm{~N}$

Fig. 21 View of the AV from behind $(-y)$, showing the folded configuration of the wings for packaging within the Entry Vehicle (EV) for delivery to Titan

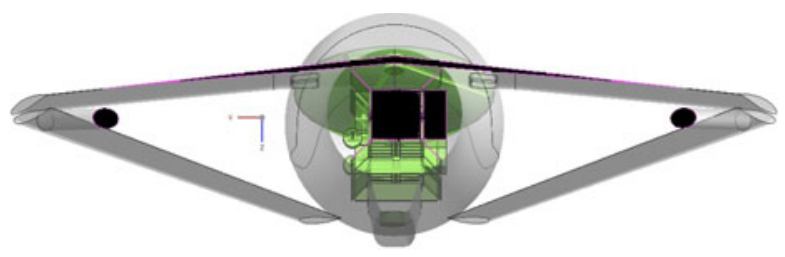


Fig. 22 Rendering of the AVIATR Space Vehicle (SV) (cruise stage): shown as viewed from the $+z$ direction where the EV is attached (a), from the side (b), and as viewed from $-z$ where the $\mathrm{SV}$ mounts to the launch vehicle (c)

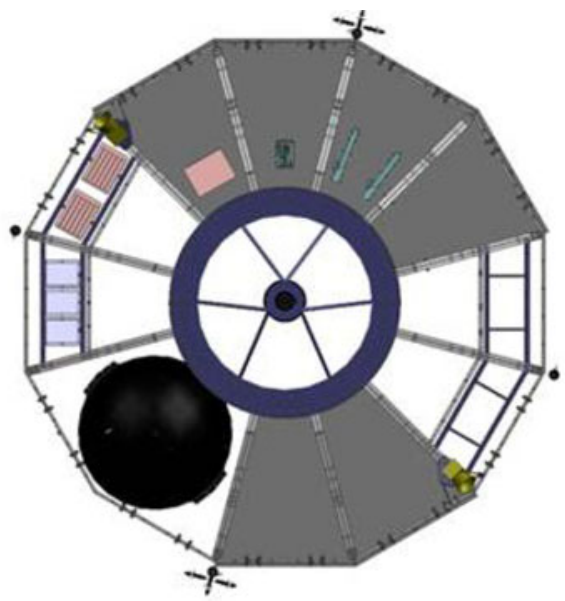

(a)

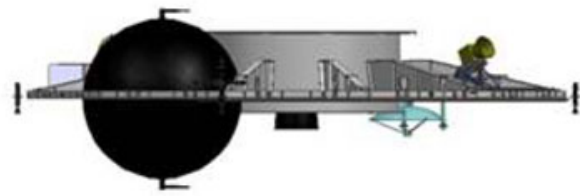

(b)

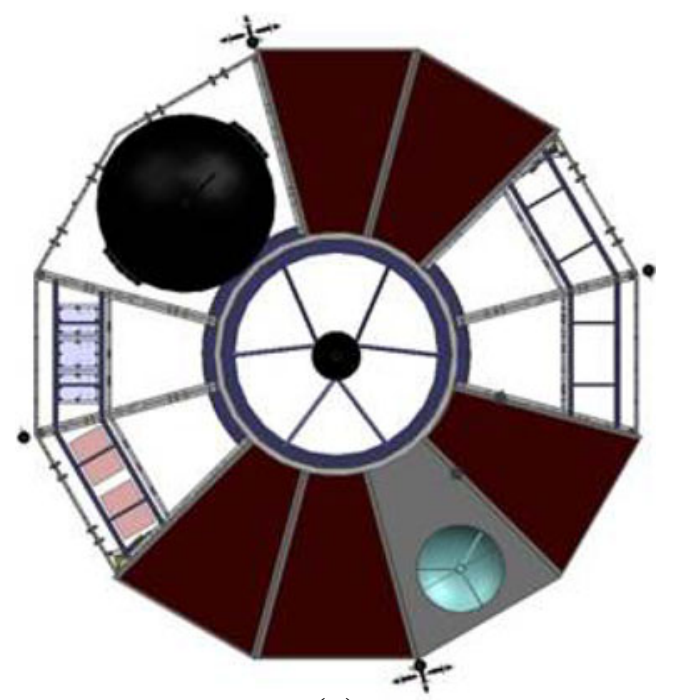

(c)

thrusters for attitude control, together with associated lines, fill, purge, and check valves, regulators, and filters. Hydrazine $\left(\mathrm{N}_{2} \mathrm{H}_{4}\right)$ would be used for propellant. 
The Guidance, Navigation, and Control (GN\&C) subsystem consists of a STA with 2 redundant star trackers and 4 coarse (1 arcsecond accuracy) sun sensors. Because no science is done in cruise configuration, the only pointing requirements come from engineering constraints, leading to pointing knowledge to within $0.5^{\circ}$, stability to within $1.0^{\circ} \mathrm{s}$, and pointing control to within $1.0^{\circ}$ (needed for telecommunications). The system would be spin-stabilized in flight at a rate of $3 \mathrm{rpm}$. In lieu of a second IMU in the SV, the SV computer would have access to the single IMU on-board the AV during cruise.

The SV Command and Data Handling (C\&DH) system (Fig. 23) is composed of a single off-the shelf flight computer. For dual-string redundancy during the long 7-year cruise, the $\mathrm{C} \& \mathrm{DH}$ computer on board the AV is identical, and would serve as a cold spare capable of stepping in to control the SV if needed.

The power subsystem consists of two redundant $40 \mathrm{~A}$-hr rechargeable lithium-ion battery packs, PCU, power cabling, and switching relays for each power-consuming component. During deep space cruise, primary power is supplied from the ASRGs in the AV to the PCU located in the SV. The Power Control Unit (PCU) has heritage from the JPL MSL and SMAP missions. Commanded by the flight computer, the PCU is capable of switching power to or from the battery pack and to or from the power consuming components.

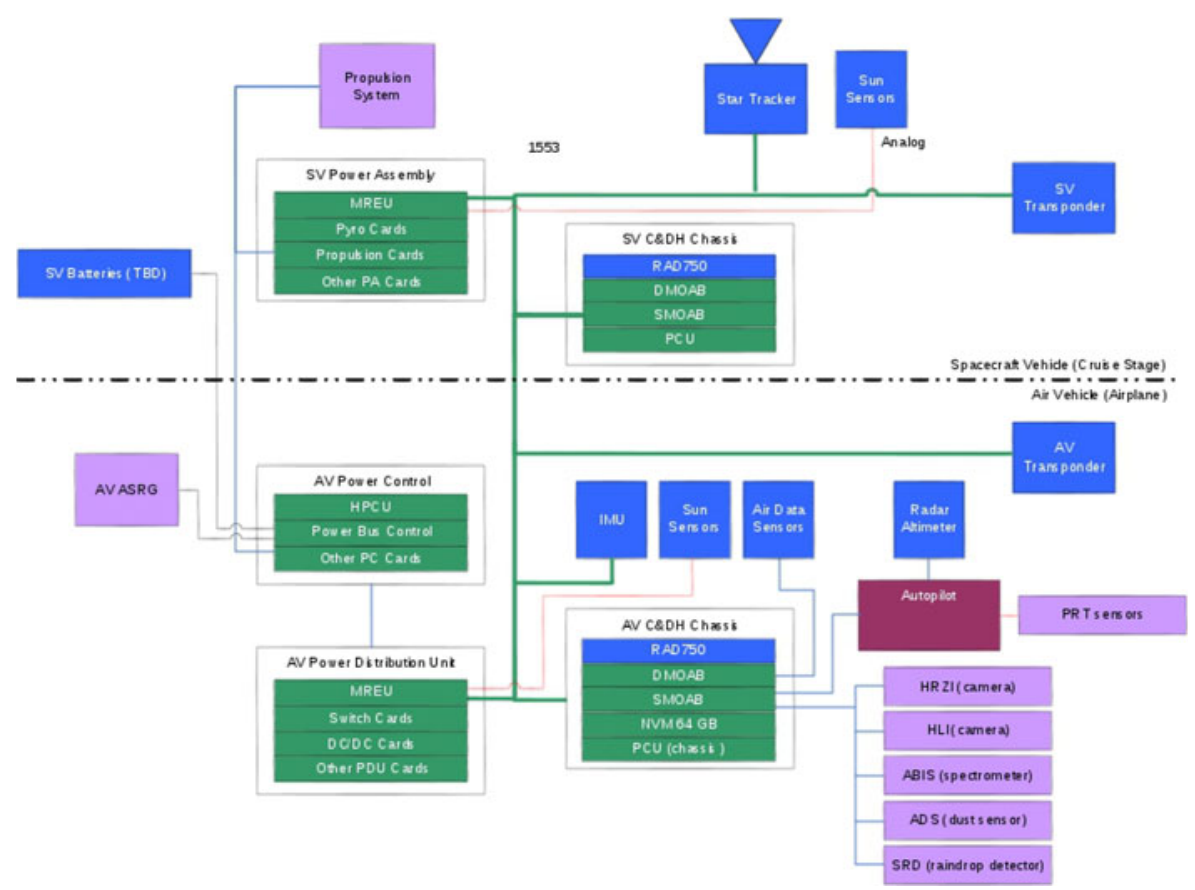

Fig. 23 Block diagram showing the power, GN\&C, and C\&DH systems on-board both the AV and the SV 
The SV contains an X-band Small Deep Space Transponder (SDST) capable of both uplink and downlink communications with the DSN, with the AV SDST providing reduncancy in cruise flight. Two low-gain antennae are mounted parallel to the spin axis, one in each direction. One $0.5 \mathrm{~m}$ mediumgain antenna is fixed to the $\mathrm{SV}$ in the $-z$ direction. The $\mathrm{SV}$ has two redundant $25 \mathrm{~W}$ TWTAs. The combined telecommunication system between the AVIATR SV and AV is diagrammed in Fig. 24.

An active heat transport subsystem employing CFC-11 coolant (Freon) is required to remove heat from the ASRGs while enroute to Titan. This thermal control subsystem makes use of the fluid handling components developed for the MER and MSL missions, including high reliability pump motors developed by Pacific Design Technologies. Two CFC-11 pump motors are connected in parallel and each may be selectively activated or deactivated by command from the ground. Only one active pump motor is required to maintain the SC internal temperature within nominal limits. Warm CFC-11 fluid is pumped from a cold plate on the ASRGs through aluminum tubing to a thermal radiator mounted on the SV (mass breakdown for the SV is shown in Table 2).

\section{Spacecraft}

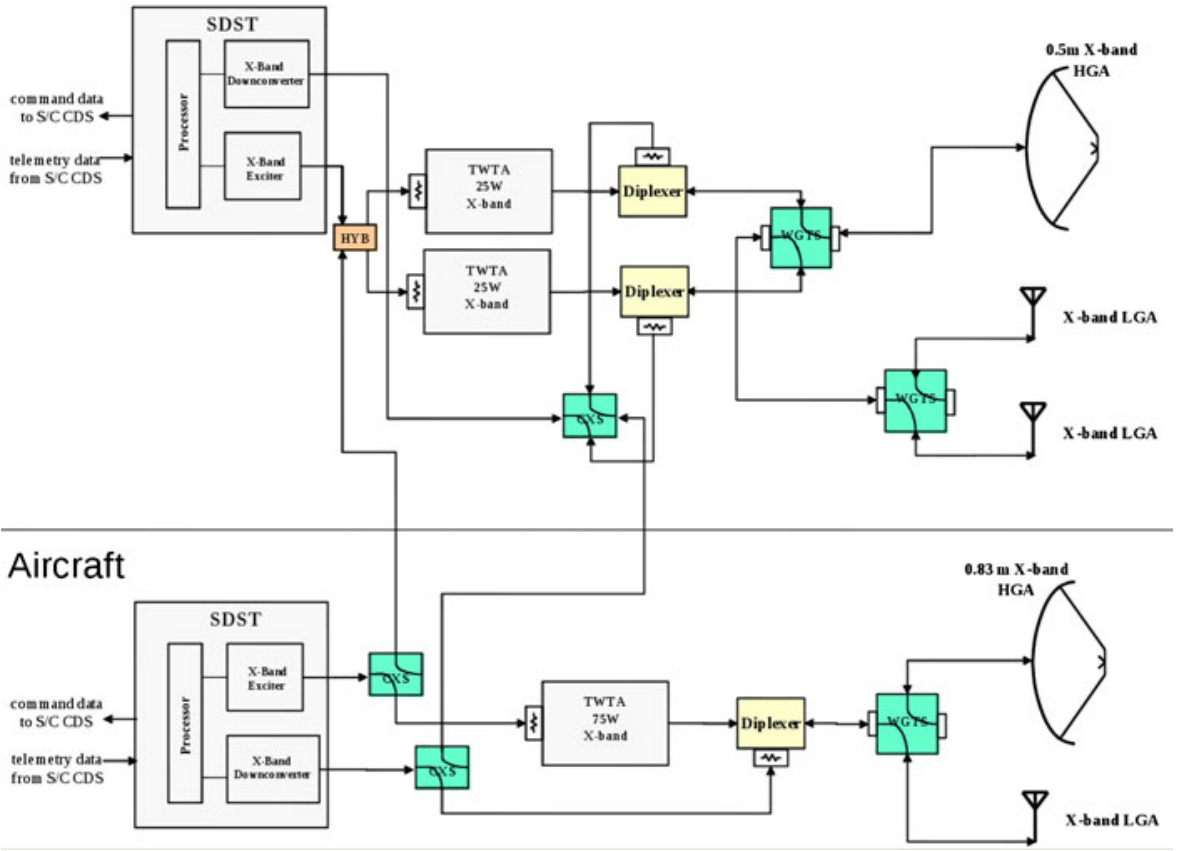

Fig. 24 Block diagram for the AVIATR telecommunications systems 
Table 2 SV mass budget

\begin{tabular}{lc}
\hline Space Vehicle (SV) & \\
\hline System & Mass $(\mathrm{kg})$ \\
\hline Attitude control & 2.5 \\
C\&DH & 5.2 \\
Power & 38.6 \\
Propulsion & 23.2 \\
Structures & 145.5 \\
Cabling & 12 \\
Telecom & 42 \\
Thermal & 85.5 \\
Bus total & 330.7 \\
EV+AV & 389 \\
Contingency & 142.2 \\
SC total (dry) & 862 \\
Propellant & 432.2 \\
SC total (wet) & 1,294 \\
LV capability $C_{3}=52.7$ & 1,488 \\
LV margin & 193.4 \\
\hline
\end{tabular}

\subsubsection{Entry Vehicle}

The Entry Vehicle (EV) (Fig. 25) is a purpose-built unit composed of primary structure, a thermal control system, mechanisms, and a wiring harness. The EV load bearing structure geometry consists of a right circular conical base of 60 degree half-angle, fairing smoothly into a spherical nose. This geometry is a scaled-up duplicate of the EV geometry utilized on the Huygens probe. The EV structure is a monocoque shell manufactured from roll-formed, isogrid milled aluminum plate, $2 \mathrm{~cm}$ thick. The EV structure is designed to accommodate a peak atmospheric deceleration load of $12.25 \mathrm{~g}$, with $50 \%$ margin.

The aft of the EV forms the separation plane between the EV and the SV. The thermal control system consists of an ablative Thermal Protection

Fig. 25 The AVIATR Entry

Vehicle (EV), shown transparent with the Air Vehicle (AV) inside

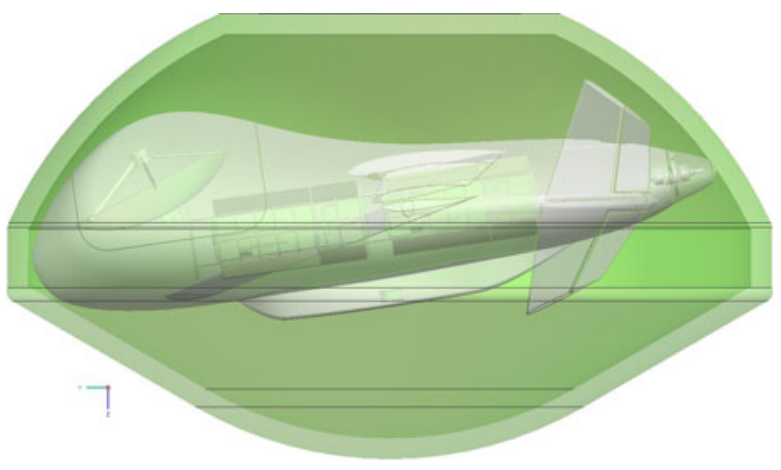


System (TPS) located on the outer (forward facing, $+z$ ) surface of the EV and a radiative barrier consisting of MLI on the inside surface of the EV. The TPS material is a $3 \mathrm{~mm}$ thick uniform layer of SIRCA-15 $(260 \mathrm{~kg} / \mathrm{m} 3)$ attached to Nomex felt SIPs with silicone adhesive. The TPS material properties are selected to withstand a peak heating rate of $21 \mathrm{~W} / \mathrm{cm}^{2}$ and a peak dynamic pressure of 7,160 $\mathrm{Pa}$. The radiative barrier consists of a 10-layer MLI blanket attached to and entirely covering, the back (inner) surface of the EV. The MLI blanket properties are selected to ensure that the thermal power radiated into the AV at peak heating conditions (3 min after atmospheric entry; $300 \mathrm{~km}$ altitude) does not exceed $100 \mathrm{~W}$.

The back face of the EV is secured to the front face of the SV by means of taper pins (providing X-Y relative location) and pyrotechnically actuated separation bolts. A wiring harness terminated in an electrical separation block (located at the EV-SV separation plane) carries signals from the SV to the EV separation bolts.

The parachute subsystem mounted on the EV consists of a supersonic drogue parachute, a supersonic main parachute, a deployment mortar, and a parachute containment can. Both parachutes are of the disk-gap-band construction design and are scaled versions of those used on Huygens. Given that the TPS would oriented toward Titan during EDD, the AV is mounted upsidedown inside the EV for launch-i.e. at launch the top surface of the AV wings are oriented in the $-z$ direction, toward Earth (mass breakdown for the EV is shown in Table 3 ).

We gave special consideration to accommodations for easy and safe integration of the ASRGs into the AV at as late a time as possible. As such, the AV is oriented inside the EV with a pitch not quite equal to $180^{\circ}$. This additional pitch angle is to allow for late ASRG integration. To do so a door mounted in the EV backshell would be removed, providing access to the $-y$ end of the AV (the pusher-propeller end). Hinges built into the AV would allow the rear of the AV fuselage to be folded out of the way, allowing access to the AV fuselage interior. The ASRG would then be slid into the AV on a rail system. This event would occur on the launch pad, after full integration of the LV with the rest of the SC and after each of the SC elements have been integrated with one another. After installation of the ASRGs inside the AV and proper connection of the coolant loops, the AV would be closed up and the EV door reinstalled for flight (Fig. 26).

Table 3 EV mass budget

\begin{tabular}{lc}
\hline Entry Vehicle (EV) & \\
\hline System & Mass $(\mathrm{kg})$ \\
\hline Structures & 167.9 \\
Cabling & 9.3 \\
Thermal & 11 \\
AV & 120 \\
EV total & 308.1 \\
Contingency & 80.9 \\
EV w/contingency & 389 \\
\hline
\end{tabular}


Fig. 26 Diagrams of the ASRG integration procedure. The procedure requires a door in the aft shell of the Entry Vehicle (EV) that would open to allow last-minute installation of the ASRGs after the spacecraft stack has already been mounted to the launch vehicle

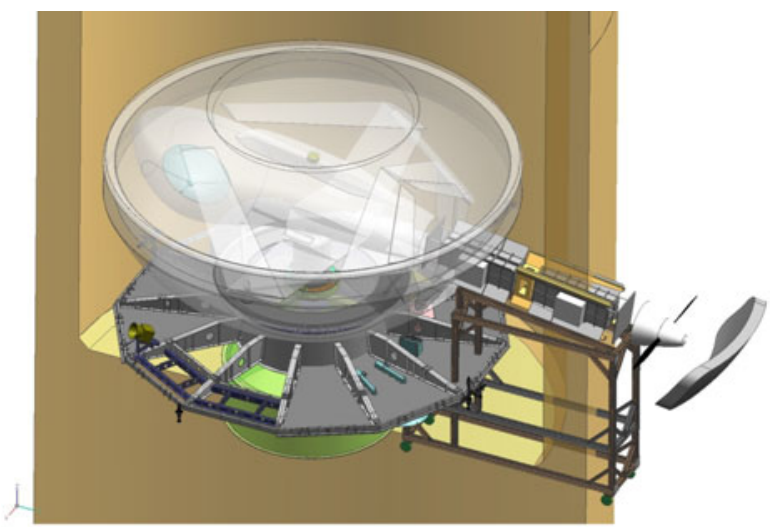

(a) ASRG Assembly: Oblique

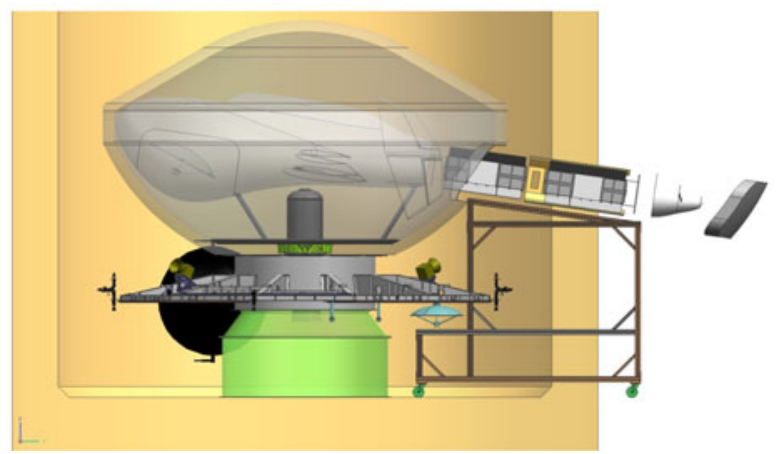

(b) ASRG Assembly: Side

\subsection{Science instruments}

Our scientific instrumentation set is designed to take advantage of the mobility and flexibility of our airplane platform wherever possible. Thus instead of a 2-axis actuated set of cameras, we have the cameras fixed to the aircraft body and we tilt the aircraft itself around instead of the cameras (Fig. 27). As a result there are no moving parts in any of the science instruments. A summary of the instruments and their parameters is in Table 4.

With our science requirement of 1-meter resolution imaging of Titan's surface (similar to that of TSSM), the wavelength at which we choose to image becomes a crucial parameter. Short wavelengths (0.3-2 microns) have greater solar illumination that lead to higher signal-to-noise ratios for a given optical system, but are strongly affected by scattering off of atmospheric haze particles. Very long wavelengths, like the $2.2 \mathrm{~cm}$ used by Cassini's RADAR, experience no scattering but require an active illumination source (Fig. 28). We choose to use 2 microns for nadir imaging with HR2I, and 5 microns for the Horizon-Looking Imager (HLI). 
Fig. 27 This rendering from below, to the side, and ahead of the AVIATR air vehicle shows the locations of the scientific instruments on the underbelly of the fuselage

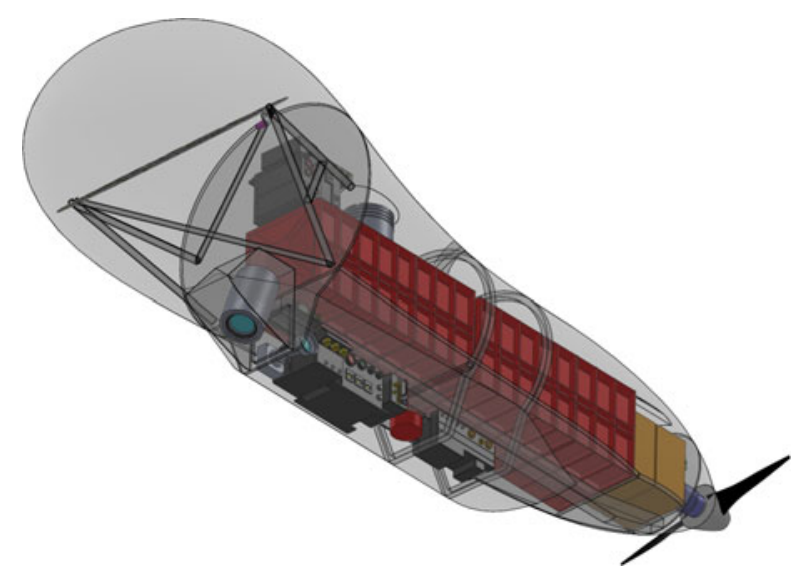

Titan surface illumination at wavelengths of $\sim 1 \mu \mathrm{m}$ is ample. Cassini's ISS was able to see Titan's surface at $0.938 \mu \mathrm{m}$ [113] despite having to look through an estimated 3.5 normal optical depths of haze scattering (extrapolated from Fig. 29). This works because Titan's haze is highly forward-scattering, which allows the preservation of some directional information from photons detected above the atmosphere. The scattering is sufficiently severe, however, to limit the fundamental resolution of ISS imaging to $1 \mathrm{~km}$ regardless of the pixel scale. Smaller pixels do not improve the resolution because it is limited by the atmosphere, not the instrumental optics. If AVIATR were to image at a short wavelength where the scattering optical depth between the aircraft and the surface was high, then our resolution would be degraded.

Cassini's VIMS instrument shows good contrast and signal-to-noise ratio in the 2-micron window. A study of Titan's emission function from VIMS T38 observations of Ontario Lacus imply a 2-micron normal scattering optical depth of 1.12 for Titan's full atmosphere [10], consistent with an extrapolation of the DISR observations [156]. Using the DISR extrapolation and applying it to AVIATR, however, as in Fig. 29, shows that the normal scattering optical depth at 2 microns between $14 \mathrm{~km}$ altitude and the surface is 0.20 , and that between $3.5 \mathrm{~km}$ altitude and the surface is just 0.05 . Since at AVIATR's

Table 4 AVIATR's scientific instruments, including current best estimates for mass and power usage

\begin{tabular}{llll}
\hline Instrument & Description & Mass & Power \\
\hline HR2I & High-Resolution 2-micron Imager & $3.5 \mathrm{~kg}$ & $12 \mathrm{~W}$ peak, $8 \mathrm{~W}$ idle \\
HLI & Horizon-Looking Imager & $2.2 \mathrm{~kg}$ & $12 \mathrm{~W}$ peak, $8 \mathrm{~W}$ idle \\
ABIS & AirBorne Imaging Spectrometer & $3.6 \mathrm{~kg}$ & $10 \mathrm{~W}$ \\
Altimeter & Engineering RADAR Altimeter & - & - \\
WASS & Winds and Atmospheric Structure Suite & $0.3 \mathrm{~kg}$ & $\sim 1 \mathrm{~W}$ \\
ADS & Aerosol Density Sensor & $0.110 \mathrm{~kg}$ & $0.5 \mathrm{~W}$ \\
SRD & Student Raindrop Detector & $0.3 \mathrm{~kg}$ & $\sim 1 \mathrm{~W}$ \\
\hline
\end{tabular}



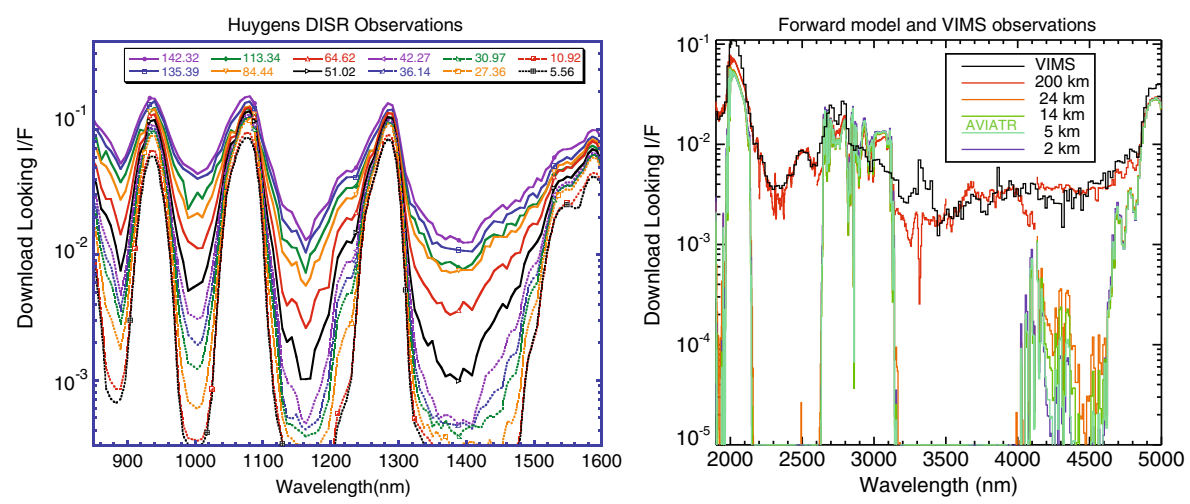

Fig. 28 DISR-measured downward-looking spectra at varying altitudes above Titan's surface are shown at left. At right are model-predicted downward-looking spectra for longer wavelengths from altitudes of interest for AVIATR.

minimum altitude of $3.5 \mathrm{~km} 95 \%$ of the photons from the surface arrive at our detector unscattered, our spatial resolution is not degraded from aerosol scattering.

While the Sun is dimmer within the 5-micron atmospheric window, it is the best choice for our Horizon-Looking Imager (HLI). Three different techniques $[10,21,121]$ indicate that the normal optical depth of the total Titan atmosphere at 5 microns is very low. With such a low normal optical depth, $90 \%$ of incoming solar photons are unimpeded by atmospheric scattering (at zero incidence angle). Our HLI, looking through a much larger slanted path through Titan's atmosphere than the HR2I, would still have negligible image degradation due to scattering off of aerosols if it operates at 5 microns

Fig. 29 Here we plot the normal scattering optical depth of Titan's atmosphere (black, with scale at left) from an altitude of $14 \mathrm{~km}$ (top, black) and $3.5 \mathrm{~km}$ (bottom, black). These values come from the DISR

parameterization, and are extrapolated beyond the DISR wavelength cutoff at $1.6 \mu \mathrm{m}$. Also shown is a typical exoatmospheric Titan spectrum from VIMS (blue, with scale at right); the atmospheric windows show up as relative peaks in the VIMS spectrum

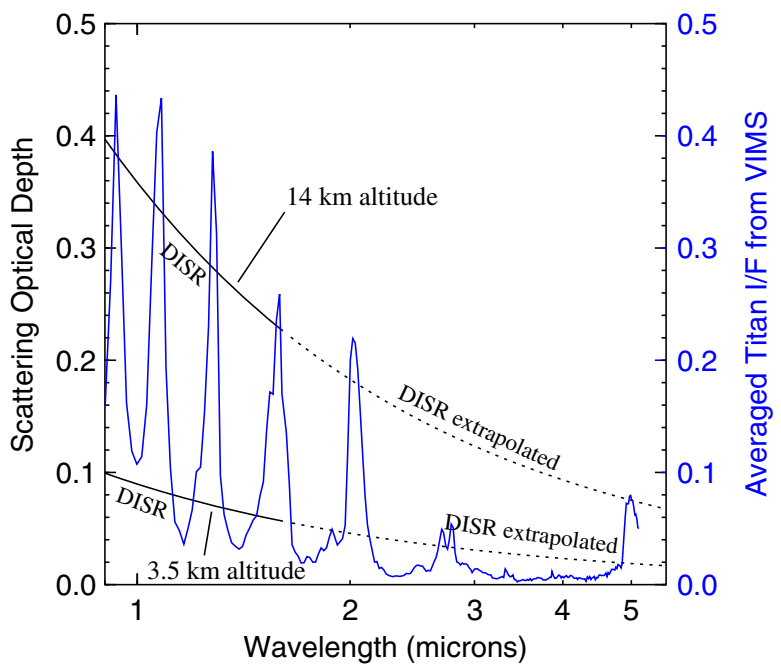


wavelength. That low scattering also means that the surface is most directly illuminated at 5 microns, meaning that observations of shadows and shading can enhance scientific interpretation of the resulting images. It also means that specular reflections of the Sun can be seen off of liquids and wetted surfaces (Fig. 4c).

For spectrometry, observing from beneath most of Titan's atmosphere does not afford as many advantages as might be expected. Atmospheric absorption by methane creates the spectral windows in Titan's atmosphere in the 1$10 \mu \mathrm{m}$ wavelength range. While AVIATR has a much smaller atmospheric path length between its cameras and the surface, the large path length between the surface and the illumination source (the Sun) means that Titan's surface cannot be seen by AVIATR outside the methane spectral windows (Fig. 28a).

Thus AVIATR is limited to the same spectral windows as exoatmospheric spacecraft — though the windows themselves are slightly wider. An advantage that we have over orbiting spacecraft is that the total additive component due to atmospheric scattering is much lower than it is when viewed from above the atmosphere.

\subsubsection{High Resolution 2-Micron Imager}

Our high-resolution camera, the High Resolution 2-micron Imager (HR2I), operates with a bandpass of 1.97-2.09 $\mu \mathrm{m}$. It is equipped with a $1,024 \times 1,024$ $\mathrm{HgCdTe}$ detector with HAWAII-2RG heritage. The detector itself is cooled to $94 \mathrm{~K}$ using a coldfinger to the exterior air flow. Given a focal length of $0.125 \mathrm{~m}$ and a focal ratio of 1.2, the IFOV is 0.144 milliradians/pixel, corresponding to a ground footprint of $0.5 \mathrm{~m} / \mathrm{pixel}$ at $3.5 \mathrm{~km}$ altitude. A signal-to-noise ratio of 100 is then expected for $25 \mathrm{~ms}$ integration time for zero-incidence and a surface albedo of 0.2 (typical of the VIMS data).

The instrument has a current-best-estimate mass of $3.5 \mathrm{~kg}$, dimensions of $23 \mathrm{~cm}$ length and $15.3 \mathrm{~cm}$ diameter, and draws $12 \mathrm{~W}$ at peak power and $8 \mathrm{~W}$ when idle. It is mounted into the forward section of the scientific pannier of the AV (Fig. 27) at an angle of $15^{\circ}$ forward of nadir (for stereo; see Section "Mosaics").

\subsubsection{Horizon-Looking Imager}

The Horizon-Looking Imager (HLI), a wide-field imager, uses a bandpass of 4.87-5.15 $\mu \mathrm{m}$. It uses the same detector as the HR2I. It has a focal length of $12 \mathrm{~cm}$ and a focal ratio of 2.5, leading to an IFOV of 1.538 milliradians/pixel. Like the HR2I, it uses a 1,024 × 1,024 format detector array. It achieves a signal-to-noise ratio of 50 using a $1 \mathrm{~s}$ integration, assuming a surface albedo of 0.2 (probably high for Titan's true albedo).

This instrument masses $2.2 \mathrm{~kg}$ and has rectangular dimensions of $9 \mathrm{~cm} \times$ $9 \mathrm{~cm} \times 20.3 \mathrm{~cm}$. Its expected power usage is the same as that of the HR2I. The HLI is mounted looking out the port side of the aircraft, with boresight at the horizon. 


\subsubsection{Near-infrared imaging spectrometer}

AVIATR's AirBorne Imaging Spectrometer (ABIS) is based on the one designed for the ESA-led hot-air balloon (Balloon Imaging Spectrometer (BIS)) intended for implementation with TSSM [33], with some modifications. It operates in the spectral range $1-5.6 \mu \mathrm{m}$ with a spectral resolution of 103 . It has a focal length of $0.174 \mathrm{~m}$ and a focal ratio of 3.7, leading to an IFOV of 0.24 milliradians per pixel. It operates in a pushbroom mode using its $270 \times 436$ pixel $\mathrm{HgCdTe}$ array with 256 spectral elements and 436 spatial elements. Its cost and complexity relative to use on a balloon are decreased by allowing the electronics box to operate at near room temperature within the AVIATR WEB. Further optimization for an airplane-borne environment are possible; we leave such studies for future work.

ABIS masses $3.6 \mathrm{~kg}$, has optics of dimensions $26 \mathrm{~cm} \times 24 \mathrm{~cm} \times 15 \mathrm{~cm}$ and a $20 \mathrm{~cm} \times 30 \mathrm{~cm} \times 10 \mathrm{~cm}$ electronics box. It draws $10 \mathrm{~W}$ of electrical power. ABIS is nadir-looking, mounted in the aft end of the science pannier below the main fuselage.

\subsubsection{Radar altimeter}

The AVIATR autopilot uses a radar altimeter. We plan to re-use the altimetric data from the autopilot for science purposes. As such science levies no constraints on the altimeter, and its capabilities should be determined by engineering requirements.

\subsubsection{Winds and Atmospheric Structure Suite}

The Winds and Atmospheric Structure Suite (WASS) is composed of several sensors designed for measurement of atmospheric properties. For atmospheric pressure and temperature, we would query the engineering sensors from the AV autopilot.

We would measure methane humidity by measuring the optical depth of methane absorption through a short path length of ambient air. The methane sensor is mounted inside the vehicle, and uses air from the ASRG-cooling intake to perform its work without distrupting exterior airflow. The instrument itself would be designed specifically for the mission, but is based on similar devices used to monitor methane gas buildup on Earth [91].

The final element of the WASS is an ultrastable oscillator. The oscillator will be used to allow precise Doppler measurements of AVIATR's absolute motion during radio uplinks and downlinks.

\subsubsection{Aerosol Density Sensor}

To measure haze concentrations, we baseline a design for a laser-based Aerosol Density Sensor (ADS) originally developed to monitor dust in the Martian atmosphere from in-situ elements [100,101]. That precise unit can 
accurately measure the number density and velocity of entrained particles larger than $\sim 1 \mu \mathrm{m}$. As most Titan haze is around that size or smaller, further optimization should be done for eventual Titan use of this type of device. It can detect concentrations between 1 and 1,000 particles $/ \mathrm{cm}^{3}$ at speeds between 0.2 and $15 \mathrm{~m} / \mathrm{s}$.

The ADS masses just $110 \mathrm{~g}$ and consumes only $0.5 \mathrm{~W}$ of power. It would be placed inside the fuselage to sample air via the ASRG-cooling intake airflow so as to not increase drag by disrupting airflow around the vehicle.

\subsubsection{Student Raindrop Detector}

The Student Raindrop Detector (SRD) is an instrument designed to detect the impacts of raindrops and to both count them and measure their size. It is envisioned as a $10-\mathrm{cm}$ diameter metallic strike plate mounted on the AVIATR vehicle exterior flush with the skin. On the back of the plate is a piezoelectric microphone, which is then connected to electronics inside the WEB. This type of instrument was used on the ESA Giotto mission to detect dust impacts from the coma of comet Halley [92].

While a significant contribution to the science, the SRD is neither necessary nor required for the threshhold AVIATR science mission. It is envisioned as a student-led effort that could improve the mission's science and simultaneously involve STEM educational opportunities at the undergraduate and graduate levels. We are presently developing and testing a prototype in collaboration with a group of undergraduate engineering students at the University of Idaho; that work will be presented in a future publication with more details about this instrument.

\section{Operation}

\subsection{Launch and in-space cruise}

Getting to Titan requires putting the spacecraft into a heliocentric orbit with aphelion at 10 AU. A direct Hohmann transfer trajectory to Titan requires a $C_{3}$ of over $110 \frac{\mathrm{km}^{2}}{\mathrm{~s}^{2}}$. Even using the largest medium-lift launch vehicle, like those allowed by the Discovery AO, such a trajectory is possible only for spacecraft that mass less than $100 \mathrm{~kg}$. That mass is less even than the AVIATR Air Vehicle (AV), much less the entire spacecraft stack.

We determined that the use of an Earth Gravity Assist was the best way to overcome this problem. A launch into a 2-year dVEGA trajectory can be accomplished with a $C_{3}$ of $53 \frac{\mathrm{km}^{2}}{\mathrm{~s}^{2}}$. That $C_{3}$ allows a spacecraft mass large enough with the medium launch vehicle to accommodate everything needed by AVIATR with adequate margin - including a standard monopropellant blowdown propulsion system that can deliver the approximately $725 \mathrm{~m} / \mathrm{s}$ of post-launch $\Delta V$ needed to accomplish the mission. The 3-year addition to the 


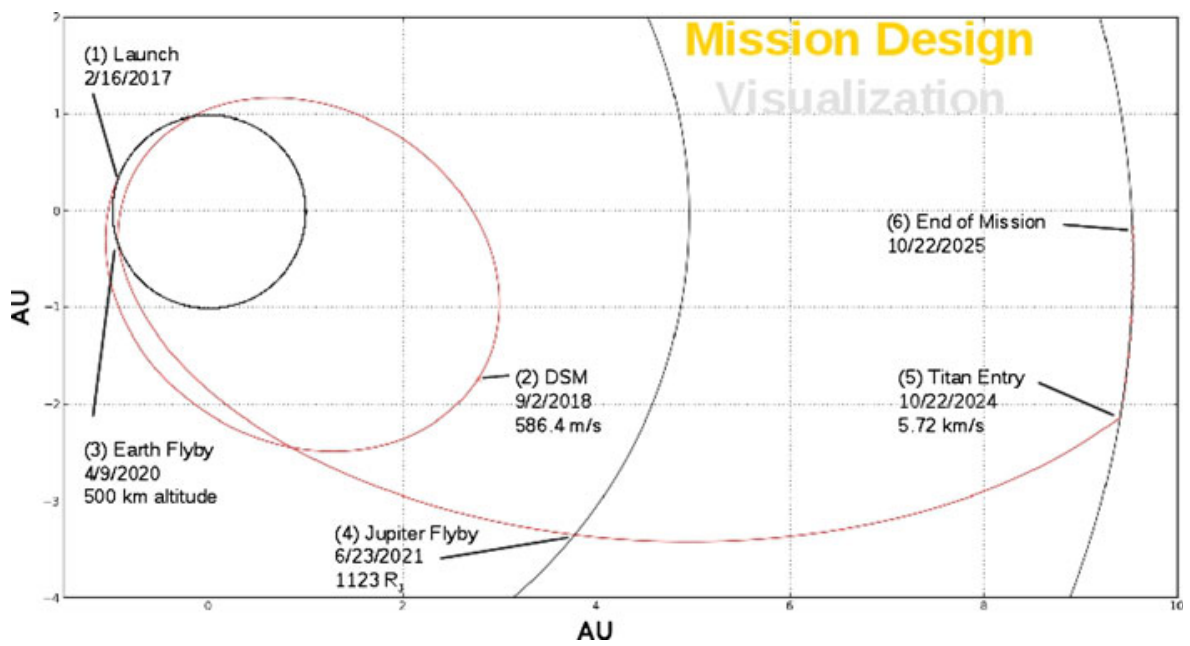

Fig. 30 The AVIATR trajectory through the solar system from Earth departure, through Deep Space Maneuver (DSM), by Earth and Jupiter for gravity assists, and then on to Titan

flight time, over direct trajectories, is modest for a mission that would need a minimum of 4 years in any case. The Earth gravity assist enables AVIATR to arrive at Titan with a much lower cost than would using a larger launch vehicle and a direct trajectory. Similar trajectories enabled the NEAR and Stardust Discovery missions, as well as Galileo and Cassini, which had RTG power systems and an Earth flyby at an altitude of $303 \mathrm{~km}$ for Galileo $(0.048$ Earth radius) (Fig. 30).

In order to develop a notional operations scenario for this study, we will assume that the AVIATR Spacecraft (SC) stack would be launched on an Atlas V 521 Launch Vehicle (LV) on 16 February 2017 at the start of a 20day launch window. The SC is injected by the LV upper stage directly onto a departure trajectory with a $C_{3} \leq 52.7 \frac{\mathrm{km}^{2}}{\mathrm{~s}^{2}}$ and is separated from the LV using the LV-supplied clamp band assembly (Table 5).

Table 5 This table shows the parameters of the AVIATR mission design trajectory

\begin{tabular}{lll}
\hline Parameter & Value & Unit \\
\hline Target or destination & Titan & \\
Mission type (flyby, rendezvous, lander/cruise stage, etc.) & EDL & \\
Cruise duration & 92 & Months \\
Delivery trajectory type & $\Delta \mathrm{V}(3+)$ EJGA & \\
Entry velocity (inertial) & 5.42 & $\mathrm{~km} / \mathrm{s}$ \\
Entry flight path angle (inertial) & -62 & $\mathrm{deg}$ \\
Max S/C-Sun distance (cruise) & 9.67 & $\mathrm{AU}$ \\
Max S/C-Sun distance (A/C mission) & 9.66 & $\mathrm{AU}$ \\
Max Earth-S/C range (cruise) & 10.12 & $\mathrm{AU}$ \\
Max Earth-S/C range (A/C mission) & 10.60 & $\mathrm{AU}$ \\
\hline
\end{tabular}


After SC functional checkout and commissioning, a preplanned TCM is performed with the SC main propulsion thruster to place the SC on the nominal departure trajectory. The SC is then spin stabilized using the ACS thrusters, with the nose of the Entry Vehicle (EV) (i.e. the entry heat shield) pointing toward the Sun. Preplanned attitude adjustment burns are performed with the ACS thrusters at intervals throughout the mission to maintain the Sun-pointing attitude for thermal control purposes. On 2 September 2018 (for a launch at the beginning of the launch window), a major TCM propulsive maneuver is performed to place the SC on an Earth Gravity Assist (EGA) flyby trajectory. The EGA flyby occurs on 9 April 2020, regardless of the launch date within our window, at a distance of $1.1 R_{\oplus}$ from Earth's center so as to be high enough to avoid debris in low Earth orbit. Additional adjustment TCMs are performed with the main propulsion thruster, in order to prepare for Jupiter flyby and Saturn arrival. On 23 June 2021, a Jupiter gravity assist flyby occurs, placing the SC on a trajectory to encounter Saturn. On 22 October 2024, the SC arrives at Saturn, using Saturn's gravity to place it on a trajectory for Titan entry. To prepare the SC for direct entry into Titan's atmosphere, the SC vents the propellant remaining in the propellant tanks into space just prior to entry interface. Table 6 summary of the in-space timeline of propulsive maneuvers.

\subsection{Entry, descent, and deployment}

AVIATR's atmospheric transition sequence, which we call Entry, Descent, and Deployment (EDD), is based on that of the Huygens probe. EDD starts when the Space Vehicle (SV) places the SC in the proper attitude for entry, spins the stack up for spin-stabilization, and then blows the explosive bolts to separate the SV from the Entry Vehicle (EV). The EV (with Air Vehicle

Table 6 This table summarizes the critical propulsive maneuvers during the AVIATR cruise phase

\begin{tabular}{lllll}
\hline Event & Date & Relative time ${ }^{+}$ & $\Delta \mathrm{V}(\mathrm{m} / \mathrm{s})$ & \# Maneuvers \\
\hline Launch (L) & $2 / 16 / 2017$ & & - & - \\
Deep Space Maneuver (DSM) & $9 / 2 / 2018$ & $\mathrm{~L}+563$ & 586 & 1 \\
DSM cleanups & & DSM $+14,+21$ & 57 & 2 \\
Earth Gravity Assist (EGA) & & EGA -60 & 15 & 3 \\
$\quad$ argeting and biasing & $4 / 9 / 2020$ & $\mathrm{~L}+1148$ & - & - \\
EGA & & EGA +14 & 5 & 1 \\
EGA cleanup & & $\mathrm{JGA}-120$ & 2.5 & 2 \\
Jupiter Gravity Assist & & & & \\
$\quad$ (JGA) targeting & $6 / 23 / 2021$ & $\mathrm{~L}+1588$ & - & - \\
JGA & & $\mathrm{JGA}+120$ & 2.5 & 2 \\
JGA cleanup & & $\mathrm{T}-30, \mathrm{~T}-5$ & 5 & 2 \\
Entry targeting & $10 / 22 / 2024$ & $\mathrm{~L}+2805$ & - & - \\
Titan entry (T) & & - & 50 & Many \\
DV margin* & & & 725 & Many \\
Total & & &
\end{tabular}


(AV) still inside) then enters Titan's atmosphere nose-first ( $+z$ toward Titan) at a relative velocity of $5.72 \mathrm{~km} / \mathrm{s}$ and performs a hypersonic, non-lifting deceleration to parachute deployment speed and altitude $($ Mach $=1.5$, altitude $=$ $175 \mathrm{~km}$ ) in $270 \mathrm{~s}$. A supersonic drogue parachute is deployed, which decelerates the $\mathrm{EV}$ to Mach $=0.5$, at which speed a subsonic, main parachute is deployed. The main parachute decelerates the EV to terminal velocity $(20 \mathrm{~m} / \mathrm{s})$ at which speed the Entry Vehicle (EV) heat shield is separated from the EVbackshell/AV combination. Due to the difference in ballistic coefficients, the EV heat shield falls away from the remaining EV stack (to which the AV is still attached), which is suspended on the main parachute. The EDD sequence ends when the $\mathrm{AV}$ is released from the EV backshell (still under parachute) to begin flight operations at an altitude of $\sim 40 \mathrm{~km}$ (Fig. 31).

\subsection{Flight operations}

During flight operations, the science data acquisition for AVIATR would generally occur in short bursts a few hours long interspersed by periods without data acquisition. The nature of the data acquisition operations depends on the objective of the observation. In addition to the unique observations during the Entry, Descent, and Deployment (EDD) phase (see below), there are three modes for surface observations and two modes for atmospheric observations. All are detailed below.

The limiting factor governing AVIATR's scientific capability is bandwidth. The aircraft can generate far more data, and far faster, than it can transmit back to Earth.

While the total downlink is limited to a minimum requirement of 1 gigabyte (GB) (8 gigabits (Gbs)), non-volatile solid-state data storage today can easily store our planned 64 GB cheaply, reliably, and with low mass, volume, and power (a nice $64 \mathrm{~GB}$ flash memory card massing $6 \mathrm{~g}$ costs $\$ 157$ today on amazon.com-we budgeted $\$ 1 \mathrm{M}$ for a space qualified version-future missions studies might consider multiple cards deployed in a RAID). Imaging and spectroscopy would occupy most of the data volume. Therefore our strategy to maximize the science that is possible per bit would be to downlink just thumbnails of the images that we require. We keep the full-resolution image on-board the aircraft.

Once the science team sees each thumbnail, we would identify which portions of the remaining data that we want to downlink. We would use a JPEG2000-like coding scheme so as to make use of the data that we already have without duplication. ${ }^{6}$ The data can be downlinked either losslessly or with a lossiness appropriate for the science to conserve bandwidth.

\footnotetext{
${ }^{6}$ This works as follows. If we were to downlink an image binned $2 \times 2$, and then later request the full-resolution image, then the aircraft would only downlink the values for 3 of the full-resolution pixels in each $2 \times 2$ bin. We can then recreate the last pixel based on the $2 \times 2$ binned value and the sum of the other three, rather than retransmit the value of the fourth pixel.
} 
Fig. 31 An artist's

conception of the parachuted descent portion of the AVIATR EDD sequence

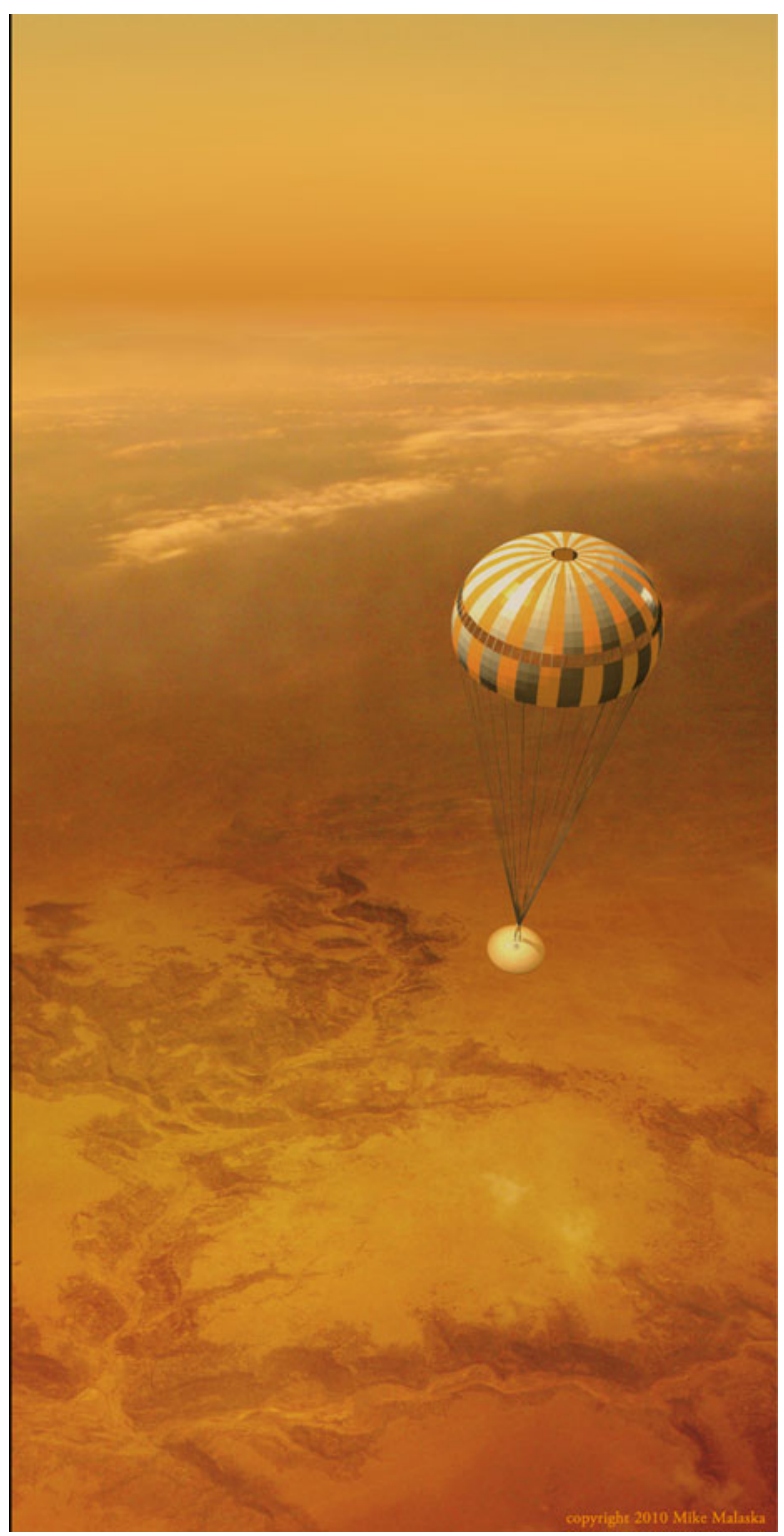

One full, uncompressed mosaic would occupy around 0.5 Gbs on disk. Thus if we were to downlink full, uncompressed mosaics, we would only get 2 for the whole mission. As it is we can acquire over 100 mosaics and leave them all stored on-board the AVIATR air vehicle, downlinking only the portions that we want at the quality and binning mode needed to achieve the science objectives. If more data are needed later during the prime mission, we can always downlink them. 


\subsubsection{Surface science observations}

Surface observation campaigns are designed around acquiring sufficient data and context in a single area in order that it be scientifically interpretable. AVIATR would not snap single high-resolution images in the midst of flight. When we need a surface observation, we either acquire a mosaic, a linear profile, or a specular lightcurve.

Mosaics Acquisition of imaging mosaics allows us to build up the most complete geologic picture of a given surface target area and its setting. Although each individual mosaic may be tweaked in order to tailor it to the science goals of that particular observation, all would be derived from the baseline mosaic described here and shown in Fig. 32.

To start, we align the aircraft to fly parallel to the predicted prevailing wind direction to minimize cross-track errors. The initial altitude is $14 \mathrm{~km}$. We fly a raster pattern, covering the surface with images by the HR2I to build up a 3by-3 context mosaic at $1.2 \mathrm{~m}$ per pixel and with surface spectra from ABIS. We then turn around and fly back along our old track, acquiring a second 3-by-3 mosaic of the area. Because the HR2I points $15^{\circ}$ off-nadir, flying over in each direction allows us to acquire stereo that can be processed into a DEM.

We then descend to $3.5 \mathrm{~km}$ altitude for high-resolution operations. Flying to the center of the 3-by-3 context mosaic, we then fly a single 5-by-5 HR2I route

Fig. 32 This planform diagram shows the flight path for the AVIATR AV when acquiring an area mosaic for surface science

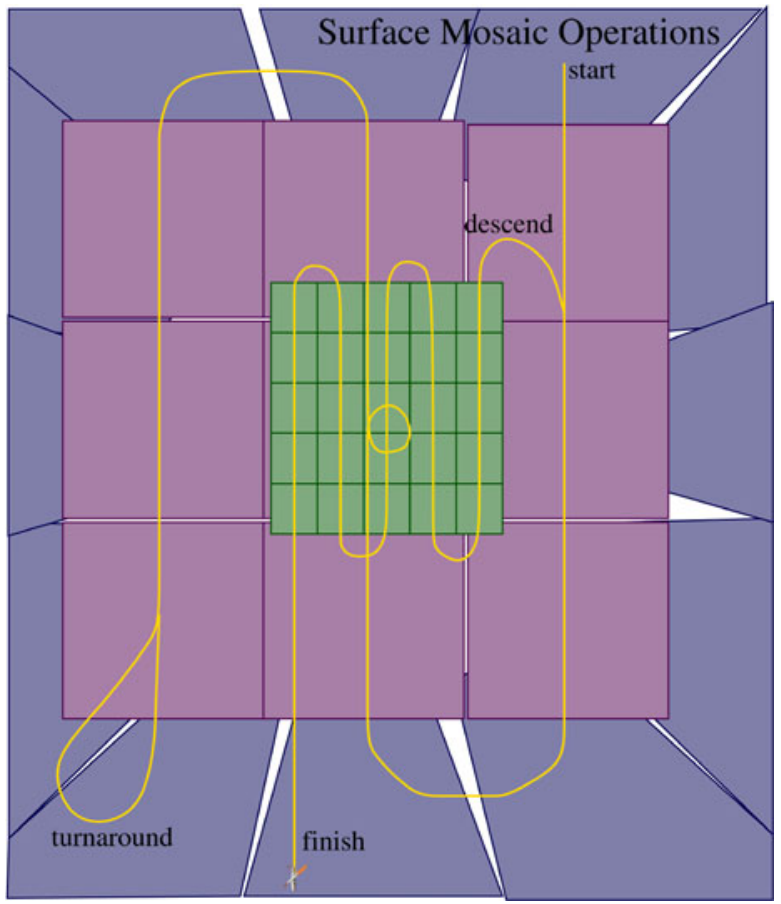


for high resolution imaging at $50 \mathrm{~cm} /$ pixel. In the middle of the high-resolution route we perform a $360^{\circ}$ left turn, pointing the HLI toward the ground as we acquire HLI images of the target area's large-scale geologic setting.

The pointing requirement for the HR2I is for momentary pointing stability only. If the airplane is flying through turbulent air, then it may be buffeted to the degree that maintaining continuous pointing stability is prohibitively difficult. For each image that we need we would actually acquire 8 separate images 1 second apart, and keep the one that is least smeared. ${ }^{7}$

By default only thumbnails of the 3-by-3 context mosaic would be downlinked. Once those are on the ground, the cognizant Co-I or their designee would determine whether the area imaged is pertinent to the intended science goal. If so, spectroscopy and the relevant portions of the high resolution images would be downlinked as necessary to achieve the science goals.

Linear profiles For observing one-dimensional targets like channels and shorelines we use a different approach. Here we set the vehicle up to fly perpendicular to the object of interest and acquire imaging, spectroscopy, and RADAR altimetry as we fly past the target. We select the flight altitude based on the resolution requirements for the science, $14 \mathrm{~km}$ for $1.2 \mathrm{~m} /$ pixel down to $3.5 \mathrm{~km}$ for $0.5 \mathrm{~m} /$ pixel.

Operating this way allows us to accommodate for errors in the aircraft's navigation. When crossing channels, we downlink the RADAR altimetry for the linear profile, and then select the imaging and spectroscopy from the center of the valley for downlink to Earth. These images are again downlinked in thumbnail size initially, and at progressively higher resolutions as necessary. For shorelines, versions of the HR2I images binned 1,000 by 1,000 (i.e. one pixel per image) would easily show the location of the shoreline. We can then downlink the images as needed relative to the shoreline location without having to target the vehicle to $1 \mathrm{~km}$ accuracy.

Specular lightcurves Based on the VIMS $5 \mu \mathrm{m}$ specular reflection off of Jingpo Lacus seen on T58 (see also Fig. 4c [144]), Barnes et al. [11] showed that temporally resolved specular reflection lightcurves can be used to constrain wave activity and the existence of surface liquids. To search for either of those, AVIATR would fly a course such that the Sun is directly to the port side of the aircraft and the specular point is within the HLI field-of-view. We would then repeatedly acquire HLI images as we fly along. A few of these might be

\footnotetext{
${ }^{7}$ Determining the least-smeared image can be quite easy. When the images files are compressed, smeared images compress more effectively than unsmeared images. Since there is by definition less high-frequency spatial information in a smeared image, the resulting image file size is smaller for most image compression algorithms, including JPEG and JPEG2000. We thus just look at the file sizes for all 8 images, then, and delete the 7 smallest images. This experiment can be easily done. By holding an iPhone at arm's length while moving it rapidly, a smeared picture can be acquired. Then a steady picture of the same area can be acquired without camera motion. When both images are emailed, the steady picture always has a larger file size.
} 
downlinked at full resolution, but for the science it will usually suffice to return a subwindow of the image at the specular point binned appropriately.

\subsubsection{Atmospheric campaign}

Atmospheric structure profiles The ultrastable oscillator (part of the WASS) allows continuous Doppler tracking of the vehicle's radial velocity throughout transmissions during descents to measure wind speed. The HR2I would acquire overlapping image pairs every $5 \mathrm{~km}$ in altitude to measure the $2 \mathrm{D}$ wind strength and direction during ascents after telecommunications uplinks (the 'climb' part of the climb/glide strategy). Also during ascent he pressure and temperature sensors, Aerosol Density Sensor (ADS), and the AirBorne Imaging Spectrometer (ABIS) acquire measurements every $1 \mathrm{~km}$ in altitude to determine atmospheric structure. These profiles would be acquired on every ascent and descent pair which occur roughly once per day during the 1-year nominal mission.

Cloud search When in locations where we expect to find clouds, AVIATR would do a $360^{\circ}$ right turn with $30^{\circ}$ bank angle. The turn points the portboresighted $(-x)$ Horizon-Looking Imager (HLI) toward the sky, where it acquires a continuous mosaic of individual images to look for clouds.

\subsubsection{Entry, descent, and deployment science}

AVIATR's initial plunge through Titan's atmosphere represents the only opportunity to acquire data on Titan's upper troposphere above our nominal maximum altitude of $14 \mathrm{~km}$. The AV deploys from the SV at an altitude of $40 \mathrm{~km}$. After initial wing unfolding and starting the propeller, the aircraft turns to fly toward the Sun in a nose-down descent and points its high-gain antenna at the Earth. We then begin a high-bandwidth transmission to the DSN.

The science instruments would acquire data during the rest of the descent into the nominal flight envelope. The observation plan would be nearly identical to that of a normal atmospheric structure profile (see Section 4.3.2 above) with image pairs for 2D wind determination.

\subsubsection{Telecommunications}

AVIATR would typically have one $\sim 8 \mathrm{~h}$ downlink session to Earth each day. In order to maximize the power that the aircraft can expend on the radio transmitter, we need to store up excess power from non-downlink times to use during the downlink. To do so, we use a technique that we call a "gravity battery" (Fig. 33).

The excess power could be stored as electrical energy in the form of either a battery or a capacitor. But a battery with sufficient capacity to store the required energy would be too massive to fit onboard the airplane. Our solution is to again use the flexibility of our platform to provide the desired power use 


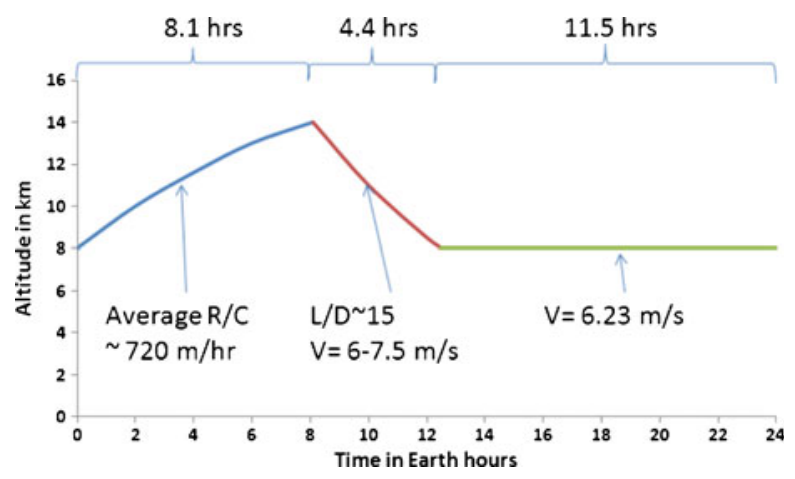

Fig. 33 Sample altitude profile for AVIATR's climb/glide strategy-our nominal lowest altitude of $3.5 \mathrm{~km}$ allows for a longer glide than this notional profile indicates. AVIATR's nominal altitude envelope is $3.5-14 \mathrm{~km}$ altitude. The lower end is set by easy clearance of Titan's highest mountains (1.5 km above the datum) and at the upper end by avoidance of cold air that could induce methane/ethane icing. We calculate aircraft performance using a fully-developed flight model that incorporates Titan's atmospheric structure as measured by Huygens' HASI [39]. The effects of decreasing air density with altitude can be seen in this plot-note how the predicted climb performance and glide angle are reduced at high altitude as evidenced by the curvature of the altitude profile as a function of time during climb and descent

distribution without additional hardware. We use the excess power during nondownlink periods to have the aircraft climb to our maximum altitude of $14 \mathrm{~km}$. This stores the excess power that we have in that flight mode in the form of gravitational potential energy.

At the start of a downlink we cut power to the propeller, using that power instead to improve the total radiated power from the telecommunications dish. The airplane then glides for the entire duration of the roughly 8-h downlink (Fig. 34). Once we arrive at our lowest safe altitude of $3.5 \mathrm{~km}$ we return to straight and level flight and reduce the transmitter power if the downlink session is still ongoing. Otherwise at the cessation of the downlink we would

Fig. 34 Artist's rendering of

AVIATR gliding while transmitting back to Earth

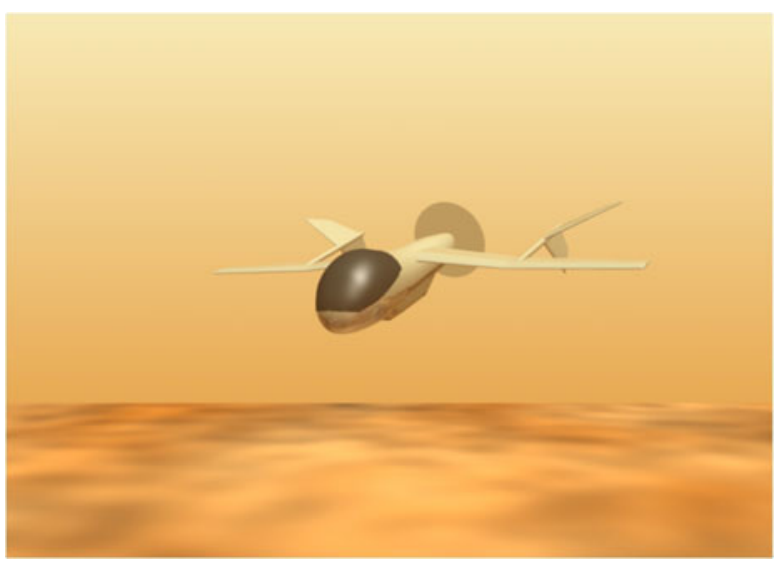


Table 7 Nominal power management states for the climb/glide aircraft operation strategy

\begin{tabular}{lccc}
\hline Power subsystem & Configuration & & \\
\cline { 2 - 4 } & Glide & Climb & Cruise \\
\hline Transmit (W) & 155 & 0 & 0 \\
Payload (W) & 0 & 0 & 40 \\
Avionics (W) & 40 & 40 & 40 \\
Actuators \& misc (W) & 25 & 25 & 25 \\
Propulsion (W) & 0 & 155 & 115 \\
Total (W) & 220 & 220 & 220 \\
\hline
\end{tabular}

Power can be diverted from the radio transmitter on glide or from propulsion on cruise to power scientific instruments on an as-needed basis, with a corresponding hit to bandwidth or climb performance respectively

again pour the extra energy into the propeller, beginning a new climb. We call this mode of operation "climb/glide". A summary of the resulting power management states is shown in Table 7.

On days when mosaics are being acquired as described above, this pattern would be modified. We have no downlinks on days with mosaics in them, devoting that entire day to science observations before returing to the climb/glide operational pattern.

The critical factor governing the total amount of science that AVIATR can do is the amount of data it can uplink to Earth via the RF beam. We thus investigate the total AVIATR HGA link budget in moderate detail. Using the worst-case values for input parameters shown in Table 8, the AV-to-Earth data rate is 850 bps. When Titan is more than $30^{\circ}$ in altitude above the horizon as viewed from the DSN station, the data rate can be stepped up to 1350 bps with a $3 \mathrm{~dB}$ margin. The total mission downlink, assuming 850 bps for one 8-hour pass per day for 350 days comes to $1.071 \mathrm{~GB}$, which exceeds our requirement of $1 \mathrm{~GB}$ for the mission. Achieving this total downlink rate requires knowledge of the AV latitude and longitude on Titan to within $\sim 23 \mathrm{~km}$. We would achieve this using the AV sun sensors to track the Sun's location over time, along with an accurate on-board clock and ephemeris, combined with data from the IMU, to continually evaluate the most probable AV position. With that position and

Table 8 Parameters used in the AVIATR link budget calculation

\begin{tabular}{ll}
\hline Parameter & Value \\
\hline HGA diameter & $0.874 \mathrm{~m}$ \\
Pointing error & $0.5^{\circ}$ \\
Circuit losses & $1 \mathrm{~dB}$ \\
RF power & $75 \mathrm{~W}$ \\
Earth-Titan range & $11.2 \mathrm{AU}$ (worst case) \\
DSN dish & $34 \mathrm{~m}$ \\
DSN altitude & $10^{\circ}$ \\
Earth weather & 90 th percentile for Canberra \\
Frequency & $\mathrm{X}-$ band $(8.4 \mathrm{GHz})$ \\
Titan atmosphere losses & $1 \mathrm{~dB}$ \\
\hline
\end{tabular}


knowledge of the position of the Sun in the sky, the HGA can be pointed at Earth within the necessary accuracy.

\subsubsection{Planned nominal mission schedule}

We show a candidate tour outline in Table 9. The tour would be broken into 16-day segments based on Titan's local solar day. We call these "TRot"s for Titan Rotations. Each TRot has a goal. A single Co-I would be responsible for leading the route, data acquisition, and telecommunications planning within each TRot using the planning tools that we develop during cruise. The planning structure resembles that used by HiRISE wherein there is a "Co-I of the pay period" who is responsible for 2 weeks' worth of planning.

A candidate set of goals and/or themes for each TRot is shown in Table 9. Ascertaining the global wind field is the top priority for early in the tour. These measurements would then refine our ability to plan the aircraft's route and would improve the fidelity of the predicted time between surface targets. Next we get a first epoch on change detection targets at the northern lakes. The middle of the tour involves targeted mosaics and linear profiles of various surface sites of interest. Near the year's end we again look at our change detection targets before looking for cloud activity at the end of mission.

Table 9 This table delineates an example outline of the sequence of scientific campaigns to be undertaken during the AVIATR 1-year prime mission

\begin{tabular}{lcl}
\hline TRot\# & DOM & TRot theme \\
\hline 1 & $1-16$ & N. hem winds and struct \\
2 & $17-32$ & S. hem winds and struct \\
3 & $33-48$ & Change detect targets \\
4 & $49-64$ & Change detect targets \\
5 & $65-80$ & Mountains \\
6 & $81-96$ & Dunes diversity \\
7 & $97-112$ & N polar maria \& lakes \\
8 & $113-128$ & N polar dry lakes \\
9 & $129-144$ & Tui/Hotei Regios \\
10 & $145-160$ & Mid-latitude explore \\
11 & $161-176$ & Ontario lacus \& S pole \\
12 & $177-192$ & Atm struct diversity \\
13 & $193-208$ & Dunes diversity \\
14 & $209-224$ & Atm struct diversity \\
15 & $225-240$ & Huygens landing site \\
16 & $241-256$ & Virgae/tectonism \\
17 & $257-272$ & Xanadu \\
18 & $273-288$ & Change detect targets \\
19 & $289-304$ & Change detect targets \\
20 & $305-320$ & Cloud search \\
21 & $321-336$ & Cloud search \\
22 & $337-352$ & Storm hunting \\
23 & $353-368$ & End of nominal mission \\
\hline
\end{tabular}




\subsection{End-of-mission scenarios}

While we have baselined a 1-year nominal mission, there are no expendables that limit AVIATR's total lifetime except the slow radioactive decay of the ${ }^{238} \mathrm{Pu}$ fuel in the ASRGs. The AV can keep flying until a mechanical failure (likely a servo) or until funding termination, whichever happens first. In the event that the mission is ended due to a programmed end of funding, we would intentionally command the AV to descend slowly into a large sand sea (possibly Belet). The dunes make for a soft target, maximizing the probability of surviving ground impact. The dune sands' organic, non-icy composition would reduce the probability for creating a water melt-pool that could affect planetary protection (see next section). AVIATR would collect both atmospheric and remote sensing data during its descent into the sand sea. If it survives impact, and if the resulting orientation is favorable, it may survive for a brief period of landed science. Long-term survival depends on the cooling behavior of the ASRG without advection of ambient air-it is beyond the scope of the project as envisioned to modify the AV in any way for landed science due to cost and mass constraints.

\subsection{Planetary protection plan}

As a solar system exploration mission, the AVIATR project shall comply with the PP requirements established by NASA policy NPD 8020.7E and detailed in NPR 8020.12B, "Planetary Protection Provisions for Robotic Extraterrestrial Missions". The planetary protection category of a mission is formally established by the NASA Planetary Protection Officer in response to written request from the Project Manager, typically submitted by the end of Phase A. Nevertheless, the expected category for the AVIATR project may be determined by reference to NPR $8020.12 \mathrm{~B}$ and a consideration of the mission.

This mission does not include a sample return to the Earth (or to the Moon). This mission encounters and/or targets the following named solar system bodies: Jupiter, Titan.

The Jupiter encounter is part of a gravity trajectory assist maneuver. As the closest approach to Jupiter is at 1,123 $\mathrm{R}_{\text {Jup }}$, well beyond the domain of the Galilean satellites (Callisto's semimajor axis is $26.3 \mathrm{R}_{\mathrm{Jup}}$ ), this encounter imposes no specific additional planetary protection consideration apart from ensuring that the encounter proceeds as planned without impacting satellites of biological interest.

This mission consists of an aircraft with ASRGs eventually landing on the surface of Titan. The thermal output of each ASRG (2 Pu heating units) is $500 \mathrm{~W}$. Assuming this unit lands on the surface and is embedded in ice we can compute the temperature, $T$, of the surface of the ASRG in contact with the ice that results:

$$
T=T_{0}+\frac{q}{4 \pi R k},
$$


where $T_{0}$ is the ambient surface temperature of $95 \mathrm{~K}, q$ is the thermal heat production, $R$ is the radius of the ASRG, and $k$ is the thermal conductivity of ice ( $\sim 3 \frac{\mathrm{W}}{\mathrm{Km}}$ at Titan temperatures). If we assume $q=500 \mathrm{~W}$, and $R=$ $0.5 \mathrm{~m}$ we derive for $T$ a value of $122 \mathrm{~K}$-well below the melting point of ice (and benzene). This rough calculation could be enhanced by a more detailed evaluation during Phase A but we expect that the result would be the same: Titan is too cold for the ASRGs to create a meltpool. One consideration of a more advanced calculation would be consideration of the remote possibility of in-flight vehicle breakup and subsequent freefall impact of the ASRG. Inclusion of convective cooling, for instance, would lower the derived final temperature. Thus we believe the mission planetary protection category will be II.

Category II missions comprise all types of missions to those target bodies where there is significant interest relative to the process of chemical evolution and the origin of life, but where there is only a remote chance that contamination carried by a spacecraft could jeopardize future exploration. The requirements are for simple documentation only. Preparation of a short planetary protection plan is required for these flight projects primarily to outline intended or potential impact targets, brief pre and post-launch analyses detailing impact strategies, and a post-encounter and End-of-Mission Report that provides the location of impact if such an event occurs.

\section{Conclusion}

The stand-alone Titan airplane mission that we outline here, Aerial Vehicle for In-situ and Airborne Titan Reconnaissance (AVIATR), is capable of answering important fundamental scientific questions within a New-Frontiers class cost and scope. Such a mission would be programmatically viable either by itself, in which case it would allow a reduced cost, scope, and risk for a future flagship, or as part of a sustained Titan Exploration Program involving one \$1B-class mission launched every decade or so.

AVIATR's science objectives are to explore the pole-to-pole diversity of Titan's surface and lower atmosphere. It would explore Titan's lakes and seas, methane hydrology, sand dunes, and mountains, as well as exploring new areas and laying the groundwork for future landed missions by characterizing potential landing sites. By flying through the lower troposphere, AVIATR would characterize the full diversity and variability of Titan's winds, atmospheric structure, clouds and rain, and haze. These objectives would build on Cassini and Huygens science, and help to place the Earth into context among solar system worlds.

Airplane flight on Titan is easier than anywhere else in the solar system. Our design for the AVIATR Air Vehicle (AV) uses an electrically-powered pusher propeller for propulsion, with the electricity provided by two ASRGs. The ability to operate with an ASRG and the flexibility to direct the craft to explore anywhere on Titan are fundamental advantages of an airplane to 
achieve our scientific objectives. The airplane masses $120 \mathrm{~kg}$, and has singlyfolded wings that allow it to fit within the entry vehicle aeroshell. The entry vehicle is coupled to a cruise stage (space vehicle) that guides the spacecraft stack through its 7.5-year cruise, using an Earth and Jupiter gravity assist to propel it to Titan.

Once at Titan, our aircraft operations strategy is designed to use the flexibility of the platform to accomplish the most science possible from our limited payload mass ( $12.5 \mathrm{~kg}$, compared to $\sim 26 \mathrm{~kg}$ for various hot-air balloon options). Surface studies can use a predesigned flight pattern to build up low-resolution, high-resolution, and context mosaics all of the same target areas. Flight perpendicular to the solar illumination would allow monitoring of specular reflections from the surface, characterizing the distribution of surface liquids. AVIATR would use a climb/glide energy management strategy, using excess available power during off-peak periods to climb in altitude, and then using that gravitational potential energy to glide during uplinks so as to devote greater power to the antenna beam. This allows us a total expected data return for the mission of more than $1 \mathrm{~GB}(8 \mathrm{~Gb})$. The nominal mission length is 1 Earth year.

A run through JPL Team-X 3-5 August 2010 priced the mission at FY2010 $\$ 715 \mathrm{M}$ using the recent Discovery AO conditions. The mission is thus likely a viable New Frontiers candidate, and should be considered for inclusion on the New Frontiers menu list either at the next planetary science decadal survey or during a mid-decadal update.

In the meantime, the future prospects of an ASRG-based Titan airplane would benefit from future studies. A better understanding of the expected power output of the ASRG in the Titan environment with advective cooling would greatly reduce the uncertainties in aircraft design. Similarly, a study of what parts of the ASRG could be removed as unnecessary for an advectivelycooled design, like the radiator fins, would also be of benefit. Finally, more development of the proposed instrumentation would be helpful, particularly deriving Titan-airplane specific versions of the dust sensor and near-infrared spectrometer. In the end, there are no technological show-stoppers, and Titan airplanes should be strongly considered for all future Titan in situ missions, both stand-alone and as part of a potential flagship.

\section{List of abbreviations and acronyms}

$\begin{array}{ll}\text { ABIS } & \text { AirBorne Imaging Spectrometer } \\ \text { ACS } & \text { Attitude Control System } \\ \text { ADS } & \text { Aerosol Density Sensor } \\ \text { AO } & \text { Announcement of Opportunity } \\ \text { ASRG } & \text { Advanced Stirling Radioisotope Generator } \\ \text { BIS } & \text { Balloon Imaging Spectrometer } \\ \text { bps } & \text { bits per second } \\ \text { AV } & \text { Air Vehicle }\end{array}$


AVIATR Aerial Vehicle for In-situ and Airborne Titan Reconnaissance

C\&DH Command and Data Handling

DC Direct Current

DISR Descent Imager Spectral Radiometer

DEM Digital Elevation Model

DSM Deep Space Maneuver

DSN Deep Space Network

EDD Entry, Descent, and Deployment

EDL Entry, Descent, and Landing

EGA Earth Gravity Assist

ESA European Space Agency

EV

$\mathrm{Gb}$

Entry Vehicle

GB gigabit

GCM Global Circulation Model

GCMS Gas Chromatograph Mass Spectrometer

GN\&C Guidance, Navigation, and Control

HASI Huygens Atmosphere Structure Instrument

HiRISE High Resolution Imaging Science Experiment

HGA High Gain Antenna

HLI Horizon-Looking Imager

HLS Huygens Landing Site

HR2I High Resolution 2-micron Imager

HST Hubble Space Telescope

IFOV Instantaneous Field Of View

IMU Inertial Measurement Unit

ISS Imaging Science Subsystem

JET Journey to Enceladus and Titan

JPL Jet Propulsion Laboratory

LV Launch Vehicle

MER Mars Exploration Rover

MLI Multi-Layer Insulation

MMRTG Multi-Mission Radioisotope Thermoelectric Generator

MRO Mars Reconnaissance Orbiter

MSL Mars Science Laboratory

MTBF Mean Time Between Failures

NRL Naval Research Laboratory

OML Outer Mold Line

OPAG Outer Planets Assessment Group

PCU Power Control Unit

PP Planetary Protection

RF Radio Frequency

RTG Radioisotope Thermal Generator

SAR Synthetic Aperture RADAR

SC Spacecraft

SDST Small Deep Space Transponder 


$\begin{array}{ll}\text { SHARAD } & \text { Shallow Radar } \\ \text { SIP } & \text { Strain Isolation Pad } \\ \text { SMAP } & \text { Soil Moisture Active Passive } \\ \text { SRD } & \text { Student Raindrop Detector } \\ \text { STA } & \text { Star Tracker Assembly } \\ \text { STEM } & \text { Science, Technology, Engineering, and Mathematics } \\ \text { SV } & \text { Space Vehicle } \\ \text { TAE } & \text { Titan Aerial Explorer } \\ \text { TCM } & \text { Trajectory Correction Maneuver } \\ \text { TiME } & \text { Titan Mare Explorer } \\ \text { TPS } & \text { Thermal Protection System } \\ \text { TSSM } & \text { Titan Saturn System Mission } \\ \text { TWTA } & \text { Traveling Wave Tube Amplifier } \\ \text { UAV } & \text { Unpiloted Aerial Vehicle } \\ \text { VIMS } & \text { Visual and Infrared Mapping Spectrometer } \\ \text { VIRTIS } & \text { Visible InfraRed Thermal Imaging Spectrometer } \\ \text { WASS } & \text { Winds and Atmospheric Structure Suite } \\ \text { WEB } & \text { Warm Electronics Box } \\ \Delta \text { VEGA } & \Delta V \text { Earth Gravity Assist }\end{array}$

Acknowledgements The authors acknowledge support from the Idaho Space Grant Consortium, Idaho NASA EPSCoR, the University of Idaho, the University of Idaho College of Engineering, the University of Idaho College of Science, and California Institute of Technology Jet Propulsion Laboratory.

Open Access This article is distributed under the terms of the Creative Commons Attribution Noncommercial License which permits any noncommercial use, distribution, and reproduction in any medium, provided the original author(s) and source are credited.

\section{References}

1. Ádámkovics, M., Wong, M. H., Laver, C., de Pater, I.: Science 318, 962 (2007)

2. Aharonson, O., Hayes, A.G., Lunine, J.I., et al.: Nature Geoscience 2, 851 (2009)

3. Anderson, R.S.: Sedimentology 34, 943 (1987)

4. Andreotti, B., Fourrière, A., Ould-Kaddour, F., Murray, B., Claudin, P.:, Nature 457, 1120 (2009)

5. Barnes, J.W., Brown, R.H., Turtle, E.P., et al.: Science 310, 92 (2005)

6. Barnes, J.W., Brown, R.H., Radebaugh, J., et al.: Geophys. Res. Lett. 33, L16204 (2006)

7. Barnes, J.W., Brown, R.H., Soderblom, L., et al.: Icarus 186, 242 (2007)

8. Barnes, J.W., Radebaugh, J., Brown, R.H., et al.: J. Geophys. Res. (Planets) 112, E11006 (2007)

9. Barnes, J.W., Brown, R.H., Soderblom, L., et al.: Icarus 195, 400 (2008)

10. Barnes, J.W., Brown, R.H., Soderblom, J.M., et al.: Icarus 201, 217 (2009)

11. Barnes, J.W., Soderblom, J.M., Brown, R.H., et al.: Icarus 211, 722 (2011)

12. Barnes, J.W., Bow, J., Schwartz, J., Brown, R.H., Soderblom, J.M., Hayes, A.G., Vixie, G., Le Mouélic, S., Rodriguez, S., Sotin, C., Jaumann, R., Stephan, K., Soderblom, L.A., Clark, R.N., Buratti, B.J., Baines, K.H., Nicholson, P.D.: Organic sedimentary deposits in Titan's dry lakebeds: probable evaporite. Icarus 216, 136-140 (2011)

13. Barth, E.L., Rafkin, S.C.R.: Geophys. Res. Lett. 34, L3203 (2007)

14. Barth, E.L., Rafkin, S.C.R.: Icarus 206, 467 (2010) 
15. Benner, S.A., Ricardo, A., Carrigan, M.A.: Curr. Opin. Chem. Biol. 8, 672 (2004)

16. Beyer, R.A., McEwen, A.S., Kirk, R.L.: J. Geophys. Res. (Planets) 108, 8085 (2003)

17. Bird, M.K., Allison, M., Asmar, S.W., et al.: Nature 438, 800 (2005)

18. Bourgeois, O., Lopez, T., Le Mouélic, S., et al.: In: Lunar and Planetary Inst. Technical Report, vol. 39, Lunar and Planetary Institute Science Conference Abstracts, p. 1733 (2008)

19. Braun, R., Croom, M., Levine, J., Spencer, D., Wright, H.: J. Spacecr. Rockets 43, 1026 (2006)

20. Brown, M.E., Bouchez, A.H., Griffith, C.A.: Nature 420, 795 (2002)

21. Brown, R.H., Soderblom, L.A., Soderblom, J.M., et al.: Nature 454, 607 (2008)

22. Brown, M.E., Schaller, E.L., Roe, H.G., et al.: Geophys. Res. Lett. 36, L1103 (2009)

23. Brown, M.E., Smith, A.L., Chen, C., Ádámkovics, M.: Astrophys. J. Lett. 706, L110 (2009)

24. Brown, R.H., Lebreton, J.-P., Waite, J.H.: Titan from Cassini-Huygens (2009)

25. Brown, M.E., Roberts, J.E., Schaller, E.L.: Icarus 205, 571 (2010)

26. Burr, D.M., Jacobsen, R.E., Roth, D.L., et al.: Geophys. Res. Lett. 36, L22203 (2009)

27. Carr, M.H.: In: Carr, M.H. (ed.) Water on Mars (1996)

28. Chuang, F.C., Weitz, C.M., Dobrea, E.N., Hirise Team: In: Lunar and Planetary Inst. Technical Report, vol. 39, Lunar and Planetary Institute Science Conference Abstracts, p. 2074 (2008)

29. Clark, R.N., Curchin, J.M., Barnes, J.W., et al.: J. Geophys. Res. (Planets) 115, 10005 (2010)

30. Collins, G.C.: Geophys. Res. Lett. 32, L22202 (2005)

31. Combes, M., Vapillon, L., Gendron, E., et al.: Icarus 129, 482 (1997)

32. Coustenis, A., Atreya, S.K., Balint, T., et al.: Exp. Astron. 23, 893 (2009)

33. Coustenis, A., Matson, D., Hansen, C., Lunine, J., Lebreton, J.-P.: ESA-SRE(2008)4. http://sci.esa.int/science-e/www/object/index.cfm?fobjectid=44185 (2009)

34. Coustenis, A., Atkinson, D., Balint, T., et al.: Proc. Inst. Mech. Eng., G J. Aerosp. Eng., 225(2), 22 (2011)

35. Donahue, T.M.: Icarus 141, 226 (1999)

36. Dorrington, G.E.: Adv. Space Res. 47, 1 (2011)

37. Dundas, C.M., McEwen, A.S., Diniega, S., Byrne, S., Martinez-Alonso, S.: Geophys. Res. Lett. 37, L07202 (2010)

38. Elachi, C., Wall, S., Allison, M., et al.: Science 308, 970 (2005)

39. Fulchignoni, M., Ferri, F., Angrilli, F., et al.: Nature 438, 785 (2005)

40. Gehrels, T., Baker, L.R., Beshore, E., et al.: Science 207, 434 (1980)

41. Graves, S.D.B., McKay, C.P., Griffith, C.A., Ferri, F., Fulchignoni, M.: Planet. Space Sci. 56, $346(2008)$

42. Griffith, C.A.: Philos. Trans. R. Soc. A Math. Phys. Eng. Sci. 367, 713 (2009)

43. Griffith, C.A., Owen, T., Wagener, R.: Icarus 93, 362 (1991)

44. Griffith, C.A., Owen, T., Miller, G.A., Geballe, T.: Nature 395, 575 (1998)

45. Griffith, C.A., Penteado, P., Baines, K., et al.: Science 310, 474 (2005)

46. Griffith, C.A., Penteado, P., Rannou, P., et al.: Science 313, 1620 (2006)

47. Griffith, C.A., McKay, C.P., Ferri, F.: Astrophys. J. Lett. 687, L41 (2008)

48. Griffith, C.A., Penteado, P., Rodriguez, S., et al.: Astrophys. J. Lett. 702, L105 (2009)

49. Hall, J.L., Lunine, J., Sotin, C., et al.: In: Proceedings of the Interplanetary Prove Workshop 8, Portsmouth, VA (2011)

50. Hapke, B.: J. Geophys. Res. 86, 3039 (1981)

51. Hayes, A., Aharonson, O., Callahan, P., et al.: Geophys. Res. Lett. 35, L9204 (2008)

52. Hoffman, P.F., Kaufman, A.J., Halverson, G.P., Schrag, D.P.: Science 281, 1342 (1998)

53. Hueso, R., Sánchez-Lavega, A.: Nature 442, 428 (2006)

54. Hunten, D.M.: Nature 443, 669 (2006)

55. Irwin, R.P., Howard, A.D., Craddock, R.A., Moore, J.M.: J. Geophys. Res. (Planets) 110, 12 (2005)

56. Janssen, M.A., Lorenz, R.D., West, R., et al.: Icarus 200, 222 (2009)

57. Jaumann, R., Brown, R.H., Stephan, K., et al.: Icarus 197, 526 (2008)

58. Kasting, J.F., Pollack, J.B.: Icarus 53, 479 (1983)

59. Kattenhorn, S.A., Hurford, T.: In: Pappalardo, R.T., McKinnon, W.B., Khurana, K.K. (eds.) Tectonics of Europa, p. 199 (2009) 
60. Kazeminejad, B., Atkinson, D.H., Pérez-Ayúcar, M., Lebreton, J., Sollazzo, C.: Planet. Space Sci. 55, 1845 (2007)

61. Lancaster, N.: The Geomorphology of Desert Dunes. Routledge, Evanston (1995)

62. Lancaster, N., Kocurek, G., Singhvi, A., et al.: Geology 30, 991 (2008)

63. Lavvas, P., Yelle, R.V., Vuitton, V.: Icarus 201, 626 (2009)

64. Le Corre, L., Le Mouélic, S., Sotin, C., et al.: Planet. Space Sci. 57, 870 (2009)

65. Le Mouélic, S., Paillou, P., Janssen, M.A., et al.: J. Geophys. Res. (Planets) 113, 4003 (2008)

66. Le Mouélic, S., Rannou, P., Rodriguez, S., et al.: Planet. Space Sci. (2012, in press)

67. Lemke, L.G.: In: International Planetary Probe Workshop (2008)

68. Levine, J.S., Wright, H.S., Gasbarre, J.F., et al.: NASA GSFC Vision Mission Study (2005)

69. Lindal, G.F., Wood, G.E., Hotz, H.B., et al.: Icarus 53, 348 (1983)

70. Lopes, R.M.C., Mitchell, K.L., Stofan, E.R., et al.: Icarus 186, 395 (2007)

71. Lopes, R.M.C., Stofan, E.R., Peckyno, R., et al.: Icarus 205, 540 (2010)

72. Lorenz, R.D.: J. Br. Interplanet. Soc. 53, 218 (2000)

73. Lorenz, R.D.: J. Aircr. 38, 208 (2001)

74. Lorenz, R.D.: Aeronaut. J. 112, 353 (2008)

75. Lorenz, R.D.: J. Br. Interplanet. Soc. 61, 118 (2008)

76. Lorenz, R.D.: J. Br. Interplanet. Soc. 62(5) (2009)

77. Lorenz, R.D.: J. Br. Interplanet. Soc. 63, 9 (2010)

78. Lorenz, R.D., Radebaugh, J.: Geophys. Res. Lett. 36, L3202 (2009)

79. Lorenz, R.D., Leary, J.C., Lockwood, M.K., Waite, J.H.: In: El-Genk, M.S. (ed.) Space Technology and Applications International Forum-STAIF 2008. American Institute of Physics Conference Series, vol. 969, pp. 380-387 (2008)

80. Lorenz, R.D., Wall, S., Radebaugh, J., et al.: Science 312, 724 (2006)

81. Lorenz, R.D., Lopes, R.M., Paganelli, F., et al.: Planet. Space Sci. 56, 1132 (2008)

82. Lorenz, R.D., West, R.D., Johnson, W.T.K.: Icarus 195, 812 (2008)

83. Lorenz, R.D., Claudin, P., Andreotti, B., Radebaugh, J., Tokano, T.: Icarus 205, 719 (2010)

84. Lorenz, R.D., Jackson, B., Hayes, A.: Planet. Space Sci. 58, 724 (2010)

85. Lorenz, R.D., Newman, C., Lunine, J.I.: Icarus 207, 932 (2010)

86. Lunine, J.I., Stevenson, D.J., Yung, Y.L.: Science 222, 1229 (1983)

87. Lunine, J., Lorenz, R.D., Smith, M., et al.: NASA JPL Vision Mission Study (2005)

88. Lunine, J.I., Elachi, C., Wall, S.D., et al.: Icarus 195, 415 (2008)

89. Malin, M.C., Edgett, K.S.: Science 288, 2330 (2000)

90. Malin, M.C., Bell, J.F., Cantor, B.A., et al.: J. Geophys. Res. (Planets) 112, E05S04 (2007)

91. Massie, C., Stewart, G., McGregor, G., Gilchrist, J.: Sens. Actuators B-Chem. 113, 830 (2006)

92. McDonnell, J.: J. Phys. E-Sci. Instrum. 20, 741 (1987)

93. McEwen, A.S., Eliason, E.M., Bergstrom, J.W., et al.: J. Geophys. Res. (Planets) 112, E05S02 (2007)

94. McEwen, A.S., Banks, M.E., Baugh, N., et al.: Icarus 205, 2 (2010)

95. McKay, C.P.: Icarus 91, 93 (1991)

96. McKay, C.P., Smith, H.D.: Icarus 178, 274 (2005)

97. McKay, C., Zahnle, K.: In: Cottini, V., Nixon, C., Lorenz, R. (eds.) Through Time; A Workshop On Titan's Past, Present and Future, pp. 85-86 (2010)

98. McKay, C.P., Griffith, C.A., Ferri, F., Fulchignoni, M.: Planet. Space Sci. 57, 1996 (2009)

99. Melosh, H.J.: In: Melosh, H.J. (ed.) Impact Cratering: A Geologic Process (1989)

100. Merrison, J.P., Gunnlaugsson, H.P., Jensen, J., et al.: Planet. Space Sci. 52, 1177 (2004)

101. Merrison, J.P., Gunnlaugsson, H.P., Kinch, K., et al.: Planet. Space Sci. 54, 1065 (2006)

102. Mitchell, J.L., Vallis, G.K.: J. Geophys. Res. (Planets) 115, E12008 (2010)

103. Mitchell, J.L., Pierrehumbert, R.T., Frierson, D.M.W., Caballero, R.: Proc. Natl. Acad. Sci. 103, 18421 (2006)

104. Mitchell, J.L., Pierrehumbert, R.T., Frierson, D.M.W., Caballero, R.: Icarus 203, 250 (2009)

105. Mitri, G., Showman, A.P., Lunine, J.I., Lorenz, R.D.: Icarus 186, 385 (2007)

106. Moore, J.M., Howard, A.D.: Geophys. Res. Lett. 37, L22205 (2010)

107. Neish, C.D., Lorenz, R.D., O’Brien, D.P., Team, T.C.R.: Int. J. Astrobiol. 5, 57 (2006)

108. Neish, C.D., Somogyi, Á., Lunine, J.I., Smith, M.A.: Icarus 201, 412 (2009)

109. Neish, C.D., Somogyi, Á., Smith, M.A.: Astrobiology 10, 337 (2010)

110. Nelson, R.M., Kamp, L.W., Matson, D.L., et al.: Icarus 199, 429 (2009) 
111. Niemann, H.B., Atreya, S.K., Bauer, S.J., et al.: Nature 438, 779 (2005)

112. Pappalardo, R.T., Collins, G.C., Head, III, J.W., et al.: In: Bagenal, F., Dowling, T.E., McKinnon, W.B. (eds.) Geology of Ganymede, pp. 363-396 (2004)

113. Porco, C.C., Baker, E., Barbara, J., et al.: Nature 434, 159 (2005)

114. Radebaugh, J., Lorenz, R.D., Kirk, R.L., et al.: Icarus 192, 77 (2007)

115. Radebaugh, J., Lorenz, R.D., Lunine, J.I., et al.: Icarus 194, 690 (2008)

116. Radebaugh, J., Lorenz, R.D., Wall, S.D., et al.: Icarus 211, 672 (2011)

117. Rages, K., Pollack, J.B.: Icarus 55, 50 (1983)

118. Rannou, P., Hourdin, F., McKay, C.P.: Nature 418, 853 (2002)

119. Reh, K., Manger, T., Matson, D., et al.: Jet Propulsion Laboratory (2007)

120. Reh, K., Manger, T., Matson, D., et al.: Task Order \#NMO710851 (2009)

121. Rodriguez, S., Le Mouélic, S., Sotin, C., et al.: Planet. Space Sci. 54, 1510 (2006)

122. Rodriguez, S., Le Mouélic, S., Rannou, P., et al.: Nature 459, 678 (2009)

123. Rodriguez, S., Le Mouélic, S., Rannou, P., Sotin, C., Brown, R.H., Barnes, J.W., Griffith, C.A., Burgalat, J., Baines, K.H., Buratti, B.J., Clark, R.N., Nicholson, P.D.: Titan's cloud seasonal activity from winter to spring with Cassini/VIMS. Icarus 216, 89-110 (2011)

124. Roe, H.G., Bouchez, A.H., Trujillo, C.A., Schaller, E.L., Brown, M.E.: Astrophys. J. Lett. 618, L49 (2005)

125. Roe, H.G., Brown, M.E., Schaller, E.L., Bouchez, A.H., Trujillo, C.A.: Science 310, 477 (2005)

126. Rubin, D.M., Hesp, P.A.: Nature Geoscience 3, 139 (2010)

127. Sagan, C., Dermott, S.F.: Nature 300, 731 (1982)

128. Schaller, E.L., Roe, H.G., Schneider, T., Brown, M.E.: Nature 460, 873 (2009)

129. Schulze-Makuch, D., Grinspoon, D.H.: Astrobiology 5, 560 (2005)

130. Seu, R., Phillips, R.J., Biccari, D., et al.: J. Geophys. Res. (Planets) 112, E05S05 (2007)

131. Silvestro, S., Fenton, L.K., Vaz, D.A., Bridges, N.T., Ori, G.G.: Geophys. Res. Lett. 37, L20203 (2010)

132. Sittler, E.C., Cooper, J.F., Mahaffey, P., et al.: In: AAS/Division for Planetary Sciences Meeting Abstracts \#38, vol. 38, p. 1300, Bulletin of the American Astronomical Society (2006)

133. Smith, B.A., Soderblom, L., Beebe, R.F., et al.: Science 212, 163 (1981)

134. Smith, P.H., Lemmon, M.T., Lorenz, R.D., et al.: Icarus 119, 336 (1996)

135. Soderblom, L.A., Kirk, R.L., Lunine, J.I., et al.: Planet. Space Sci. 55, 2025 (2007)

136. Soderblom, L.A., Tomasko, M.G., Archinal, B.A., et al.: Planet. Space Sci. 55, 2015 (2007)

137. Soderblom, L.A., Brown, R.H., Soderblom, J.M., et al.: Icarus 204, 610 (2009)

138. Soderblom, J.M., Brown, R.H., Soderblom, L.A., et al.: Icarus 208, 905 (2010)

139. Sotin, C., Jaumann, R., Buratti, B.J., et al.: Nature 435, 786 (2005)

140. Sotin, C., Altwegg, K., Brown, R.H., et al.: In: AAS/Division for Planetary Sciences Meeting Abstracts, vol. 42, \#49.31 (2010)

141. Spencer, J.R., Barr, A.C., Esposito, L.W., et al.: In: Dougherty, M.K., Esposito, L.W., Krimigis, S.M. (eds.) Enceladus: An Active Cryovolcanic Satellite, pp. 683-724 (2009)

142. Squires, S., Soderblom, L.A.: Vision and Voyages for Planetary Science in the Decade 20132022. National Academies Press, Washington, DC (2011)

143. Sromovsky, L.A., Suomi, V.E., Pollack, J.B., et al.: Nature 292, 698 (1981)

144. Stephan, K., Jaumann, R., Brown, R.H., et al.: Geophys. Res. Lett. 37, L7104 (2010)

145. Stofan, E.R., Lunine, J.I., Lopes, R., et al.: Icarus 185, 443 (2006)

146. Stofan, E.R., Elachi, C., Lunine, J.I., et al.: Nature 445, 61 (2007)

147. Stofan, E.R., Lorenz, R.D., Lunine, J.I., et al.: LPI Contributions, vol. 1538, 5270 (2010)

148. Strobel, D.F.: Icarus 208, 878 (2010)

149. Tobie, G., Lunine, J.I., Sotin, C.: Nature 440, 61 (2006)

150. Tokano, T.: Icarus 173, 222 (2005)

151. Tokano, T.: Icarus 194, 243 (2008)

152. Tokano, T.: Planet. Space Sci. 58, 814 (2010)

153. Tokano, T., Neubauer, F.M.: Icarus 158, 499 (2002)

154. Tokano, T., McKay, C.P., Neubauer, F.M., et al.: Nature 442, 432 (2006)

155. Tomasko, M.G., Archinal, B., Becker, T., et al.: Nature 438, 765 (2005)

156. Tomasko, M.G., Doose, L., Engel, S., et al.: Planet. Space Sci. 56, 669 (2008)

157. Toon, O.B., Turco, R.P., Pollack, J.B.: Icarus 43, 260 (1980) 
158. Turtle, E.P., Perry, J.E., McEwen, A.S., et al.: Geophys. Res. Lett. 36, L2204 (2009)

159. Turtle, E.P., Perry, J.E., Hayes, A.G., et al.: Science 331, 1414 (2011)

160. Turtle, E.P., Perry, J.E., Hayes, A.G., McEwen, A.S.: Icarus 212, 957 (2011)

161. Wall, S.D., Lopes, R.M., Stofan, E.R., et al.: Geophys. Res. Lett. 36, L04203 (2009)

162. Wall, S., Hayes, A., Bristow, C., et al.: Geophys. Res. Lett. 37, L5202 (2010)

163. West, R.A., Brown, M.E., Salinas, S.V., Bouchez, A.H., Roe, H.G.: Nature 436, 670 (2005)

164. Wilson, E.H., Atreya, S.K.: AGU Fall Meeting Abstracts, G1188 (2009)

165. Wood, C.A., Lorenz, R., Kirk, R., et al.: Icarus 206, 334 (2010)

166. Wye, L.C., Zebker, H.A., Lorenz, R.D.: Geophys. Res. Lett. 36, L16201 (2009)

167. Zimbelman, J.: Geomorphology 37, 179 (2001)

168. Zubrin, R.: 26th AIAA Meeting Proceedings (1990)

169. Zubrin, R.: Ad Astra (1991) 